\title{
Three Nations, One Place
}

A Comparative Ethnohistory of Social Change Among the Comanches and Hasinais During Spain's

Colonial Era, 1689-1821

Martha McCollough

Routledge
(2)
Taylor \& Francis Group
LONDON AND NEW YORK 


\section{Other Books in the Native Americans Interdisciplanary}

Perspectives Series:

Edited by John R. Wunder and Cynthia Willis Esqueda

The Power of the Land

Identity, Etbnicity, and Class Among the Oglala Lakota

Paul Robertson

Political Principles and Indian Sovereignty

Thurman Lee Hester, Jr.

Dance Lodges of the Omaha People

Building from Memory

Mark Awakuni-Swetland

Blood Matters

The Five Civilized Tribes and the Search for Unity

in the 20th Century

Erik March Zissu 
Dedicated to $\mathrm{B}^{3[1957-2003]}$, a good friend and probably the wittiest and most gentle person

I have ever known. 
First published 2004 by Routledge

Published 2017 by Routledge

2 Park Square, Milton Park, Abingdon, Oxon OX14 4RN

711 Third Avenue, New York, NY 10017, USA

Routledge is an imprint of the Taylor \& Francis Group, an informa business

Copyright $\mathbb{C} 2004$ Taylor \& Francis

The Open Access version of this book, available at www.tandfebooks.com, has been made available under a Creative Commons Attribution-Non Commercial-No Derivatives 4.0 license.

Library of Congress Cataloging-in-Publication Data

McCollough, Martha, 1956-

Three nations, one place : a comparative ethnohistory of social change among the Comanches and Hasinais during Spain's colonial era, 1689-1821 / Martha McCollough.

p. cm.-(Native Americans-interdisciplinary perspectives)

Includes bibliographical references and index.

ISBN 0-415-94394-9

1. Comanche Indians-History. 2. Hasinai Indians-History.

3. Social change-Great Plains. 4. Mexico-History-To 1810. I. Title.

II. Series.

E99.C85M385 2003

$978.004^{\prime} 9745-\mathrm{dc} 21$

2003041403

Publisher's Note

The publisher has gone to great lengths to ensure the quality of this reprint but points out that some imperfections in the original may be apparent

ISBN 9780415943949 (hbk) 


\section{CONTENTS}

ACKNOWLEDGMENTS

VII

I The Colonial imperative and Indigenous Perspectives

2 Interpretations of the Comanches and the Hasinals Prior to the Reservation ERa

3 ETHNOHISTORIC INTERPRETATIONS OF POSTCONTACT COMANCHES AND HASINAIS 29

4 World Systems Perspective 43

5 Regional Analysis 67

6 Social History 91

7 CONCLUSION III

$\begin{array}{ll}\text { BiBLIOGRAPHY } & 119\end{array}$

$\begin{array}{lr}\text { INDEX } & 137\end{array}$ 



\section{ACKNOWLEDGMENTS}

Throughout my student years, I've had many great teachers and colleagues. At the University of Alaska, Richard Scott, Rodger Powers, Lydia Black, and Jean Aigner completely captured my interest in anthropology. Richard Scott also taught me the humor of missteps and past anthropological conundrums. At the University of Oklahoma, my chair, Morris Foster, introduced me to the intricacies of political, linguistic, and social theory. John Moore's courses on political economy were always excellent. Susan Vehik, Ryan Vehik, and Joe Whitecotton always provided great reality checks. They are also a great deal of fun. My colleagues at the University of Nebraska have been incredibly helpful. They are also friends. I am very fortunate to have the opportunity to work with Mark Awakuni-Swetland, Peter Bleed, Peter Collings, Pat Draper, Ray Hames, Bob Hitchcock, Ron Stephens, Luann Wandsnider, and Mary Willis. Each of these individuals makes the Anthropology Department a pleasant and even fun place to work. Cynthia Willis-Esqueda has been an incredible mentor during my purgatory years as an assistant professor. Someday I'll figure out how to return the favor. Thanks to John Wunder for his insights into the political economies of the Southern Plains. His helpful comments on an earlier version of this manuscript were invaluable. I would also like to thank the University of Nebraska's Research Council for their financial support. 
In addition to having great colleagues, I am also lucky to have supportive neighbors. Donna Awakuni-Swetland, Alexis De Vries, and her mother, Candace Alesio-De Vries, and Randy Thomas are constantly pitching in to help. Friends such as Lavri Block, Karen Van Slyke, and Sandra Sheppard have always made life more fun.

Kathy, Billy, Mark, and Lisa keep me focused on the important things in life. I'm so grateful to be related to such great siblings and inlaws. Anna Bell Baker has been supportive in all my various enterprises.

I would also like to thank the patient editors at Routledge.

None of this would have been possible or even interesting without the support of my husband, Berkley Bailey, daughter, Brooks and my dad, William Hugh McCollough. 


\section{THE Colonial IMPERATIVE AND INDIGENOUS PERSPECtIVES}

During Spain's colonial era (1689-1821) in the Southern Plains, Native Americans in the region encountered new material goods, religious ideas, political economies, and exposure to deadly diseases. If communities managed to survive the devastating effects of epidemics, then access to utilitarian metal objects, firearms, and horses became politically and economically critical to the continued stability of Native societies. Locations of trade routes, and colonial trading posts, as well as the political ability of Native peoples to navigate the colonial landscape, all played a dominant role in determining whether an indigenous nation successfully obtained those commodities necessary to its survival and prosperity. Two other important factors also affected access to trade goods: exposure to epidemics and the trading policies instituted in the region by colonial governments.

Continual epidemics, particularly those associated with typhoid, smallpox, and measles, decimated entire indigenous populations (Thornton 1987: 44-45). For example, numerous Native nations located along the lower Rio Grande and the upper coast of Texas succumbed to the relentless epidemics sweeping the region (Aten 1983; Campbell 1988; Schuetz 1980). Communities that survived did so by merging with other nations (Anderson 1999; Aten 1983; Carter 1995; Gunnerson 1974; La Vere 2000; Lee 1990; Perttula 1992; Smith 1995 ) and/or migrating from the region (Gunnerson 1974; Ramenofsky 1985; Reff 1991; Robles 1938). In a number of cases, indigenous communities, particularly those associated with nomadic economies, managed to prosper during this often dangerous era (Anderson 1999; Hämäläinen 2001).

Of particular interest in this regard are the political and economic strategies implemented by the nomadic Comanches and the 
semisedentary Hasinais, the most populous of the southern branches of the Caddoan linguistic family, to survive Spain's tumultuous colonial era. Both the Comanches and the Hasinais mitigated the effects of colonialism through reorganizing their patterns of settlement, economic livelihoods, and political organizations. In the Comanches' case, mobility increased, their economy became more specialized, and, for a brief period, they adopted a more centralized political organization. Among the Hasinais, a number of villages merged and their political organization became not only more secular but also less hierarchical during Spain's colonial era.

A number of internal as well as external factors contributed to the reorganization of these two communities. One significant event entailed the emergence of colonially controlled markets in western Louisiana, in the Puebloan villages along the upper Rio Grande, and in population centers in eastern and central Texas. Comanches migrated near these establishments in order to increase their access to trade items. As a result, the Comanches gained access to agricultural products, textiles, metal tools, and silver (Hämäläinen 2001).

In the Hasinais' territory, Spain initially limited its expansion to the establishment of Franciscan missions. Until France's retreat from the region in 1763, French nationals operated trading posts in the area. After France vacated the area, entrepreneurs supported by British and American businesses increased. A number of Spanish traders, often lacking government approval, also began operating in the region.

Although Spanish missions offered few opportunities for trade, the French merchants exchanged firearms, textiles, jewelry, and metal utilitarian objects with the Hasinais (Bolton 1914; Flores 1985; Leutnegger 1977). In addition, French traders opened small trading posts in many of the Hasinais' villages (Smith 1995). At these places, the Hasinais could legally buy firearms, have their guns repaired, and buy items on credit (Allain 1988).

Even though Spain forbade the sale of firearms to Native peoples, both the Comanches and the Hasinais still participated in Spanish markets. No matter which colonial government sponsored the trading post, these two communities exchanged horses, bison, and other indigenous animals and their by-products for manufactured commodities (Albers 1991, 1992; Bamforth 1988; Hall 1989; Hämäläinen 1998, 
2001; Kavanagh 1996; Klein 1993). Unlike the French, British, and American traders, however, Spain banned the trade of firearms.

In order to secure their role as suppliers of colonial commodities, the Comanches and the Hasinais negotiated trade and peace agreements with the Spanish and the French (Hall 1989; Kavanagh 1996; La Vere 1998, 2000; Perttula 1992; Smith 1995). They also reorganized their political economies, which increased their competitive edge in these emerging trade opportunities (Hämäläinen 1998, 2001; Kavanagh 1996; La Vere 1998, 2000; Perttula 1992).

Strategies implemented by the Comanches to remain competitive included raiding, territorial expansion, (often at the expense of local indigenous communities), more frequent migrations, and the negotiation of numerous alliances and peace accords with the Spanish. Being semisedentary, the Hasinais had fewer options. They did, however, have access to firearms. In order to participate in the firearms trade, the Hasinais increased agricultural production to meet the growing demands of colonial settlers. In addition, they decentralized and secularized their once highly centralized theocracy.

Ultimately, however, the Comanches became more effective traders than the Hasinais. Being nomadic, the Comanches developed a complex and successful raiding system as well as a highly mobile military force (Albers 1991, 1992; Foster 1991; Hall 1989; Hämäläinen 1998, 2001; Kavanagh 1996; Mishkin 1940; Secoy 1953). Each of these skills enabled the Comanches to raid Spanish ranchers and other Native communities with relative impunity. In addition, their military prowess permitted them to not only forestall colonization by the Spanish but also block the access of Native competitors to trading routes, organized markets, and habitats rich in bison and grazing lands (Albers 1992; Alcocer 1958; Hämäläinen 1998, 2001; Kavanagh 1996).

Initially, the Hasinais played a critical role in the expansion of French firearms (Smith 1995; Wyckoff and Baugh 1980). By increasing agricultural production, the Hasinais not only fed colonists in the region but also emerged as middlemen in the firearms trade (Hickerson 1996, 1997; La Vere 1998, 2000; Perttula 1992; Smith 1995). Because of their horticultural economy, however, the Hasinais lacked the mobility of the Comanches. This, in turn, limited their capacity to participate in raiding ventures or military actions against potential competitors. It 
also diminished their ability to garner large herds of horses or to generate surpluses of wild game by-products (Bolton 1914; Bridges and De Ville 1967; Griffith 1954; Kinnaird 1946; Morfi 1935).

By the 1770 s, the Comanches had begun to surpass the Hasinais' importance within the emerging Southern Plains regional economy. For example, their expansion into central Texas permitted the Comanches to successfully bypass middlemen and instead trade directly with American, British, Spanish, and remnant French traders (Bolton 1914; Hämäläinen 1998, 2001; Kavanagh 1996; Sibley 1922). An indication of the Comanches' power over events in the region's political economy is evidenced by their ability to intervene in the Hasinais' political negotiations with other indigenous communities. For example, the Comanches successfully terminated an economic treaty made between the Hasinais and the Lipan Apaches in the 1770s.

After the 1763 Treaty of Paris - resulting in France's retreat from the area-the Comanches' dominance in the eastern portion of the Southern Plains accelerated. Using both force and diplomacy, the Comanches developed trading and military alliances with Native communities located along strategic transportation routes (John 1975, 1984). Some of these were short-term opportunistic endeavors, such as their brief alliance with the Utes. Others, however, such as their treaties with the Taovayas (later known as the Wichitas), the Kiowas, the Cheyennes, and eventually their past enemies, the increasingly powerful Osages, led to long-term and generally peaceful relations (Richardson 1929, 1933).

Spain's role in the Comanches' growing importance in the region's political economy is difficult to assess. The initial antipathy of the Spanish toward the Comanches slowed the community's ability to gain a foothold in the upper Rio Grande region. After the Comanches had all but annihilated the Lipan Apaches, once the major indigenous economic force in the Puebloan region, the Spanish aided the Comanches in their efforts to dislodge newly established settlements of the Lipans in central and northeastern Texas (Dunn 1911). In addition, colonial officials supported the Comanches' ban on the Hasinais' alliance with the Lipans.

Unable to maintain a foothold in this expanding economy, the Hasinais became peripheral to the region. Lacking powerful allies, 
decimated by disease, and feeling pressure from the expansion of colonists within their territory, this once powerful nation migrated from their homeland to Oklahoma in the 1830s. Unlike the Hasinais, the Comanches continued to persevere until weakened by the growing presence of American colonists and military personnel. By the 1870 s, the Comanches' waning importance in the region compelled them to sign the Treaty of Medicine Lodge, thereby submitting to a reservation economy.

Frequently, much is known about both the battles fought between Western nations competing for resources peripheral to their political economy as well as the policies instituted by these nations to negotiate with the nonstate communities already occupying these regions. Less well understood is the myriad of strategies implemented by nonstate societies attempting to retain sovereignty and maintain control over their relations with these encroaching colonial nations. Many recent Great Plains scholars have addressed these lacunae by focusing on the changing political and economic landscape of either the Comanches or the Hasinais. In the case of this book, though, these two nations are compared rather than discussed singularly. An advantage of this approach is that it exposes similarities and differences in the strategies used by two separate communities to negotiate with the same colonial presence. Core to this venture are four areas of study. These include Spain's colonial trading policies as well as the changing alliances and settlement and political organizations of the Comanches and the Hasinais.

The book explores these four variables within the context of three different theories. These theories include world systems perspectives, regional analysis, and social history. As Chapter 2 illustrates, each of these theories contributes to the development of a framework for understanding changes within the political economies of the Comanches and the Hasinais between 1689 and 1821. Through an analysis of earlier anthropological approaches applied to the Great Plains, Chapter 2 illustrates the potential of these three theories to gain greater insight into the activities of the Comanches and the Hasinais during Spain's colonial era.

As Chapter 2 makes apparent, theoretical approaches prior to the emergence of these three theories lacked the ability to explain a 
Native community's political economy without relying on environmental variables, internal social constraints, or the creative aspects of novel colonial trade goods. For example, warfare in the region tended to focus on a society's norms rather than regional events. Wallace and Hoebel describe it thus:

The prosecution of warfare was very much a matter of individual discretion. Any Comanche was theoretically eligible to lead a war party, and there was no power to restrain him.... If his military reputation had been established in combat, if his "medicine" was powerful, and if he was known to be liberal in the division of the spoils, he seldom had difficulty securing a large following. (Wallau and Hoebel 1952: 216)

Regional and global events tended to be perceived as mere epiphenomena. Ignored in this type of descriptive account are the conditions responsible for the emergence of endemic warfare in the region. History cannot be dichotomized between the colonial and indigenous residents.

Researchers who collapse the complexities of these shared histories into a descriptive account of specific events or actions often are trapped into giving too much emphasis to either colonial forces or local conditions. In the first category, colonialism becomes a monolithic enterprise with global proportions. For example, according to Karl Marx and Friedrich Engels:

The cheap prices of its commodities are the heavy artillery with which it batters down all Chinese walls, with which it forces barbarians' obstinate hatred of foreigners to capitulate. It compels all nations, on threat of extinction, to adopt the bourgeois mode of production; it compels them to introduce what it calls civilization into their midst, i.e., it becomes bourgeois themselves. In one word, it creates a world after its own image. (Marx and Engels 1959: 11)

The perception that colonial intrusion inexorably creates itself in temporally and spatially distant places leads to the marginalization of the policies, goals, and histories of the colonized.

If, on the other hand, only the colonized are the focus, external conditions imposed by colonialism may be ignored. Indigenous actions can then be perceived as autochthonous responses to a small and locally 
generated spectrum of factors. Societies are then viewed as static except when faced by ecological change, epidemics, and/or novel commodities. Only by integrating theoretical perspectives that permit a closer study of global, regional, and local conditions can a more complete explanation of social change be explained.

In order to more fully show the theoretical advantages of world systems perspectives, regional analysis, and social history, Chapter 3 provides an ethnohistorical account of the Comanches and the Hasinais. Specifically, the patterns of settlement, political, and economic organization of both of these communities are studied in detail. These theories are then applied to specific aspects of these changing patterns. This is due to the fact that each theory encompasses particular strengths. As a result, Chapter 4 uses world systems perspectives to more clearly understand the relationship between Spain's colonial trading policies and changes within the political economies of the Comanches and the Hasinais.

Chapter 4 shows that Spain understood the strategic use of trade in the development of alliances. Because Spain's occupation of the Southern Plains stemmed from a mercantile economic philosophy, however, the government implemented restrictive financial policies, which arrested the development of viable trade outlets, colonial industries, and Spanish emigration (McNeil 1985: 3). Lack of a strong economic base meant that settlers in the region had to rely on imports in order to sustain their colonies. In addition, Spain, unlike their competitors the French, implemented restrictive trade practices that forbade the sale of firearms to Native peoples. This made it necessary for the Comanches and the Hasinais to maintain colonial allies beyond the Spanish.

Through a world systems perspective, a framework for understanding the impetus for the expansion of the Spanish and the Comanches and the contraction of the Hasinais becomes clearer. In addition, this approach permits a closer study of the strategies used by the Spanish to incorporate the Comanches into the region's economy. It also aids in efforts to understand the strategies of the Comanches and the Hasinais to forestall incorporation.

As Chapter 5 illustrates, regional analysis emphasizes the relationship between a community's political activities and the flow of 
commodities. By focusing on the strategic need for the Comanches and the Hasinais to maintain access to firearms and horses, the reasons behind the development of alliances and the location of settlements become clearer. Because horses were the main items exchanged for firearms, the Comanches worked to maintain their own herds and to gain access to wild herds. Due to the pasturage needs of horses, the Comanches were highly mobile. In order to successfully trade their horses for needed commodities, the Comanches also developed alliances with strategically located communities. Through regional anal$y$ sis, the expansion of Spanish markets into certain regions as well as the involvement of the Comanches and Hasinais in these trading centers becomes more apparent.

Among the Hasinais, settlements became more concentrated and tended to relocate closer to sources of high-demand commodities (Smith 1995). After France left the region, alternative trading routes developed in eastern Texas. Located north of the Hasinais, these routes permitted other indigenous communities to act as middlemen in trade networks. This, in turn, weakened the Hasinais' political and economic importance in the region. Migrating closer to potential sources of firearms and negotiating alliances with equally marginalized communities, such as the Lipan Apaches, can be better understood through the use of regional analysis.

To more fully explain strategies used by the Comanches and the Hasinais to participate in the region's political economy necessitates the inclusion of local social histories. An exploration of local histories augments explanations of indigenous involvement in colonial processes. As Chapter 6 shows, the use of localized histories permits a more transparent representation of the plural and particularized expressions of colonial encounters (Thomas 1994: ix-x).

Changes in the political organization of the Comanches and the Hasinais provide a window into specific local change. In the Comanches' situation, political organization remained diffuse except for a brief period of forced centralization. A decentralized power structure diminished the control Spanish officials could exert over the community. Among the Hasinais, political control fluctuated between centralized and dispersed systems of power sharing. Having one leader proved useful as a broker between the competing French and Spanish governments. After France's retreat from the region, having one leader 
became a liability, as Spain could sanction the entire community through the auspices of this one representative.

Combining world systems, regional analysis, and social history allows the study of different types of strategies implemented by Native communities. Consequently, Chapter 4 emphasizes colonial interactions in relation to global and regional realities. Chapter 5 focuses more closely on the strategic use of alliances and settlement patterns in order for the Comanches and the Hasinais to remain competitive in the region's political economy. Lastly, Chapter 6 explains local changes implemented within these two communities in order to maintain sovereignty.

Political and Economic Processes During Spain's Colonial Era

The southern Great Plains encompasses an area extending from the Arkansas River east to the Mississippi River, south to the Gulf of Mexico, and west to the upper Rio Grande. Spain's colonial efforts in the region began in 1680 with the establishment of Franciscan missions in east Texas and ended with the completion of the Mexican Revolution in 1821. Throughout this period, Spain endeavored to increase its role in the global economy. This in turn affected colonial policies in the Southern Plains.

Spanish colonialism did not follow a Cartesian plan in the Southern Plains. Rarely unified, Spanish colonial agents competed not only with other Euroamerican colonies but also with the Church and each other. This led to frequent changes in the focus of local policies, strategies, and actions. Adding to the unpredictability of colonial mandates was Spain's overseas meddling in the region. Blanket legislation would be passed that had little to do with the realities of the Southern Plains. Probably the two most egregious of these were the restriction of firearm sales to Native peoples and the prohibition on settlers trading with colonies backed by other foreign nationals. These two bans led to endemic smuggling and the increased importance of France to indigenous people residing in the area.

Actions in one regional locality often bore little resemblance to those in another. Consequently, Spain's attempts to establish political and economic links with Native communities varied both spatially 
and temporally. Studying shifts in alliance and settlement patterns of the Comanches and the Hasinais can show this. For example, the Comanches utilized their relations with colonial agents to expand their territory. On the other hand, Spain's policies caused the Hasinais to experience a diminishment of their importance in trade networks.

Neither global nor regional political economies entirely controlled the means by which the Comanches and the Hasinais participated in the colonial landscape. An added dimension involves each society's own history. Although both of these communities experienced colonial encounters, their involvement with colonialism differed both temporally and spatially. In the Comanches' case, production became more specialized, mobility increased, and bison hunting probably decreased as more opportunities for exchange developed. Among the Hasinais, agricultural production and bison hunting increased but opportunities for exchange decreased.

By studying archival and published documents, it becomes apparent that the changing circumstances of the Comanches and the Hasinais stemmed from a mixture of local, regional, and global processes. Applying world systems, regional analysis, and social history approaches to focus on specific actions, such as alliances, Spanish trading policies, and patterns of settlement and political organization permits the development of a more comprehensive understanding of social change among the Comanches and the Hasinais during Spain's colonial era. 


\section{2 \\ INTERPRETATIONS OF THE CoMANCHES AND THE HASINAIS PRIOR TO THE RESERVATION ERA}

Throughout the twentieth century anthropological researchers have applied numerous models to better understand the histories of Native peoples residing in the Great Plains. Scholars have frequently focused on questions concerning the origins, political economies, kinship systems, and material cultures of the indigenous peoples residing in the region prior to the reservation era in order to explain similarities and differences between them. Four main approaches have been used to discuss these topics. These included Boasian historicism as well as ecological, functional, and economic models. Although each of these efforts added to the knowledge of the area, none of them alone had sufficient breadth to account for the diversity and complexity of the histories of Native inhabitants.

Starting in the 1980s, anthropologists began adapting three new theories to Native American studies. These included world systems perspectives, regional analysis, and social history. Each of these approaches contributed a more in-depth understanding of the complex histories of colonial encounters. This can be illustrated by focusing on the Comanches and Hasinais during Spain's colonial era. In order to illustrate the contributions each of these models has made to a better understanding of the Comanches and Hasinais, they will be discussed in a historical context.

\section{Boasian Historicism}

The work of early anthropologists frequently perpetuated the romantic myths initially constructed by Euroamerican interpretations of Native American actions. As a result, many articles and books written during 
the early decades of the twentieth century focused on the descriptive aspects of tobacco societies (Lowie 1920), Sun Dances (Grinnell 1910; Kroeber 1907; Spier 1921), military societies (Lowie 1916; Richardson 1933; Wissler 1907), and folklore (Lowie 1956). Each of these broad topics became an archetype for all Native communities residing in the Great Plains.

Working from a historicist viewpoint, Boasian researchers related social change to a community's own internal developmental structure. By rejecting the evolutionary models proposed by Morgan (1877), Spencer (1896), Tylor (1889), and others, the Boasian model limited itself to a

detailed study of customs in their relation to the total culture of the tribe practicing them, in connection with an investigation of their geographical distribution among neighboring tribes, [which] affords us almost always a means of determining with considerable accuracy the historical causes that led to the formation of the customs in question and to the psychological processes that were at work in their development. (Boas 1896: 905)

Boasian ethnographers derived their interpretations from two separate assumptions. First of all, many of these researchers visualized Plains communities as distinct bounded societies characterized by internal homogeneity. As a result, these ethnographers believed in the possibility of reconstructing the true essence of Native peoples. Second, by tracing similar traits present in separate communities, Boasian scholars tried to attribute the origins of specific behaviors to a particular Native community (Grinnell 1923; Wissler 1914, 1922).

In order to pursue these two themes, fieldworkers interviewed numerous tribal elders about pre-reservation-era activities. The fallacy of this approach stemmed from the permeability of indigenous populations as well as the reality that "contamination" from Euroamericans had been occurring since the sixteenth century. By ignoring these facts, a timeless, almost mythic past became the currency of many of these studies. Grinnell (1923), Richardson (1933), and Wissler (1914, 1922) typified this method, focusing their studies on either the militant aspects of Native communities or the functional necessity of various cultural traits. For example, explanations of military activities adhered to the colonial notion that the underlying basis of nomadic warfare 
involved highly individualized motives that ultimately originated from a military ethos. Generally, these accounts abstained from studying the economic roots of military actions (Foster 1992: v). Consequently, indigenous warfare became interpreted as honorable forays that provided a brief respite from the lure of the bison hunt and sacred, though picturesque, ceremonial activities.

The romanticizing of Plains warfare not only obfuscated Euroamerican perception of indigenous behaviors, but also salved American guilt surrounding the Indian wars of the nineteenth century (Berkhofer 1978). This invented history gained symbolic resonance in the public sphere through the publication of studies written in the ethnographic present. As they mined the memories of elders, rarely did fieldworkers address the impingment of colonial policies such as allotment, loss of religious freedoms, and forced education. As Trouillot commented, "Once revealed, the harsh realities of neocolonialism take such grand dimension that little else seems to matter" (1984: 181).

While ignoring external social relations, not only with Euroamericans but also other Native communities, many researchers focused on the functional aspects of indigenous actions. Because idealized traditions had already been created, the essentialist functions of all actions were interpreted as maintaining a community's social order.

While it is true that cultures are rooted in nature, and can therefore never be completely understood except in reference to that piece of nature in which they occur ... the immediate cause of cultural phenomena are other cultural phenomena. (Kroeber 1939: 11)

No mention was made that a society is a heterogeneous population with differing views of what constitutes social order. Dismissing discordant actions within a population resulted in the homogenization of the entire Great Plains region. It was conjectured that similarities between separate Native societies arose from their functional equivalence. Therefore, all Plains populations could be lumped together into the same analytical category. As a result, scholars such as Kroeber (1907, 1939), Lowie (1909, 1916, 1954, 1956), Richardson (1933), and Wissler (1907) essentialized distinctive features of Plains Indians. An example of this practice can be found in Lowie's assertion that 
the introduction of horses into the Great Plains elaborated an already existing cultural pattern:

Though the horse became integrated with daily life, it did not evoke much originality except in a minor way ... the economic utility of horses ... lay in enabling riders to kill large numbers of big game animals more rapidly and efficiently than was otherwise possible and in facilitating transport. (Lowie 1954: 42-43)

In a similar vein, James Mooney (1898: 161) perceived the horse as a means to more efficient hunting that in turn not only permitted more time for military engagements but also expanded the range in which soldiers could engage in battles. No mention of the external factors contributing to warfare was offered. This perception of stasis among peoples of the region allowed anthropologists to easily document traits considered immutable and thus able to act as identifiers of Plains Indians. In retrospect, the reification of these traits led "to an exaggerated and even false sense of difference" between the colonizers and the colonized (Carrier 1992: 71).

Through these representations, scholars sanitized the realities of colonial encounters and ignored the contextual emergence of indigenous actions. Explanations of Great Plains history centered on local conditions and failed to explore linkages to regional and global political economies. Whether ecologically or culturally derived, interpretations of Native peoples assumed that indigenous actions could be understood by solely focusing on local histories.

\section{Ecology and the Culture Area Concept}

Predictably, the development of Boasian historicism coincided with the emergence of the culture area concept. Steeped in the idea of a true Plains essence, this concept stressed the perceived homogeneity of the Plains social and material landscape. Accepting the notion that similar habitats caused analogous constraints and possibilities, subsistence was portrayed as the key mediator between habitats and cultures (Eggan 1937: 82; 1952: 39; Mooney 1898: 161; Powell 1898: lxvii-lxix; Wissler 1914: 12; 1926: 216-17).

Political and economic variables were treated as epiphenomena in these early and sometimes mechanistic schemes. Frequently, 
researchers conceived of changes in the political economy of indigenous populations as a material expression of the local environment. With ease, differences in the cultural traits of Native peoples were attributed to environmental variations. Instead, the focus of the research remained centered on local intrasocietal events.

Inevitably, the Plains cultural area became the embodiment of a bounded universe that remained static. Bypassing these issues, Wissler concentrated on the origins of an invented Plains culture. He concluded that

no one group of people on the Plains can as yet be set down as the originators of Plains culture. There seems to have been a constant giving and taking until the whole area reached a general level of uniformity, bearing important differences... but differences that seem to be normal tribal variations rather than distinctive characteristics. (Wissler 1907: 49)

Following his lead, other anthropologists studied the origins of Plains traits. Like Wissler, many of these individuals assumed that social and cultural changes within the Great Plains region stemmed from internal sources, and as a result, significant breaks with the status quo related to interactions between local indigenous communities. Lowie (1916: 948) and Lehmer (1954: 154) typified this perception by concluding that the traits used to demarcate the Plains culture area originated with Plains village groups.

The simple explanation is that many essential aspects of Plains culture were pre-existent in the "Eastern Maize Area," not dependent on horse breeding and came to be imported into the Plains by migration either of peoples or of ideas from the woodlands. (Lowie 1982: 200)

Not until the rejection of environmental determinism by Steward (1955) and White (1959) did more complex ecological models of the Great Plains region emerge.

\section{Systems Approach to Ecology}

Both Steward and White rejected unilineal determinism and strived to incorporate a larger array of variables into their environmental modes. Each of these researchers rejected the notion of static communities 
and instead addressed social change. In their case, resource utilization became the main focus of analysis. Special attention was paid to the processes associated with the production and consumption of subsistence items. Still, internal factors such as demographic pressures, past traditions, and available resources organized these processes (Eggan 1966; Hoebel 1940, 1954; Oliver 1962). Novel resources, such as the horse and firearms, acted as the catalyst for changes in production and subsistence. Invariably, these changes resulted in greater homogeneity or increased stratification (Blakeslee 1975; Moran 1982: 235; Oliver 1962: 12).

When Native communities failed to meet the criteria used to define the Plains culture area, researchers pointed to their divergent pasts as an explanation. For example, according to Oliver (1962: 3), Native communities stemming from a horticultural origin tended to be more politically complex than those derived from a hunting and gathering origin.

Although an improvement over earlier ecological studies, these new paradigms regarded the analysis of a specific cultural community as qualitatively different from one directed toward the interactions between culturally different populations. Ultimately, this led to the polarization of production and exchange. Production was treated as the primary element within a supposedly bounded unit, while exchange was viewed as basic to intersocietal relations (Rowlands, Larsen, and Kristiansen 1987: 3).

Divorcing production from exchange once again led to the interpretation that local communities represented timeless entities, cloistered within their own bounded universes. Rooted in local conditions, the structural order of production provided the framework for understanding exchange. As an adjunct to production, exchange differed little from Lowie's explanation of the horse's role in social change: "though [exchange] became integrated with daily life, it did not evoke much originality in a minor way" (Lowie 1954: 42).

In the 1960s the systems approach to ecology arose as a means to end the dichotomy between exchange and production. It also introduced the idea that "similarity of social organization is not necessarily an indicator of similar histories or evolutionary trajectories" (Hall 1989: 11). Key to the systems approach were the adaptations and interactions 
of a population. Culture became redefined as the "extrasomatic means of adaptation... an extrasomatic adaptive system that is employed in the integration of a society with its environment and other sociocultural systems" (White 1959: 8).

Using this scenario, culture acts as the dominant mechanism for exchanging matter, energy, and information within the environment. Mapping the flow of matter, energy, and information across space permitted researchers to develop concepts such as carrying capacity, limiting cycles, predator-prey models, and the impact of patchy environments. Circumventing the potential tautology if adaptation is equated with an end state rather than a continual process, numerous ideas associated with biological evolution have been incorporated into the systems approach. Concepts such as specialization, adaptive radiation, laws of cultural dominance, and evolutionary potential inform much of the literature associated with this theory (Baugh 1982; Hass 1990; Reher 1974; Spielman 1983). Rarely do researchers relying on this approach fall into the trap of describing actions as adaptive simply because they exist. It also ended the assumption of bounded ahistorical societies. As a result, ecologically oriented scholarship continues to flourish.

Currently, the ecosystem approach dominates the archeological literature. The circulation of matter, energy, and information are easily translated into the study of goods, services, and trade (Paynter 1982: 13). In addition, many of the biological concepts have proven invaluable to an understanding of local constraints and possibilities. Ignored in these accounts, however, is the factor that "transforms problems of ecological limitations into decisions of a political economy" (Cole and Wolf 1974: 285). Like earlier models, the ecosystem approach has the propensity to ignore the organizational capacity of the economy. When this occurs, the flow of matter, energy, and information remains the template used by some scholars to explain the essence of social life.

\section{Economic Models of Social Change}

Prevalent in the early ethnographic literature was the idea that trade between indigenous groups operated under a different social construct than exchange networks concurrently utilized by Euroamericans 
(Blakeslee 1975; Wood 1972, 1973, 1980). This conception may have its origins in the Weberian notion that the development of capitalism introduced novel attributes such as trade for profit rather than social status, and therefore capitalist systems could not be compared with precapitalist systems (Weber 1976).

Beginning in the 1940s, anthropologists began developing more sophisticated economic models. Stimulating the development of these approaches was the publication of a corpus of classic ethnographies by scholars such as Redfield (1940), Leach (1954), and Barth (1969). Rivaling the dominant ecological models of social change, each of these scholars subscribed to a common critique of prior anthropological analyses. This critique argued that human communities should not be conceptualized as autonomous entities existing in historical isolation. Through the contextualization of a region's spatial, temporal, and social data, these scholars promoted the idea that the scale of social processes encompassed more than one cultural group. Usually these processes are described as regional in scale, but they have also been characterized as global. By emphasizing the importance of interaction, it became possible to develop more sophisticated techniques for studying populations within a historical framework.

A number of Great Plains specialists such as Ewers (1955), Goldfrank (1945), Jablow (1950), Lesser (1933), Lewis (1942), Mishkin (1940), Secoy (1953), and Richardson (1940) utilized this approach by exploring the economic and political consequences of Euroamerican penetration into the area. Invariably, though, many of these researchers perceived change within indigenous structures as reactions to Euroamerican actions rather than as a more complex interface between external and internal realities. Thus, according to Secoy, a Plains culture arose from

a phase of cultural creativity that was based upon the Southwestern Plains center, and that flowered into the superstructure of elements and complexes which distinguished Wissler's most characteristic Plains tribes of the late 19th century. (Secoy 1953: 90)

Ignored in this account is the development of Euroamerican markets and the commodification of local products, such as horses and 
bison. Scholars such as Ewers (1955), Jablow (1950), and Lewis (1942) endeavored to rectify this deficiency. Reacting to epistemological critiques of the culture area concept, each of these researchers attempted to provide a more contextual understanding of sociocultural change in the region. Eschewing the vague language of independent invention and subsequent diffusion, these writers aspired to explicate the interconnections between differing populations. Thus, they replaced earlier models of sociocultural change with one that explained regional similarities through a shared economy.

These scholars rarely systematically address the linkages between local, regional, and global political economies, however. By ignoring the unitary effects of these three levels of analysis on social action, instead focusing primarily on just the regional economy, these researchers often provided a one-dimensional analysis of the creation and modification of structural arrangements. Though their regional level of analysis moved beyond diffusion, social change was regularly portrayed as reactive. Economic forces were treated as impinging on a community and structuring the acquisition of critical resources, such as firearms and horses. As necessary as water, these two items were described as the new catalysts of social change.

Within the framework of this trading economy there existed cultures of different basic subsistence types (which might be viewed as technologies exploiting different aspects of a similar environment), whose production was geared to the requirements of trade. (Jablow 1950: 88)

Through conceptualizing trade "as a set of mechanisms designed to challenge local adaptations and reallocate resources ways unique at the local level" (Cole and Wolf 1974: 285), these authors lacked the methodologies to clearly illustrate the connections between the local, regional, and global economies.

In an attempt to redress this problem, a number of scholars have incorporated the theoretical concerns of a world systems approach into their research (Albers 1991, 1993; Hall 1989; Klein 1993). Like earlier economic models, these individuals recognized that shared economies created linkages between populations. Invariably, the organization of this regional economy was attributed to global forces. Mercantilism 
and, later, capitalism became the means for understanding Native American production and/or political organization. The dynamism of local activities became subsumed under this larger force.

Only by combining the models developed for local, regional, and global political economies is it possible to provide a clearer understanding of the relations between indigenous and colonial populations in the Southern Plains. By integrating these three levels of analysis, the relationship between internal arrangements of cultural communities and their external linkages to regional and global political economies becomes clearer.

\section{Integrating the Global, Regional, and Local}

The utility of research that links the local, regional, and global political economies became apparent after the groundbreaking work done by Steward and his followers (Steward 1955; Wolf 1955, 1957, 1959; Wolf and Mintz 1957). Through their research, anthropologists began to emerge from the Boasian legacy of historicism. Shattering the idea of internally derived and organized worldviews, they explored culture as "open fields" of interaction. Consequently, each of these scholars focused on the actual linkages or articulating structures connecting communities.

For example, Mintz (1972) explored the relationship between sugar consumption and the history of Caribbean communities. Wolf (1969) discussed the connection between the organization of peasant communities and the emergence of commercial capitalism. In both of these cases, however, local history was understood within the broader social and economic landscape. More recently, Hall $(1989,2000)$ and Klein (1993) applied the theoretical aspects of world systems to regional economies and local change within the Great Plains.

\section{World Systems Theory}

A world systems approach focuses on the penetration of a global economy into regional political economies. The theory provides a unified explanation for varying degrees of social complexity across spatial and temporal divisions. In this model, differences in social complexity are all part of a single spatiotemporal process defined within a regional or 
an interregional scope. Relationships between different communities form the key to world systems theories. Arguments abound among theorists utilizing this type of approach. Generally, these controversies center on the emergence of capitalism and its importance as an outside agent of intrasocietal transformation (Ekholm and Friedman 1982; Friedman 1993; Schneider 1977).

The more traditional of these approaches focuses on the impact of capitalism on regional economies. Building on Adam Smith's ideas presented in The Wealth of Nations, political economists argue that once capitalism became the means for producing wealth, it overshadowed the power of the government and became the dominant institution organizing society. André Gunder Frank $(1966,1969)$ and Immanuel Wallerstein $(1974,1979)$ developed one of the most sophisticated models of this aspect of political economies. Frank's suggestion that capitalist penetration caused the perpetuation of underdevelopment led researchers away from the idea that the underdevelopment of regions resulted from their own internal and archaic social structures. Embedded entirely within the structure of capitalism, marginal economies were destined to remain impoverished and dependent upon centers of capitalist accumulation.

Delving deeper into the global economic structure, Wallerstein conceptualizes the world's regions as organized into cores, peripheries, and semiperipheries. The relative position held by an area within the global economy is based on its control of resources, labor, production, and exchange. In addition, their division of labor ultimately structures the internal organization and external relations of each of these. Since Wallerstein (1974) equates capitalism with the advent of production for exchange, he views the division of labor as the critical linkage between social units. His approach is analogous to Durkheim's (1915) use of observable social data to unearth the hidden realities of social organization. As Roseberry (1991: 151) notes, followers of Wallerstein's methods perceive the capitalist system as the fundamental unit of analysis and the needs of the core as the driving force.

While many theorists recognize the heuristic utility of Frank's and Wallerstein's model of a global economic system, there is considerable debate over the causative factors responsible for a region's structure at any particular point in time. Significant differences center on issues such as the organizational primacy attributed to capitalism, the actual 
nature of exchange, and the reasons for local variations within an expanding economic system. Many scholars argue that capitalism is not the only economic system able to unify and dominate a region. Rather, similarities in processes of economic domination give rise to parallel developments across time and space. Crucial to this viewpoint is the notion that other arrangements, based on a variety of production types, are equally able to articulate large areas. Essential to these critics is the idea that economic domination ultimately results from social relations based on unequal access to wealth and power. Scholars such as Ekholm and Friedman (1982), Friedman (1992, 1993), Schneider (1977), and Schneider and Rapp (1995) suggest that the accumulation of capital rather than an economic system based on capitalism causes structural changes within a peripheral society's economic and political organizations. Levels of access continue to be structured and linked through an extrasocietal economy, however.

Disputes over the nature of exchange continue to absorb the attention of many scholars and critics of world systems theory. Major disagreements have erupted over Wallerstein's assertion that capitalism is the only economy to orient production toward exchange, which is often asymmetrical. As ethnographers and archeologists have discovered, production for the purpose of exchange exists under numerous economic systems. In addition, the exchange that occurs is often onesided. For example, systems of prestige and bridewealth as well as other types of kinship and tribute organizations can create production for exchange (Amin 1989; Godelier 1972; Schneider 1977, 1978; Smith 1976, 1985). Each of these formations causes specific kinds of exchange relations that unify an area in a particular way. Furthermore, variations in the types of linkages between global and peripheral systems determined a community's ultimate pattern of capital absorption and distribution.

In contrast to Frank and Wallerstein, current world systems theorists stress that the social organization of a community is more than a mere reflection of the global economy. According to Friedman, the global or regional economy stems from the articulation of numerous local and regional processes: "It is not, as often represented, an overlay that descends from above onto the sum total localities in the world" (1993: 210). The political and social processes of a local unit are more than a reflexive response to the requirements of capital accumulation in 
the core. Consequently, the effects of incorporation and resistance to incorporation by populations being engulfed into an expanding economy are major topics to be explored.

Critical to recent proponents of world systems theories is the degree of control a peripheral group exerts over its penetration by an external economic system (Hall 1989). Prior to these more sophisticated works, earlier writings intimated that the global market led to the impoverishment of peripheral regions. Across time and space, the intersection of this type of economy with one based on different principles such as barter and ritualized exchange is said to have led to the coercion of labor, technological stagnation, increased warfare, expropriation of resources, and the disappearance of indigenous processes of production, reproduction, and distribution (Faiman-Silva 1997). The insatiable needs of the core and the strategies used to exploit peripheral areas unleashed these negative factors. Peripheral groups might resist, but the destruction of their own political and economic structures was predestined.

Keeping this caveat in mind, a world systems perspective remains a powerful tool for understanding the complexities of colonial contact. For example, by exploring the connections between the global economy, Spain's occupation of the Southern Plains, and its colonial economy, the structuring of the region's political economy becomes more transparent. Paying attention to colonial structures, such as missions, presidios, settlements, and markets, permits a window into the nature of the linkages between the economies of indigenous communities and global and regional forces. Another component critical to a better understanding of social change in the region involves the commodification of horses and firearms. Both of these items illustrate incipient forms of capital accumulation in the region. By focusing on the nomadic Comanches and the more sedentary Hasinais, greater insight into the linkage of the Southern Great Plains with the wider economic arena can be explored.

\section{Regional Analysis}

Individuals such as Christaller (1966), Haggett, Cuff, and Frey (1977), Skinner (1964), and Von Thünen (1966) developed regional analysis as a methodology for elucidating the mechanics through which a 
local community is linked to others, forming a larger organization. Researchers who adopt this technique of analysis often conceptualize regional analysis as a method that illustrated and explained the systemic interrelationships between the spatial organization of a region's social units and the dialectical actions of local and, possibly, global forces.

Although complementary to world systems theories, regional analysis derived its data from the spatial flow of commodities. Ignoring the presence or absence of a global economy, it stressed those variables that contribute to this flow. Key factors were found in a region's modes of transportation, distances between exchange loci, topographical factors, types of resources transferred, and mediating structures of social organization. The spatial organization of activities within the area studied was assumed to be associated with economic and political conditions. Structures perceived as important mediators within or between a local community, region, or cluster of communities and the global economy included alliances and kinship networks, state and political institutions, forms of production and distribution, and class systems (Smith 1985: 84). As social organization and the structure of space were interrelated, each could be used to gain insights into peripheral populations.

Ascertaining how space is structured requires studying the movements of people, information, goods, and services. The circulation of these resources is thought to follow distinctive patterns. Explaining why these patterns arise in a specific place at a particular time forms the theoretical crux of regional analysis. Generally, variations experienced in the spatial integration of a region are assumed to reflect disparities in that region's systems of distribution, production, and consumption.

Economic conditions leading to these disparities often are perceived to center on a region or community's degree of commercialization. $\mathrm{Re}-$ gions can be grouped into three categories: uncommercialized, where distribution is predicated on direct or nonmarket exchanges; partially commercialized, in which distribution is based on noncompetitive or controlled market exchange; and fully commercialized, where competitive market exchange exists (Smith 1976: 314). In market economies, resources are generally concentrated in central places that are hierarchically organized and interrelated in systematic ways (Christaller 1972: 608). There are, however, other types of centralizing structures 
that can coexist with marketplaces or in areas with weakly developed market economies and which function in similar ways to market centers. Generally, this involves enduring activities that sustain a linkage between at least two separate communities. Undertakings associated with religious sites, trade fairs, and alliances could serve this function. For example, in the Southern Plains religious activities regularly occurred on the Brazos River, where a large meteorite had hit (Flores 1985: 61, 68). In addition, trade fairs occurred at the headwaters of the Guadalupe River (Espinosa 1746: 437). Alliances were also sustained through regular trade (Smith 1976: 72).

Political factors affecting a region's systems of distribution, production, and consumption are tied to an area's degree of commercialization. This association can be most clearly seen by studying a region's distribution system. For example, in poorly integrated regions, extended network systems prevail. Thus, even though several locations are related through trade, flow is horizontally organized between equivalent centers, leading to poorly organized trade (Smith 1976:314). This type of economic system is generally found in peripheral regions. According to Rappaport (1968: 109), in communities with extended network systems production is determined not by demand for the commodity produced, but by the demand for the commodity for which it is exchanged. In the Southern Plains, local production often related to the purchase of firearms, metal tools, and horses.

Bounded network systems can also arise in partially commercialized areas. Often associated with "big man" or patron-client relationships, bounded network distribution systems occur with specialized production and greater control over trade routes (Bonacich 1973). According to Hämäläinen's (2001) model, this might be the case with the Comanches. Their expansion resulted from a need to control access to Euroamerican markets.

If, however, colonial administrators monopolize these trade routes, bounded network systems may be transformed into solar or centralplace networks. Generally, solar networks support colonial elites at the expense of the colonized (Smith 1985: 86). In the Southern Plains, Spanish populations never achieved a high enough threshold to develop this type of system. Each of these distribution systems is associated with specific settlement and political patterns. 
A key variable in the emergence of the distribution systems is the exchange value given to a resource. Clearly, not all resources are equal in terms of economic exchange. Instead, a resource's exchange value is perceived as being both culturally specific and particular to capitalism. The most control a polity exerts over the circulation of a high-value item, the more political power that polity will experience.

In the Southern Plains, with the advent of colonialism Native inhabitants modified existing patterns of production, consumption, and distribution and created new ones. This led to variations in a community's level of integration with the regional economy and changes in that unit's political position. This can be more clearly illustrated by studying alliance structures among Comanches and Caddoans in the region during Spain's colonial era. During this period, horses and guns became highly valued exchange items (Jablow 1950; Secoy 1953). In order to control the distribution of these commodities, a community had to develop and sustain strategic alliances. A combination of factors determined the success of these alliances. These included a community's location, political economy, and relationship with colonial inhabitants. Temporal and spatial variations in the alliance structures found among the Comanches and Hasinais reflected shifts in markets, colonial policies, and political organizations. Changes in any of these sectors reverberated throughout the linkages structuring the alliances of the Comanches and Hasinais. This, in turn, transformed local-level institutions. Through this level of analysis, it is possible to illustrate ways in which the Comanches and Hasinais transformed Spain's colonial venture in the Southern Plains. It needs to be emphasized, however, that changes within local structures were constructed along their own internally generated system of cultural logic.

\section{Social History}

Different approaches that can be grouped together under the rubric of social history focus on a community's culturally mediated responses to externally induced change. Attempting to overcome the bankruptcy of ethnohistorical accounts that privilege the actions and aims of the colonizers, researchers associated with this approach have focused instead on the actual interactions occurring within contact encounters. 
If we are concerned to deal more adequately with the presence of "the colonized" in colonialism, with the autonomy of their enunciations and strategies, we need to adopt a theoretical perspective that accords more importance to competence without lapsing into an uncritical, subjectcentered humanism. (Thomas 1994: 58)

Thomas's suggestion that more weight be given to competence is a rejection of reified modes, such as structuralism and ecological or economic determinism. Competence, as a concept, focuses on the creative force of a community's actions. Consequently, the actions of the Comanches or the Hasinais are analyzed as strategies, not as structural poses determined and generated by internal or external events.

Following the lead of Bourdieu (1977, 1984), Thomas-like many other scholars interested in colonial encounters-argues against normative social theories that suppressed the complex and transformational nature of action.

The language of rules and models, which seems tolerable when applied to "alien" practices, ceases to convince as soon as one considers the practical mastery of the symbolism of social interaction - tact, dexterity, or savoir-faire-presupposed by the most everyday games of sociability and accompanied by the application of a spontaneous semiology, i.e. a mass of precepts, formulae, and codified cues. (Bourdieu 1977: 10)

With varying degrees of success, scholars such as Bhabha (1986), Comaroff and Comaroff (1992), Sahlins (1993), and Todorov (1984) have attempted to deal with indigenous societies as more than passive instruments of colonialism. Critical to their approach is what Sahlins called the "structure of conjuncture," a term that references the event in its historical entirety. By drawing in varying degrees on the works of not only Bourdieu but also Braudel, Foucault, Marx, and Saussure, authors associated with this approach tried to illustrate the ways in which colonial encounters occurred within a total historical context.

In this scheme, history is interpreted as a series of events that can be understood only through the local, regional, and global context of a community's cultural categories. Key variables in this type of research include the historical context of an event, the cultural categories bounding an event, and the motivations of specific actors involved in 
the event. An event gains its historical efficacy through the local cultural interpretation of it. Understanding and exposing those indigenous meanings involves the explication of intercultural points of contact.

Political and economic practices are viewed as the most fruitful avenues of exploration, since they are the two observable regions in which intracultural and intercultural differences are made explicit. In particular, this is the realm in which a society's importation of colonial elements acquired novel local accents. Utilizing Saussure's idea that signs are given value through their relations with other, necessarily contrastive signs, Sahlins argues that indigenous communities mediate the absorption of colonialism through their own cultural categories (Sahlins 1993: 13; 1985: xv). Thus, according to Sahlins (1993: 12), novel accents associated with colonial encounters can be interpreted as positional values whose differential relations to other categories of the indigenous scheme constitute the logic of the structural effects of intrusive forces.

Through the possibility of re-creating the systematic logic of a social unit's structure seems premature, it is possible to construct a more balanced representation of colonial encounters using this approach, particularly since each community has its own cultural system that incorporates colonial realities in its own unique way. This can be accomplished by studying an indigenous community's use of foreign commodities, since these items often enrich native self-conceptions. According to Sahlins (1993: 17), "they turn foreign goods to the service of domestic ideas, to the objectification of their own relations and notions of the good life." It is assumed that through culture a population can absorb alien conceptions, commodities, and people within its own logical system of order. Therefore, a community's use of commodities should provide a window into that particular society's unique cultural order.

Exploring the ways in which the Comanches and Hasinais integrated horses and firearms into their political and economic structures provides a better understanding of the active role these communities played in defining their integration into the local, regional, and global economies. 


\section{3 \\ ETHNOHISTORIC INTERPRETATIONS OF POSTCONTACT COMANCHES AND HASINAIS}

Ever since contact, interest in the Comanches and Hasinais has been continuous. Spanish diplomats, missionaries, traders, and military sources collected information about these two communities' political organizations, demographics, religious beliefs, subsistence, and locations. Using the same methods for gathering intelligence, early American and French forays into the region continued to gather data regarding the internal organizations of the Comanches and Hasinais. Not until the development of anthropology as a discipline, however, did this past information as well as newly learned data concerning these populations become more systematized.

Early anthropological accounts tended to emphasize subjects surrounding the origins, linguistic affiliations, and material objects of these two communities. Using Mason's (1896: 646) culture area concept as a theoretical base, these early scholars discussed the Comanches and Hasinais as bounded, hermetically sealed societies. As the discipline matured, accounts of these two societies became less descriptive and more involved with their relations with the local environment, regional economy, and colonial powers.

Through all of these efforts, a fairly comprehensive picture of the Comanches and Hasinais emerged. Disagreements concerning the interpretation of specific aspects of these two societies occurred as well. Most of these focused on issues concerning the ways these populations organized themselves politically. Particularly contentious have been the varying views on the degree of autonomy leaders held in their external dealings with other nations. By reviewing the data collected 
on each of these communities separately, some of these differences in interpretations may become less problematic.

\section{Descriptive Accounts of the Comanches}

Like many other Native communities residing in the Great Plains during the 1700s, Comanches migrated into the region from elsewhere. According to an oral tradition among the Shoshones, the Comanches separated from the Shoshones in the Great Basin due to an argument over the division of game (Grinnell 1920: 260). In 1706, the first written account of the Comanches residing in the Great Plains appeared in a letter sent by a Spanish military commander to the governor of New Mexico (Thomas 1935: 16).

Beginning in the early 1900 s, many anthropologists characterized the Comanches as a "true" Plains community. As nomads, they used horses, resided in tipis, and exploited bison. Unlike other "typical" nomadic communities in the region, however, the Comanches eschewed the Sun Dance, military societies, and a centralized political system.

Conceptualizing the Comanches as a series of traits associated with the Great Plains culture area, early anthropologists debated the reasons why this community differed from others in the Plains (Oliver 1962; Shimkin 1940; Wright 1977). These scholars offered numerous explanations of the "Comanche anomaly" (Foster 1991: 52-54). Generally, these discussions focused on the Shoshone origin of the Comanches (Hoebel 1954; Oliver 1962; Zingg 1939) or on the ecological conditions unique to the Comanches (Bamforth 1988; Colson 1954; Tefft 1964).

In the former case, the Comanches' close linguistic relationship to the Uto-Aztecan-speaking Shoshones in the Great Basin was expanded to include perceived similarities in social organization (Oliver 1962; Opler 1943; Wallace and Hoebel 1952; Zingg 1939). For example, Wallace and Hoebel explained that

the Comanche band was strikingly similar in organization to the aboriginal Shoshonean groups of the Great Basin in the days preceding white contact. It ranged in size from a single family alone to the small camp of related individuals ... to large groups of several hundred people. (Wallace and Hoebel 1952: 22-23) 
Among the Comanches, the family, often composed of extended kin, acted as the basic social unit (Wallace and Hoebel 1952: 23). Each of these families linked with a few others in order to form loosely organized bands. According to Curtis (1926: 187), "At the climax of their existence the Comanches were apparently divided into ten or more bands, but through tribal disintegration this band organization is almost lost."

Internal organization of these bands seems to have been kin-based structures led by a charismatic leader who exhibited military prowess and sustained regular access to spiritual forces (Kavanagh 1996: 4243). Wallace and Hoebel described band leadership as kin-based:

The family headman - and there was at least one for each group-were the peace, or civil chiefs. When the large band was functioning as a unit, contained several peace chiefs, one of whom was recognized as the head chief of the band. The rest formed an advisory council to the leader and at the same time maintained their positions as family headmen. (Wallace and Hoebel 1952: 24)

Presently, no consensus exists concerning the degree of control that leaders of bands maintained over their followers. Using examples from Spanish and ethnohistorical sources, Kavanagh (1996: 37-38), concluded that these leaders exhibited "the culturally defined ability to influence the behavior of others." Alternately, Foster (1991: 68), Hoebel (1940: 47), and Wallace and Hoebel (1952: 124-25) surmised that these leaders could not have exercised coercive force over their followers, nor negotiated unilaterally binding agreements with other related bands. Richardson (1929: 65) noted, for example, that "the nomadic habits of the Indians and the resultant divisions and subdivisions of the bands into small parties away from responsible leaders made it impossible for the chiefs to control their own men."

Some scholars attributed the absence of a political organization emanating from a number of powerful leaders to the Comanches' recent separation from the egalitarian, peaceful, and family-oriented Shoshones (Wallace and Hoebel 1952: 22). In this model, the influence of their Shoshone heritage weakened when they migrated into the Southern Plains. Forces diffusing from other indigenous nations, as well as the Plains environment, filled the resultant vacuum. Lacking 
enough time for the Sun Dance or full-blown military societies to emerge, the Comanches only developed attenuated Plains traits. Most notably, they placed a high value on successful raiding, warfare, and individual valor (Richardson 1933; Wallace and Hoebel 1952).

Reacting against heritage models of explanations, some ecologically oriented anthropologists stressed the importance of environmental factors as an explanation for the absence of a number of Plains traits among the Comanches (Bamforth 1988; Brown 1987; Colson 1954). The constraints and limitations of the local environment formed the basis of these scholars' argument. Regardless of whether the researcher interpreted the Comanches' territory as resource-rich (Colson 1954) or resource-poor (Bamforth 1988; Brown 1987), the availability of nutrients was reflected in the community's organization. As a result, the Comanches' demography, minimal government, and nomadic lifestyle formed a closed system with local environmental conditions.

More recently, Hämäläinen has merged ecological and economic models to discuss the decentralized organization of bands among the Comanches. According to Hämäläinen (2001: 206), soon after the Comanches migrated to the Plains, they developed increasingly smaller bands due to their reliance on bison. As the community became more involved in regional trade networks, these bands became even more dispersed due to the Comanches' role as "large-scale livestock traders" (Hämäläinen 2001: 207).

Recognizing the decentralized nature of the Comanches' bands, a number of scholars have tried to identify the mechanisms used by the community to link its disparate bands in order to maintain coherence as a political entity (Gelo 1986, 1987, 2000; Kavanagh 1996; Thurman 1980, 1987). Gelo and Thurman perceived the presence of overlooked centralizing structures, such as religion (Gelo 1987) or emergent military societies (Thurman 1987). Focusing on the rituals and symbols of the Comanches, Gelo $(1987: 553,557)$ noted that these served as material expressions of unifying religious beliefs. Values placed on individualism, militarism, and generosity all stemmed from this religious source. Through these shared beliefs, the relations between separate groups of Comanches were structured and maintained (Gelo 1986: 38).

Thurman's (1987: 578-79) research identified the presence of nascent military societies among the Comanches. Basing his interpretations on a variety of sources, Thurman argued that these societies 
aided the Comanches' efforts to unify the community by crosscutting band membership (1980: 52). Following Thurman's lead, Kavanagh also discusses the importance of local societies as a means to retain the political coherence of the Comanches:

Sodalities-political support groups, small-scale medicine societies, and large-scale military societies - and the scale of the units and sodalities increased with the level of integration. The Spaniards and Mexicans generally recognized those levels; Anglo-Americans generally did not. (Kavanagh 1996: 41)

Periodically, various bands would merge into larger organizations referred to as divisions by anthropologists (Foster 1991). During the late 1740s, the Spanish commented on the presence of two unnamed divisions of Comanches that engaged in activities near New Mexico (Kavanagh 1996: 48). By the latter half of the 1700s, three major divisions existed (Kavanagh 1996: 4). These included the Cuchanecs, also referred to as the Kotsotekas, the Jupes, and lastly the Yamparicas. Current researchers studying the political history of the Comanches continue to grapple with the internal political organization of these divisions.

According to Foster, "Comanche social structure is best understood as the strategic movement and organization of personnel among different social groups, regulated by means of periodic multigroup gatherings" (Foster 1991: 70). In his view, division leaders lacked any real power, as "they dealt with Euro-Americans on specific matters relating to Comanche-Euro-American interactions and were not 'paramount' or 'principal' leaders in the way that we usually employ those terms" (Foster 1991: 68).

Kavanagh (1996: 52) describes divisions as "political organizations composed of local residential bands linked by kinship and sodality ties and recognizing a commonality of interest in group affairs, war, peace, and trade." Unlike Foster, Kavanagh (1996: 53-54) perceives the leaders of divisions as having the ability to employ coercive force and to negotiate for the community as a whole.

The frequent movements of these divisions and the lack of information concerning their internal organizational structure will continue to plague attempts by researchers to more fully understand the role of 
leaders within these structures. As is the case today, the political strategies of the divisions remain hidden from view.

Since Hall's (1989) seminal work on the regional economy of the Southern Plains during Spain's colonial era, many researchers have focused their work on the linkages between the Comanches and other nations as an explanation for the community's political organization (Anderson 1999; Chase-Dunn and Hall 1997; Foster 1991; Hall 1989; Hämäläinen 2001; Kavanagh 1996; La Vere 2000). The work of Chase-Dunn and Hall focused on the importance of frontiers as a region in flux.

Viewed from a global perspective, the frontier is relatively narrow and sharp. Viewed more closely, it is a broad zone with considerable internal differentiation, both spatially and temporally. At either level, different types of expanding systems have different types of boundary membranes, each varying in the types and degrees of permeability to flows across or through them. (Chase-Dunn and Hall 1997: 70)

Spain's northern frontier exhibited a high degree of permeability for some indigenous populations (Thomas 1932). This was particularly true in the case of the Comanches, who crossed the frontier with alacrity (Kavanagh 1996). The Comanches' ability to ignore Spain's borders provides concrete evidence that local colonial officials lacked the necessary military, political, and economic power to limit the movements of this population. Spain's weaknesses permitted the Comanches to develop their own policies toward other indigenous communities as well as to play an important role in determining the contents of trade agreements and peace accords developed by colonial administrators. As Hämäläinen's (2001) research illustrates, Spain's inability to control the Comanches' movements across the Southern Plains resulted in the nation's successful expansion of its territory and an increase in its capacity to affect the flow of trade goods.

After entering the Southern Plains, the Comanches immediately expanded their territory from the upper Arkansas south to the Llano Estacado (Hämäläinen 2001: 40). During the 1730s, the Comanches increased their territory north to the Platte River (Hackett 1941, $3: 348)$. In less than a decade, during the 1760s, the Comanches had expanded their territory across Texas (Hämäläinen 2001: 52). According 
to Hämäläinen (2001: 53-55), the vast area utilized by the Comanches aided their efforts to maintain control of the horse trade.

Anderson (1999: 228) points out that the large horse herds owned by the Comanches became a major commodity in the political economy of the Plains. Due to the strategic locations of the Comanches, they also had access to vast bison herds. Consequently, they managed to supply not only horses but also bison meat, hides, and tallow to markets and individual traders (Anderson 1999: 230). The importance of this trade can be gauged by the fact that in 1786 , the Comanches traded six hundred bison hides and numerous pounds of meat to one of the pueblos in New Mexico (Thomas 1932: 306).

In addition to the trade in horses and bison, the Comanches also played a critical role in the selling of slaves. Until formally outlawed in 1769, the Comanches provided slaves to the Spanish, French, and other Native communities (Anderson 1999: 120-21). Once the slave trade became illegal, captives were still taken in order not only to increase the Comanches' population but also to negotiate ransom payments for the prisoners (Anderson 1999: 122).

Without a centralized political organization, the Comanches' bands and divisions managed to forestall incorporation into Spain's colonial regional economy. Unlike many other Native communities in the Southern Plains, the Comanches negotiated favorable treaties and trade agreements with the Spanish. They also successfully incorporated territory rich in bison and horses. This, in turn, permitted them to engage in lucrative trade networks involving the exchange of horses, bison, and slaves for firearms and other manufactured commodities.

\section{Descriptive Accounts of the Hasinais}

Until recently, archeological concerns dominated research on the Hasinais. Generally, published accounts addressed the origins, local development, and cultural classification of the Hasinais (Davis 1961; Krieger 1946; Wyckoff 1970). Based on these types of studies, Prewitt described the Hasinais as

a large population represented by many small settlements scattered within particular resource areas; a reliance upon horticulture as one of 
the primary means of subsistence; differentiated and undifferentiated mound/habitation sites with structurally differentiated mound classes (producing an apparently hierarchic division of places on the landscape); differential treatment of the dead reflective of a system of ranking; indications of long-term cooperation in disposal of the dead by groups represented by some of the archaeological units. (Prewitt 1974: 76)

Archeologists have been riveted by the Hasinais' preferential treatment of the dead and evidence of a centralized political system. Each of these traits is assumed to relate the Hasinais to an earlier relationship with Mississippian cultures (Krieger 1946; Newell and Krieger 1949). According to Griffin (1967: 189), the Hasinais' reliance on corn, beans, squash, gourds, sunflowers, and pumpkins permitted their regional variant of the Mississippian pattern to emerge.

The Mississippian aspect of the Hasinais is often conceptualized as a baseline representation of the "true Hasinais." As a result, the Hasinais' divergence from the construction of mounds and the special care of the dead are often interpreted as evidence of cultural disruptions due to epidemics as well as the contaminating influence of Euroamericans (Perttula 1992: 78).

More recent archeological research focuses on the ecological adaptations of the Hasinais to environmental factors or Euroamerican encounters (Chafe 1983; Fritz 1989; Gregory 1986; Story et al. 1990; Sabo 1987; Trubowitz 1987).

Certain patterns, established by the 1400 s, were still functional in the eighteenth century.... This paper has attempted to remodel the eighteenth century data in such a manner that these continuities are reflected in the interpretations and so the various Caddoan enclaves can be seen in a systemic way. ... Consequently, the "changes" in Caddoan culture so often attributed to European influence merely reflect the adaptability of tradition economic strategies. (Gregory 1973: 293-94)

Historical linguists have also expressed an interest in the origins of and relations between various Caddoan communities. Relying on linguistic data, these researchers classify the Caddoans into two language families, each of which is split into smaller language communities. 
Pawnee, Wichita, and Kitsai are in relations to each other, about equally divergent, save that Kitsai in phonetic structure and some forms is probably closer to Pawnee than Wichita is to Pawnee. All three, however, are mutually unintelligible. Caddo is the most divergent of the four languages. (Lesser and Wellfish 1932: 2)

The Caddo linguistic division includes the Hasinais and Caddos proper, referred to as the Kadohadachos. These linguistic divisions are equated with political social units, often termed "confederacies" in the literature (Swanton 1952: 7). The Kadohadachos resided along the Red River, while the Hasinais maintained their villages on the banks of the Neches and Angelina Rivers.

Dense woodlands surrounded the Hasinais' villages, which provided protection from predatory neighbors (Hickerson 1997: 40). In 1686, a priest associated with La Salle's disastrous expedition into the region observed that the Hasinai area

is one of the largest and most populous that I have seen in America. It is at least twenty leagues long, not that it is evenly inhabited, but in hamlets of ten or twelve cabins, forming cantons, each with a different name.

(Cavelier 1922: 232)

The number of villages associated with the Hasinais varied through time. In 1691, a Spanish missionary counted nine villages (Swanton 1942: 246). A quarter of a century later, the Hasinais supported ten villages (Bolton 1987: 9). According to Hickerson (1997: 35), the Hasinais reached a maximum of twelve settlements during the early 1700s. As Perttula (1992: 179) explains, however, "there was continued fragmentation, there were changes in location and intergroup alliances, or there were possibly some groups that simply disappeared from the ethnohistorical and historical records."

The reduction of villages during the 1700 s has been attributed to epidemics (Smith 1995), the growing involvement of the Hasinais in the slave trade (Hickerson 1997), and pragmatic decisions made by the Hasinais to increase their accessibility to Euroamerican commodities (Carter 1995; La Vere 1998; Perttula 1992; Wyckoff and Baugh 1980). 
Ethnographic accounts of the eastern Caddos have been sporadic and frequently descriptive.

The little field work that has been published (Mooney, 1896; Dorsey, 1905a, 1905b; Parsons, 1941; Swanton, 1931, 1942; Spier, 1924) is based generally on brief visits and few informants. It also tended to be narrowly focused, emphasizing only certain aspects of cultural behavior, such as folk tales (Dorsey, 1905a) or participation in the Ghost Dance (Mooney, 1896). Sadly, there is no detailed well-balanced ethnology derived from intensive, firsthand observation and interview by a trained professional. (Story 1986: 49)

Through the use of evidence gleaned from archeological excavations and or historical documents, researchers (Gregory 1973; Hickerson 1997; La Vere 1998, 2000; Perttula 1992; Sabo 1987; Smith 1995; Wyckoff and Baugh 1980) overcame this problem by forgoing the notion of a "true Caddo" base and instead centered their research on the shared histories of the Hasinais and Euroamericans. These scholars have noted that the Hasinais vested political power within their religious leaders. The three key positions included those of the xinesi, caddi, and canahas (Wyckoff and Baugh 1980: 234-35). Each of these positions seems to be matrilineally inherited (Carter 1995; Newkumet and Meredith 1988: 56-57). Until the 1740s, the xinesi functioned as a religious and political leader. Subordinate to this leader were the caddi and canahas. The caddi served as the village leader, and the canahas functioned as the assistant to this village leader (Newkumet and Meredith 1988: 56-57).

During the 1700 s, alterations within the community's political structure led to several important changes. These included the secularization of a centralizing position that had merged political and religious functions, the expansion of political obligations practiced by the main leader residing within each village, and, until the $1780 \mathrm{~s}$, the elevation of one of these village leaders to the role of chief for the entire community of Hasinais.

Secularizing a hierarchical organization backed by religious proscriptions was a common event in Native North America after contact with the mercantile econmies of European colonists. According to Dunaway (1994: 222-25), the Cherokees shifted from leaders 
supported by religious sanctions to ones supported by secular economies. A similar transformation occurred among the Choctaws during the late eighteenth century (Faiman-Silva 1997: 26; White 1983: 112). In both of these cases, the secularization of leadership roles is attributed to the democratizing effect of manufactured commodities.

A parallel change occurred among the Hasinais during the 1740 s. In their situation, the political organization became more decentralized, with the replacement of a religiously based central authority by a leader whose power emanated from secular concerns. Village chiefs, once beholden to a central religious leader, became political competitors after the secularization of the position of xinesi. From the 1720s until the 1780 s, one community leader always emerged to represent the Hasinais' interests in negotiations with Euroamericans and other external populations. After the 1780s, however, individual village leaders no longer submitted to one authority. Instead, each town became autonomous and through their local leader negotiated their own relations with external powers.

Unlike the Comanches, the Hasinais supported a centralized government. Prior to the usurption of the position of xinesi by the caddi, the xinesis represented the entire community of Hasinais. In this political capacity, the xinesis acted as mediators between the sacred and secular realms of the Hasinais' experience (Griffith 1954: 62; Hatcher 1927: 288; Smith 1995: 10). The xinesis' religious power also extended to the well-being of the Hasinais' subsistence cycle. Their blessings were necessary aspects of ceremonies celebrating planting, harvesting, and the welcoming of first fruits (Griffith 1954: 63; Smith 1995: 9).

As Casañas points out:

The important political decisions for the chiefdom, such as those determing peace and war, also fell to the xinesis. They also assembled the leaders of individual communities of their chiefdom to demand tributes, oaths, and promises in order to appease the gods. Through their moral authority, the xinesis controlled much of the labor of their subjects. (Casañas, quoted in La Vere 1998: 14-15)

When Euroamerican commodities first entered the trade sphere of the Hasinais, items such as firearms were given to the xinesi to circulate 
among his citizens (Sabo 1987: 38-39). Forrestal (1935: 46-47) noted that the last mention of a xinesi occurred in 1721. Possibly, devastating epidemics during the early years of contact with Euroamericans initiated an ideological rebellion among the populace. Sabo (1987: 35) contended that high mortality rates from introduced diseases weakened the religious beliefs to such an extent that the connection between religious authority and cosmological notions ruptured. As a result, the distribution of surplus no longer rested on a religious foundation. Lacking the religious authority to continue monopolizing imports may have contributed to the disappearance of the xinesi (La Vere 1998: 109).

As the position of the xinesi disappeared, less powerful religious leaders, referred to as connas, became leaders of the Hasinais' resistance against Spanish encroachments. Each village supported a number of connas. Recognizing the connas' antipathy toward the evangelical activities of the Spanish, the missionaries invariably reported on the "negative" influence of these individuals. The typical missionary viewpoint can be gleaned from a quote written by Fray Espinosa.

In short, these medicine men are the greatest obstacles to the conversion of many who would receive holy baptism, if they were not afraid of their threats. They persuade the patients that life is destroyed by holy baptism; and when, in spite of them, certain persons have been baptized, the medicine men usually abandon them under the pretense that the waters of baptism have caused the disease to take such a form that all their skill can not avail to cure it. (Espinosa 1927: 165-68)

Spanish envoys attempted to weaken the connas' power by granting greater support to the xinesis (Smith 1995: 30). Apparently, however, this strategy served only to exacerbate a preexisting schism between the connas and xinesis. Jameson (1981: 269-71) noted that all communities have structural contradictions that are masked by strategies of containment. When these strategies begin to fail, a legitimization crisis can develop (Peregrine 1999: 49). In the Hasinais' case, the introduction of Christianity, trade, and political meddling by the missionaries weakened the containment of internal oppositions between the connas and the xinesis. More than likely, this contributed to the disappearance of the xinesis and the proliferation of the connas. 
Until the disappearance of the xinesis, the caddi ruled only over his village. He organized village councils, hosted important visitors, and acted as the mediator of justice (Espinosa 1927: 235). In addition, "on most matters of importance, the caddi consulted a council of elders, which was made up of heads of lineages" (La Vere 1998: 153). Because of the caddis' greater access and control over the distribution of Euroamerican commodities, they managed to usurp the importance of the xinesis. During the 1750 s, Franciscan missionaries observed that the Caddis' ability as leaders permitted them to gain regular access to French commodities (Solís 1931: 70). Without a doubt,

some imported items are employed as "political currency," that is, their distribution forges the loyal ties of clients which ultimately translate into a chief's ability to mobilize labor, encourage surplus production, and call up defensive forces. (Kipp and Schortman 1989: 370)

Until the 1780 s, one caddi represented the entire nation of Hasinais. After the 1780s, though, no caddi held sovereignty over the other villages. Instead, each community became an autonomous polity with the ability to negotiate its own terms of engagement with external governments. Strategically, the decentralization of the Hasinais' political organization lessened Spain's capacity to manipulate the nation's internal political structure. No longer could Spain sanction the entire nation of Hasinais through the auspices of one leader.

Similar to the Comanches' case, the Hasinais' decentralized political structure acted as a strategy of survival. The trend toward decentralization continued throughout the Hasinais' contact with Euroamericans. After the disappearance of a centralizing caddi, each village negotiated its own relations with colonial governments, with caddis maintaining positions of authority in their now autonomous villages. This political transformation allowed the caddis to gain access to much-needed commodities, form alliances with useful nations such as the Lipans, and continue their participation in illicit trade with French merchants.

Explaining the ways in which the local, regional, and global economies were integrated during Spain's colonial occupation of the Southern Plains involves the merging of world systems analysis, 
regional analysis, and social history. Using these approaches to identify the distribution patterns associated with alliances, exchange networks, markets, and settlement locations permits a clearer understanding of social change among the Comanches and the Hasinais.

During the 1700 s and early 1800 s, patterns of distribution as well as the actual objects circulated were continually transformed. Because the value given to exchange was mediated through culture, every population exhibited different internal and external patterns of interaction. Variations in the circulation and production of commodities can be correlated with distinct social settings (Adams 1970, 1974; Friedman 1992; Schneider 1977). This can be clearly illustrated by studying the circulation of firearms and horses. Obtaining a secure source of firearms acted as means for a community to increase its political role in a region's economy. Through the trade of surplus horses, Native traders gained access to firearms. Aiding a nation's success in its endeavor to increase its political role in the area's trade networks involved the establishment of alliance networks, the ability to participate in nascent trade fairs, and the ability to secure favorable trade terms with the Spanish and other Euroamerican powers.

As future chapters illustrate, the Comanches and Hasinais successfully avoided becoming "victims and silent witnesses" of their own subjugation (Wolf 1982: $\mathrm{x}$ ). Rather, they chose to transform their political economies in order to participate fully in the emerging political economy while also maintaining their sovereignty and avoiding becoming victims of an expanding colonial economy. 


\section{4}

\section{WorLD Systems Perspective}

Applying a world systems perspective to colonial encounters provides a useful device for illustrating the intricacies of a region's political economy. In particular, it aids efforts to understand a regional economy's articulations with an expanding colonial economy. According to theories associated with world systems analysis, the development of markets acts as the critical link between different economies. If this linkage, perceived as a conduit that structures the flow of commodities, results in unequal exchange, then the core often develops while impoverishing the peripheral economy (Hall 2000: 5). Invariably, the emergence of economic activities geared toward commodity production transforms the subsistence patterns and political organizations of participating local economies (Faiman-Silva 1997: 4).

In a number of cases, such as those presented by the Comanches and the Hasinais, changes in their subsistence and political organizations forestalled their economic submission. Many scholars used economic models to analyze postcontact changes among the region's Native communities (Albers 1991, 1993; Jablow 1950; Lewis 1942; Mishkin 1940; Moore 1987; Secoy 1953; Spielman 1983). Specific emphasis generally focused on interactions between Puebloan, nomadic, Spanish, and American populations (Albers 1993; Jablow 1950; Mishkin 1940; Spielman 1983). Through their work, not only have regional trade networks been identified but also the importance of various commodities to local systems of power has been documented.

During the last two decades, world systems perspectives have added significantly to an understanding of the interactions between the colonizers and the colonized (Anderson 1999; Baugh 1984; Hall 1987, 1989, 1994, 1999, 2000; Klein 1993). A critical aspect of this research concerns the impact of expanding markets on indigenous social organizations. Frequently, these studies highlight intersocietal relations, such as ones based on warfare, trade, and/or diplomacy (Albers 1991, 
1993; Baugh 1984; Klein 1993; Hall 1999). These efforts commonly reject the notion that a particular society's internal history controlled local structural changes. This is not to suggest these authors failed to recognize the existence of a community's own history or structure; however, they tended to subsume the trajectories of local histories into a regional or global process.

As Thomas Hall's application of a world systems perspective to the Southern Plains illustrates, the qualitatively different nature of European-derived political economies acted as a stimulus for change. Because neither Spain nor indigenous communities represented monolithic entities, Hall's research analyzed the "continuum of peripherality" within a region composed of numerous independent polities. As Hall notes, the European system of production and exchange did not completely absorb and transform local economies (1998). As a result, "more detailed local studies which attend peripheral actors and their attempts to control, shape, and resist the encroaching world-system" are necessary in order to understand how some indigenous communities managed to forestall annihilation or forced incorporation (Hall 1999: 10).

An initial step toward the application of this type of analysis to Spain's colonial era in the Southern Plains necessitates four levels of investigation. These include an examination of Spain's position in the world economy, Spain's colonial occupation of the Southern Plains, Spain's use of trade goods to articulate the trade networks used by the Hasinais and Comanches, and strategic political changes implemented by these two communities to negotiate the labyrinth of Spanish policies. Concentrating on these four areas gives a clearer view of the ways in which the linkages between colonial and peripheral political economies developed and varied. Through this analysis, it becomes evident that the Comanches and Hasinais articulated more closely with the developing regional economy as the flow of commodities became more predictable. This in turn led to greater stability in the trade networks.

\section{Spain's Position in the Global Economy}

Spain's financial commitment to colonial activities overseas stemmed from a mercantile philosophy that assumed a finite availability of global wealth and income-generating resources (McNeill 1985: 3, 47). 
Adherence to this tenet led to the conclusion that any economic gains came at the expense of another nation. Consequently, the main goals of Spain's colonial expansion involved the discovery of sources of raw materials as well as the development of markets for trade goods. Because of Spain's desire to protect its territory from the incursion of competing nations, particularly France, the Southern Plains also acted as a buffer zone. In general, however, the economic policies implemented by Spain attempted to control trade and production in the Southern Plains. Ideally, these policies aided Spain's economic sector by stressing a colony's role in providing raw materials and markets for Spain's domestic manufactures. Theoretically, these policies ensured the creation of more exports than imports. This, in turn, would grant Spain's independence from foreign markets and, thus, greater revenue for its coffers (McNeill 1985: 3). Spain's optimism about the benefits of conquering North America illustrates the government's belief in mercantilism:

[In] the conquest of the New World, the crown saw its opportunity to escape the limitations of internal Spanish policies ... a fifth of all gold and silver mined in the New World would be the king's to finance a new royal army, navy, and officialdom, to build the bases of absolutist power upon institutions wholly independent of nobility, middle classes, or peasant cultivators... The New World would not have to grow piecemeal, in the shadows of ancient complexities: it would be a planned world, projected into reality by the royal will and its executioners. Thus utopia would become law, and law utopia. (Wolf 1959: 162-63)

Alas, Spain's political economy during the seventeenth century precluded the self-sufficiency of royal power. Rather than controlling expenditures by ignoring the citizenry's demand for consumer goods, Spain exported its metal wealth in return for luxury imports. One Spanish citizen's observations during the 1600 s exemplify this lack of foresight.

That London should manufacture the finest woolens, Holland her fabrics, Florence her cloth, Indian hides, Milan its brocades, Italy and Flanders linens... for our capital to enjoy; this indeed only proves that all nations produce for Madrid and that she is the queen of cities for all serve her and she serves no one. (Pellicani 1994: 195 n. 83) 
The crown's dream of independence ended as its wealth dissipated. Instead it became necessary to more closely ally with an increasingly powerful merchant class (Wolf 1950: 9). Though this merger provided the necessary funds for Spain's colonial expansion, it also led to conflicts between the goals of the crown and the aims of the entrepreneurs. Dissension between these two groups frequently erupted over which policies to enact when responding to France's expansion into the Southern Plains.

After a period of exploration, France and Spain began to colonize the Southern Plains in the late seventeenth century. Though the impetus for these nations' expansion into the Southern Plains stemmed from a variety of reasons, both competed for the economic and political domination of the area. As both France and Spain lacked money in their royal treasuries, neither country could afford to fund colonial expansion unless it strategically benefited from such moves. Mindful of this, colonial entrepreneurs typically justified expansion into the Southern Plains by stressing the predatory nature of foreign interests in the region (Allain 1988: 50, 51).

In France's case, promoters of expansion argued their case by alluding to Spain's silver mines and the potential for hijacking this wealth once French-controlled ports were constructed somewhere along the Gulf of Mexico (Allain 1988: 44; Folmer 1953: 135; Usner 1992: 14). An added incentive for occupying the region related to the revocation of the Edict of Nantes in 1684. Prior to being revoked, the edict kept the Huguenots from emigrating to North America. After 1684, French officials became increasingly alarmed by the Huguenots' diaspora into North America. France's fear of these emigrants originated from the Huguenots' policy of actively missionizing Native Americans. Because of their historically acrimonious relationship in France, the Huguenots favored the English over the French. As a result, the French worried that the Huguenots might convince Native peoples into allying with the British rather than the French.

In addition to these anxieties, the French also worried about the rapid expansion of England's colonial population. By 1714, British officials enumerated over 250,000 colonists in America (Priestly 1939: 155). To counteract the Huguenots, English settlers, and Spanish interests in the lower Mississippi Valley, France began to pursue a 
more active policy in the region. In 1684, France granted funding for La Salle's short-lived colony on the Texas coast. After this failure, France, continually short of money, sold titles to the aristocracy and gave trading monopolies to private investors in order to accelerate settlement in the region (Priestly 1939: 145).

The government also financed the construction and maintenance of colonial settlements. Although trade had been entrusted to monopolies, lack of markets and high import-export costs negated any benefits they may have given to their holders. In addition, French policy discouraged colonial trade with foreign nations. Not wanting to risk their own capital, few merchants financed colonial ventures. Instead, they invested in the more lucrative trade occurring in the Levant (Allain 1988: 12). This was particularly true after the collapse of the Canadian fur trade in the 1690s. Because of changes in European hat styles, the price of beaver pelts plunged. Within a three-year period, traders had stockpiled 850,185 pounds of beaver, which would take ten years to absorb into the reduced European market (Innis 1973: 74).

As in Spain's case, the French government wanted the colonial areas to absorb French manufactures while exporting surplus local products. Ultimately, French economists, like the Spanish, hoped to stimulate enough trade with its colonies so that France could gain independence from foreign products.

Spanish colonization of the Southern Plains centered on four goals: protecting the region from French incursions, establishing a limited number of settlements, gaining the allegiance of Native communities, and accomplishing these three aims as cheaply as possible. Prior to the signing of the Treaty of Paris in 1763, Spain's colonial efforts in the Southern Plains competed with French activities in the lower Mississippi Valley. For example, until knowledge of La Salle's coastal colony in Texas had filtered back to the Spanish, the government's commitment to the region had been less than enthusiastic. But La Salle's colonial endeavor succeeded in finally forcing Spain to defend its territorial claims.

Spain's restrictive trade laws, promulgated by the House of Trade and the Merchant's Guild in Seville, hindered these goals, however. Since these associations' desire to protect their own industries complemented Spain's mercantile interests, Spanish policies rarely permitted 
overseas colonies to legally import or export items from foreign nations during the first half of the eighteenth century.

Unable to secure nearby French and British markets for their products, the Spanish colonists had little incentive to increase domestic production. Unless colonists engaged in smuggling and bought necessities at a cheaper rate from France's nearby colonies, they had to rely upon prohibitively expensive imports from Veracruz or Saltillo. The high transportation cost and excessive taxation of items from these two towns dissuaded most colonists from purchasing imports and led to periodic scarcities in the colonies (Hall 1989; Thomas 1935).

Spain's lack of financial investment and political commitment slowed the region's colonization and incorporation into a larger more global economy. In addition, Spain's protectionist policies limited the ability of colonialists to negotiate trade agreements with Native peoples. France's more liberal view of intercolonial trade gave French settlers far more leverage to negotiate alliances with Native Americans. This in turn gave France an edge in its political and economic impact of Native Americans. As a matter of fact, France managed to undercut the cost of Spanish imports, and as a result French commodities became critical not only to the political economies of indigenous communities but also to those of local Spanish colonies.

Until the 1763 signing of the Treaty of Paris, France continued to be viewed by Spain as a threat in the Southern Plains. The signing of the treaty, however,

closed a cycle of struggle for worldwide domination between the winner, England, and the losers, the French and the Spanish; it is the beginning of a long descending phase in the world economic cycle, which on the economic place brought with it the upsets that permitted and gave impulse to the beginning of the industrial revolution. In the political/economic area this economic decline would generate the independence of the United States, the French Revolution, as well as the change of Spanish policy toward the colonies known as economic liberalism within enlightened authoritarianism. (Braudel 1984: 107-8)

The demise of France's colonial ambitions and the liberalization of Spain's economy caused Native populations to ally more closely with the Spanish. Having fewer enemies in the region enabled Spain to 
stabilize its colonial position through the establishment of more settlements, the development of more predictable markets, and the ability to better meet the consumer demands of residents in the Southern Plains.

\section{Spain's Colonial Occupation of the Southern Plains}

Spain's occupation of the Southern Plains entailed the establishment of missions, presidios (also referred to as army garrisons), ranches, and towns. Because of financial limitations and the region's marginality to Spain's interests elsewhere in North America, the Spanish limited its initial settlements to Franciscan missions and small military garrisons. In order to defray the costs of these outposts, Spain bestowed large land grants to ranchers and farmers willing to settle the region and help support the missions. Generally, areas deemed useful for bolstering Spanish claims to contested territories determined a settlement's location. Predictably, the government's worries concerning the intentions of the French had the greatest impact on the placement of these early sites.

Spain legitimized its occupation, conquest, and appropriation of resources in an already inhabited region through the claim that all wars conducted in the interest of the Holy Church were just (Jennings 1976: 4). Any usurpation of Native American sovereignty was morally absolved if attempts were made to convert indigenous populations to Catholicism. Consequently, with a minimum of financial effort, Spain's colonial expansion invariably occurred in association with missionary activities. Religious colonialism held the promise of advancing Spain's claim over territory through incorporating local inhabitants. Spanish administrators assumed that territory could be effectively and cheaply secured through the conversion of Native inhabitants into Christian allies. Bolton points out that

the value of the missionaries as frontier agents was ... clearly recognized, and their services were thus consciously utilized by the government. In the first place, they were often the most useful explorers and diplomatic agents. The unattended missionary could sometimes go unmolested, and 
without arousing suspicion and hostility, into districts where the soldier was not welcome, while by their education and their trained habits of thought they were the class best fitted to record what they saw and to report what should be done. (Bolton 1917: 110)

Spanish administrators gained key information about the Native peoples through the initial use of religion as a mode of colonialism. As Said (1989: 6) notes, "Eurocentric culture relentlessly codified and observed everything about the non-European or presumably peripheral world, in so thorough and detailed a manner as to leave no item untouched, no culture unstudied." This classificatory discourse permitted the missionaries to construct a standardized means of interacting with Native peoples.

The Spanish missionaries in the New World thought it not only necessary but possible ... to transform the Indians into replicas of SpaniardsSpanish peasants to be more precise, and a highly idealized peasantry at that... The Spanish missionaries, with the full support of the Crown, interpreted the duty broadly as a mandate to supervise every aspect of the Indians' lives from birth to death and to modify them when necessary in accordance with the church's teachings. (Farriss 1984: 91)

Armed with this type of knowledge, the missionaries opened the door for the development of enduring alliances with indigenous communities.

Colonial settlements in Spain's three Texan provinces, east Texas, central Texas, and the Nueces Triangle, involved the construction of missions, the emigration of Franciscan missionaries, and Spanish emigrants. Responding to French expansion west of the Mississippi, in 1689 Spain established six Franciscan missions in the vicinity of the Neches River. To facilitate this effort, Spain gave land grants and some subsidies to the Franciscans to aid in the construction and management of these missions. Fifty soldiers, fourteen friars, and seven brethren took part in this effort (Morfi 1935: 152). Initially, the eight to eleven Hasinai villages in the region welcomed this colonial effort (Griffith 1954: 58; Tanner 1974: 16). At the onset, Franciscan missions, with their large land grants and herds of livestock, dominated early trading relations with the Hasinais. Generally, the missionaries offered 
training in techniques of ranching, blacksmithing, pottery production, and weaving (Spicer 1962). Even with these inducements, local missions attracted few occupants. In a period of a little less than five years, these settlers failed to secure allies or converts. A devastating epidemic in 1691, continual crop failures, and lack of converts caused the missionaries to abandon the region in 1693 (Ewers 1973).

After this failure, Spain permitted the missions to secure financial sponsors from the private sector. The viceroy passed a regulation requiring emigrant communities to contribute to the construction of local missions and to support the necessary missionary personnel. Although reestablished in 1714 with an array of soldiers, farmers, ranchers, and the help of church funds and private benefactors, missionaries again abandoned the region in 1719. Circumstances responsible for this latest desertion related to the missionaries' fears about Spain's war with France. To alleviate the concerns of the missionaries and other settlers, Spain funded the construction of army garrisons in order protect the missions, settlers, and supply routes from Native raiders, the French, and, later, British and American nationals.

In the 1720 s, alarmed at the expense, corruption, and general malaise of these garrisons, cost-conscious administrators reduced the salaries and number of soldiers serving in eastern Texas (Chipman 1992: 283 n. 13; Murphy 1937: 125). Chronically underfunded and understaffed, the presidios provided little protection against foreign encroachments, marauding nomads, or fleeing apostates. Ignoring the protests of missionaries, soldiers, and settlers, colonial officials decided to retreat from east Texas and relocate these settlers to central Texas in 1731 (Folmer 1953).

Although Spain forced the relocation of government-sponsored settlements in the region, many Spanish citizens remained in east Texas along the tributaries and river valleys of the Angelina and Sabine Rivers. When Spain liberalized its colonial economies in 1789, a number of these towns began to prosper (Haggard 1945: 70-73). For example, Nacogdoches superceded Natchitoches as the regional market center in the late 1700 s.

Unlike east Texas, central Texas's Spanish population increased continually during the $1700 \mathrm{~s}$. This occurred as a result of the relocation of east Texas communities into the region, the government's funding 
of new missions, and Spain's forced emigration of farmers from the Canary Islands into the area of current-day San Antonio. Settlements in the region prospered as colonial policies became less concerned with the French and more geared toward the activities of nomadic groups. Spain's shift in policy proved particularly important as the Lipan Apaches, who generally raided west Texas settlements, moved closer to the central Texan colonies.

The Lipans organized themselves into numerous small and autonomous communities, referred to as rancherías by the Spanish (Gunnerson 1974: 255; Opler 1983: 372; Thomas 1940: 197). Beginning with the migration of some Lipans into central Texas in the 1680 s and their virtual extinction by the 1770 s, this group continually oscillated between peace and war with the Spanish. Various governors of Texas had led or ordered expeditions against the Lipans during the first half of the 1700s. Most of these campaigns supposedly arose in response to the raiding activities of the Lipans. According to one missionary, however, a campaign waged in the 1740 s was "little more than a slave-hunting expedition" (Dunn 1911: 251-52). By engaging in a series of campaigns against the Lipans, colonial administrators protected the lives and property of settlers residing in central Texas. With additional funding for the construction of missions and presidios in areas slated for colonization, more Spanish settlers migrated into central Texas. This also attracted Native refugees from the lower courses of the San Antonio River, the Rio Grande, and the Nueces River (Campbell 1988: 91). Like missions in east Texas, those in central Texas failed to attract many converts (Leutnegger 1977: 128). From 1790 until 1810 the region "enjoyed considerable respite from hostilities and an opportunity to develop economically" (Moorhead 1968: 289).

During the 1740s and 1750s, ranchers began to settle Spain's third Texan province, the Nueces Triangle. Watered by the Rio Grande and the Nueces River, grasslands dominated this region. A number of events occurring in northern Mexico stimulated this area's population growth. These included the passage of legislation restricting ranching, the discovery and development of more silver mines, and a series of financial and agrarian crises (Meyers 1967: 87; Robles 1938; Tjarks 1974: 294). Sizeable land grants, a landscape conducive to cattle 
ranching, and an initial absence of hostile Native Americans attracted a steady migration of settlers into the region. During this era, towns, presidios, and missions as well as numerous ranches were founded. Towns constructed during this period of colonial development included Camargo (1749), Dolores (1750), Laredo (1755), Mier (1752), Revilla (1750), and Reynosa (1740). Roads and ferries connecting the region to San Antonio in central Texas, Saltillo in northern Mexico, and the port at Galveston Bay facilitated the development of these towns.

The area's growing stability was short-lived, however. Raiding activities of the Lipans, along with those of a number of other Apache groups, led to the abandonment of 116 homesteads and ranches in the area (Hoya and McLean 1964: 311). Not until after Spain's colonial involvement in the region end did reoccupation of the Nueces Triangle occur.

For a number of reasons, missions failed to facilitate Spain's expansion into Texas. Lack of commercial inducements and the mission's restrictive rules and regulations probably dissuaded potential converts (Alcocer 1958). In addition, France's establishment of local trading posts and its support of independent traders meant that Native communities did not depend on the missions for European goods (Perttula 1992: 34). Unable to set its own Indian policy through negotiations or trade, a mission offered little beyond refuge to ravaged Native American communities. To protect the refugees as well as the wealth of the missions, the missionaries relied upon the presidios. Even the presence of presidios offered little risk to converts bent on fleeing the missions or nomadic groups intent upon raiding the institution's ranch stock.

Because of the haphazard location of the presidios and the general disarray of their personnel, colonial administrators once again consolidated Spain's military presence in the Southern Plains (Moorhead 1961; Simmons 1968: 6). By the early 1770s, eight presidios had been closed and most of the remaining fifteen had been relocated (Hall 1989: 138). Without a larger military force, the missionaries could not retrieve runaways, guard against raiders, or guarantee the compliance of their workers. By 1772, Spain had secularized most missions in Texas. 
Spain's Commercial Relations with the Hasinais and the Comanches

Spain's financial interest in the Southern Plains remained centered on the region's economic potential. As a result, the political capital of indigenous populations ultimately depended on European perceptions of their ability to further this colonial aim. One critical function of Native Americans was their ability to provide valuable commodities for Spain's domestic sector while importing manufactured goods. At the local level, colonial merchants exchanged manufactured items for horses, slaves, bison products, and other types of hides. The prices paid in goods to Native Americans varied according to the supply and demand in Europe and North America.

Colonial administrators recognized that the consumer demands of Native Americans were more economically important than the external demands for North American products. As ethnohistorians have pointed out, the demand for trade goods by Native Americans was initially limited to a narrow range of items (Sahlins 1972: 313; White 1983: 57). Among indigenous populations in the Southern Plains, social constraints against hoarding limited purchases to those used primarily to meet immediate needs. As social capital within and between communities became tied to the ability to accumulate Euroamerican goods, demand increased. The most critical of these items included horses and firearms. The rapid spread of these commodities across the Southern Plains was phenomenal. Forbes (1959: 208) stated that "by 1680 the Indians of all of Texas and New Mexico were mounted ... and horses were being spread to even more northerly regions by the Plains Apaches and Utes." Though less ubiquitous than horses, French firearms were already in the hands of Apaches residing in the vicinity of New Mexico by 1706 (Thomas 1935: 74).

World systems perspectives note that one major impact of colonialism follows from its ability to create dependent communities that then become incorporated into the dominant society. According to Hall (1989: 24), Spain's control over the influx of Euroamerican commodities into the Southern Plains opened the door to the region's dependency. The introduction of novel goods led numerous indigenous communities to align themselves with colonial powers; the 
introduction of horses, guns, and other metal products of a more utilitarian nature presumably added to the urgency of this strategy.

Well aware of the strategic advantage of controlling the flow of trade goods, colonial officials attempted to develop client populations by tying the distribution of commodities to alliances. For example, Viceroy Bernardo de Gálvez claimed that Native peoples "should be made accustomed to the use of our foods, drinks, arms, and clothing, and they should become greedy for the possession of land" (Worcester 1951: 42). As the following quote illustrates, Governor Nava of New Mexico understood the advantages of endemic warfare in Spain's desire to create allies as well as a dependent population.

One of the maxims that should always be observed on our part, with respect to the nations of Indians, is to allow them to make reciprocal war on each other in order in this way to bring about a diminution of their forces, to energize their mutual hatred, and to avoid their union and alliance; we should, however, take the lead in keeping them constantly in our friendship and in our debt. (Nava, quoted in Faulk 1964: 68)

Although many colonial officials recognized methods for developing client or dependent populations, they faced continuous problems in their attempts to do so. A major impediment involved Spain's inadequate financial and military commitment to the Southern Plains. Throughout Spain's regime the region suffered from poorly developed transport networks, a shortage of Euroamerican commodities, and the lack of a sizeable colonial population with disposable incomes. This lack of aid delayed the region's commercial development. Spain's restrictive trading regulations further constrained the region's economic prospects.

Since 1536, the crown had restricted the flow of firearms to colonized populations in North America. Spain's legislation allowed only those Indians licensed by the viceroy or local governor to carry arms (Secoy 1953). Though merchants continually tried to overturn this ruling, this policy persisted and was regularly reiterated during the country's colonial occupation of the Southern Plains. Under duress from the viceroy, the governor of New Mexico in the early 1700s "prohibited the sale of arms to the tribes of the Plains or foreigners 
under heavy penalties" (Haines 1891: 115). Penalties included fines for Spanish nationals and lashings as well as imprisonment for Native peoples (Haines 1891: 115). Spain justified the restriction of gun sales on the grounds that conquest could not occur if local Spanish soldiers had to fight vastly larger and well-armed native resisters (Bolton 1914, 1:278-79).

Spain's refusal to legally trade firearms increased the importance of French traders. Unlike the Spanish, French administrators expressed no desire to restrict their trade in firearms. Although cycles of inflation in the lower Mississippi Valley caused French commodities to be too expensive for most colonists, the government generously subsidized the Natives' ability to obtain trade goods (Giraud 1974: 17). Consequently, French firearms quickly spread to the Hasinais as well as other Native communities.

The volume of firearms circulating among the Hasinais increased as more French traders moved into the area. By 1726, France had established ten trading companies in Natchitoches alone (La Vere 1993: 62). French traders further solidified their importance to the Hasinais by establishing semipermanent residents in many local villages (Perttula 1992: 21). As early as 1719 , the governor of New Mexico intercepted more than one thousand Apaches who were fleeing from armed French, Pawnees, and Jumanos (Thomas 1935: 31). One refugee, suffering from a gunshot wound, told the governor that the French had "built two towns, each as large as Taos. There they lived with the Pawnee and Jumano Indians whom they have given many guns and have taught them to shoot" (Thomas 1935: 31). A Spanish inspector traveling through Hasinai territory in 1727 observed that they were "armed with French fuciles [muskets], with flask of powder and pouches of bullets, like most expert troops" (Thomas 1935: 32).

Spain's methods for negating inroads made by foreign nations in the Southern Plains included sponsoring missionary activities, seasonal markets for allies, as well as giving gifts to secure more Native allies. In order for colonial officials to create dependent polities while facing a shortage of the requisite commodities, they had to strategically control the flow of available trade goods. Faced with this conundrum, the Spanish began limiting the distribution of commodities to favored 
indigenous communities. They also established scheduled markets for strategic allies.

Granting access to Euroamerican trade goods became an important bargaining tool during Spain's colonial occupation of the Southern Plains. Spain attempted to regulate the disbursement of commodities to strategic gift-giving events and seasonal markets for favored allies. Spain financed gift giving through two separate funds: the fund for allies and the fund of gratification (Simmons 1968: 143). Though colonial officials maintained some discretion in the administration of these funds, Spain determined the funds' political role. For example, in 1772 the newly appointed viceroy of the Provincias Internas strenuously objected to gift giving as a payment for peace (Bolton 1914, 1:271). Instead, he demanded that annual gifts be given only to those Native Americans who had demonstrated loyalty and devotion to the king (Bolton 1914, 1:271). Even with this cost cutting, 40 percent of Spain's colonial budget was earmarked for gift distributions in 1776 (Bolton 1914, 1:273).

Predictably, the giving of gifts became increasingly expensive during periods of intercolonial rivalry. Until 1763, competition with the French over allies absorbed these gifts. After the Louisiana Purchase in 1803, Spain's gift expenses rose again in order to maintain alliances with the Comanches and Hasinais in the face of American competition.

In addition to gifts, colonial administrators also developed neutral frontier trading sites for their allies. These markets were an initial stage of regional integration. Lacking a requisite threshold population in a concentrated area, however, Spanish colonists could not sustain stationary marketplaces. Instead, seasonal markets with prices and participation controlled by colonial administrators emerged. In order for the government to monopolize these events, laws were passed that forbade independent Spanish citizens from trading with Native Americans outside of the seasonal fairs (Twitchell 1914, 2:205).

By providing commodities in a controlled period of time, Spanish officials hoped not only to circumvent raiding but also to prevent lowerranking competitors, such as French entrepreneurs and Spanish settlers, from undercutting Spanish trade policies (Hodges 1982). Spain's 
shortsighted policies concerning the trade in firearms as well as the availability of horses from a multitude of alternative sources limited Spain's ability to constrain the flow of commodities and increase its influence over the Caddoans and Comanches.

Access to horses, unlike firearms, did not necessitate a European source. Favorable climatic conditions and the development of Spanish ranching guaranteed a steady supply of domesticated and feral horses. St. Denis, an early French administrator, commented in 1713 that "cattle, which in the interval of the absence of the Spaniards [from east Texas missions] have increased to thousands of cows, bulls, horses, and mares with which the whole country is covered" (Hackett 1931, 1:526). By 1805, a missionary observed that "great herds of horses and mares [are] found close to roads in herds of four to six thousand head" (Bensen 1947: 32).

In an exercise repeated regularly by many nomadic communities in the region, the raiding of horses resulted in wide circulation of this needed commodity. As a matter of fact, ranchers from the Nueces Triangle speculated that the dispersal of feral horses related entirely to raiding activities of Native peoples (Jackson 1986: 36-37). Native traders met the growing demand of horses among indigenous peoples, the French, and later the Americans (Kress and Hatcher 1931: 67). In 1749 , the Comanches maintained so many horses that the community was "dispersed, with their large droves of horses, for which reason they could not live together, having to seek sufficient pasturage and water for their horses" (Hackett 1941, 3:317). The Comanches' importance in regional trade networks is supported by the fact that Spanish settlers shifted the word for independent trader, viagero, to the word comanchero (John 1984: 346).

According to Klein (1993: 137), colonialism's creation of inequalities in the distribution of capital predicated a community's degree of dependency. As Hall explains:

The degree of incorporation may range from weak through strong. At the strong pole of the continuum essential goods are exchanged. These regions experience full scale "development of underdevelopment," and are important to core development. Influence flows both directions, but net product and capital flows are to the core.... When such pressures are sufficiently strong, and of sufficient duration, the structure of 
local groups will be changed.... If the transformations are sufficiently drastic... approaching the full-blown periphery pole of the continuum, loosening of incorporation becomes increasingly difficult. (Hall 1989: $19,21)$

Impediments to Spain's Incorporation of the Comanches and the Caddoans

A number of factors impeded or even prohibited the local integration of Comanches and Hasinais into dependent relations with the Spanish. The introduction and subsequent disbursement of these items revolutionized Native relations with each other as well as with colonial powers (Albers 1993; Hall 1989; Kavanagh 1996; Milloy 1988; Mishkin 1940; Secoy 1953). Hostilities became more deadly and frequent between Native communities (Mishkin 1940; Secoy 1953).

During this era, a community's survival depended on gaining and maintaining access to horses and firearms. Both of these items permitted the sedentary Hasianis to protect their access to hunting regions (Espinosa 1746: 422). Like the Hasinais, the Comanches also became more militarized. In 1723, New Mexico's governor wrote that

captains of the heathen Apache nation... represented to me that the heathens of the Comanche nation, their enemies, had attacked them with a large number in their rancherias in such a manner that they could not make use of weapons for their defense. They launched themselves with such daring and resolution that they killed many men, carrying off their women and children as captives. (Thomas 1935: 194)

More populous sedentary villages tied to a seasonal horticultural schedule remained easy prey for nomadic groups. For example, the Comanches scheduled their attacks on the Lipans and other Apaches during the summer months, while the Apaches were engaged in horticultural activities (Secoy 1953: 31).

Controlling the distribution of firearms and horses held the key to a polity's position of power in the Southern Plains. Spain's restrictive trade laws, the presence of foreign traders such as the French, and the self-propagation of horses precluded Spain's monopoly over the distribution of these resources. Instead, nomadic communities, such 
as the Comanches, controlled the supply of horses, while sedentary villages allied with the French, such as the Hasinais, tried to control the trade in firearms.

\section{Spanish Strategies to Incorporate the Hasinais and the Comanches}

During Spain's occupation of the Southern Plains, local administrators tried a myriad of strategies to gain greater control over the Hasinais and the Comanches. Although each of these communities supported differing types of political organizations and subsistence practices, Spain implemented similar policies for both communities. Another major difficulty Spain encountered in its desire to incorporate these two populations involved the role of France in the Hasinais' local economy and the decentralized political organization of the Comanches. Infighting between missionaries, settlers, and government administrators not only contributed to the decline of the mission's suzerainty but also aided the Hasinias' ability to protect their sovereignty. France's policy of providing traders in the Native villages ensured the Hasinais independence from Spain's governmental control. Unable to support a large military force, the Spanish failed to disrupt smuggling routes used by the Hasinais to trade with the French and the Wichitas (Bolton 1905: 105; Bolton 1913: 348; Bolton 1914, 2:104).

Not until Spain instituted less restrictive trade laws did the Hasinais begin to lose their pivotal role as middlemen in east Texas trade routes. Because of these more liberal policies, other groups, such as the Comanches and Wichitas, began to bypass the trading routes established by the Hasinais. A series of devastating epidemics in the 1700 s also contributed to the Hasinais' lessening importance to regional trade.

The diminishing importance of the Hasinais in regional trade networks is mirrored in shifts in their political organization. Until the early 1700 s, the Hasinais supported a hereditary male leader, referred to as a xinesi by the Spanish. This individual played both a spiritual and political role as a distributor of surplus domesticated and undomesticated products (Sabo 1987: 29). The xinesi's primary role in redistribution rather than production failed to adapt to the nature of firearms and horses. Neither one of these items could be monopolized; instead, 
they appear to have caused the democratization of local distribution networks (Wyckoff and Baugh 1980). Rather than providing the xinesi with surplus products, as in the past, individuals accumulated items in order to exchange them with the French for firearms, metal tools, and textiles (Sabo 1987; Griffith 1954: 138).

Like other Native communities, the Hasinais developed standardized methods for negotiating with colonial administrators. With the disappearance of the xinesis in the early 1700 s, village leaders, referred to as caddis by the Spanish, began negotiating with colonial officials (Woodall 1969: 36). By the 1730s, one caddi emerged as the secular leader of the entire nation of Hasinais. During the 1770s, however, this position became less centralized, and the Hasinais returned to a system in which each village leader autonomously negotiated with the Spanish (Smith 1995: 40). Various ideas have been proffered to explain this political transformation (Perttula 1992; Smith 1995: 85; Wyckoff and Baugh 1980). These theories range from the impact of disease to endemic warfare. Although each of these contributed to the political reorganization of the Hasinais, an additional explanation includes the advantages of a leader acting as broker between competing nations.

Presumably, one leader negotiating with separate colonial regimes could not be penalized by either of these political powers, particularly since a leader's problems with one government could be circumvented by simply allying more closely with a competing colonial power. With the loss of French allies, the Hasinais became more vulnerable to colonial sanctions promulgated by the Spanish. If they maintained one tribal leader as the main negotiator, the Spanish could transfer their colonial monopoly over the Hasinais from this individual to the tribe as a whole. Adapting to this changing political and economic landscape, the Hasinais regrouped into smaller communities, allied more closely with their nomadic neighbors, and lessened the control leaders exerted over the entire nation.

When the Comanches arrived in the Southern Plains at the beginning of the eighteenth century, Spanish officials reevaluated their involvement with the Comanches' primary enemies, the Lipans (Faulk 1964: 64-70). Ignoring the Apaches' pleas for a trade alliance, the governor of New Mexico established an exclusive trade fair between the residents of Taos and the Comanches (Kavanagh 1996: 102). Wanting 
more trading opportunities with the Puebloan area, the Comanches forced the issue by using French guns to kill 150 residents at Pecos between 1740 and 1749 (Twitchell 1914, 2:212).

Spanish officials complained bitterly about the independence and wealth of the Comanches. During the 1750s, Colonel Diego Ortiz Parilla noted, "The heathen of the north are populous and rich. They enjoy the protection and commerce of the French; they dress well, raise horses and use firearms with the greatest skill" (Parilla 1758 in Thomas 1940: 83). A portion of this wealth stemmed from the success of the Comanches' strategic alliance with the Taovaya branch of the Wichitas in the late 1740 s or early 1750s (Morris 1970: 80). Through this relationship, the Comanches secured a stable outlet for their surplus horses and a steady source of firearms.

When Spanish negotiators successfully mediated a treaty with the Taovayas in 1771, they inadvertently increased the power of the Comanches' trade network. According to the treaty's terms, the Taovayas agreed to stop raiding the Spanish and to desist from trading with other Euroamericans. In return, the Spanish guaranteed to pay them artificially high prices for their surplus products (Bolton 1914, 2:126).

A Franciscan inspector noted that the Taovayas raised an abundance of corn, beans, watermelon, and tobacco (Castañeda 1935: 9). This intensification in agricultural production probably relates to the high prices offered by Spanish traders. The more the Spanish gave, the more the Taovayas could offer the Comanches.

By the 1770s, one Spanish official complained that the Comanches

have everything at the hands of the Spaniards. In a few years we would see in their country the procreation of horses in the same abundance as that of deer and buffalo, and then not needing these animals, the acquisition of firearms in barter for hides and herds would be less difficult for them.

(Thomas 1941: 112-13)

Spanish retaliation against the Comanches' aggression in 1779 along with the southern expansion of the Osages and Pawnees pressured the Comanches into an alliance with the Spanish in 1786 (Thomas 1932: 294-321). After receiving gifts and numerous colonial emissaries, three Comanche leaders signed the 1786 peace accord with New Mexico's governor, Bautista de Anza. The Spanish made only four demands in 
the treaty, each of which was buffered by economic diplomacy. According to the document's contents, the Comanches agreed to desist from hostile actions against the Spanish and their allies residing in New Mexico, to ransom Spanish captives only to Spanish authorities, to relinquish any involvement in foreign trade, and to share the same allies and enemies as Spain. In return, the Comanches would receive full-time traders and annual gifts for the chiefs and principal tribal members (Faulk 1964: 65).

During the late 1780s, Spanish officials in New Mexico and central Texas attempted to increase their influence over the Comanches through the disbursement of gifts and the scheduling of seasonal markets. Spanish colonialists dramatically increased their contact with the Comanches after 1786. In 1787, Taos held seven fairs, Picuris sponsored another, and Pecos maintained its huge annual rendezvous (Kessell 1979: 408). In addition, San Antonio provided Comanches with a few scheduled trading fairs a year.

Predictably, the Comanches' involvement with the colonial trade in horses deepened as exchange opportunities increased. Throughout the Spanish era in the Southern Plains, the Comanches expanded their territory, increased their importance in trade networks, and developed alliances with a myriad of groups. Rather than creating a client nation, the Spanish provided the Comanches with the necessary conditions to increase their influence in the region.

The Comanches' political organization aided their ability to retain sovereignty. Comanche leaders acted as brokers or buffers between colonial authorities and the local community (Foster 1991: 74; Kavanagh 1996: 15). Because of colonial conceptions of government, the Comanche individuals termed chiefs or leaders by the Spanish became critical to intersocietal relations. This interstitial space between the local and regional was stabilized through the role of leader. Though perspectives on what defines a leader vary, the interactions between colonists and colonized was standardized through these individuals.

\section{Indigenous Interactions with Colonial} Authorities as Evidence of Independence

As the Comanches and Hasinais illustrate, they remained involved in trade networks during Spain's occupation of the Southern Plains. 
In part, this resulted from the distribution patterns of high-demand commodities such as firearms and horses. Restrictive trade regulations kept the Spanish from controlling the distribution of firearms. Additionally, the propagation of horses occurred outside the purview of colonial structures. Augmenting these facts were the political strategies used by the Comanches and Hasinais to mediate and structure their own interactions with colonial authorities.

Until 1763, France's continual involvement in the Southern Plains exchange routes precluded Spain's dominance over the regional economy. French traders situated among the Hasinais periodically traveled west or utilized nomadic groups as middlemen to trade firearms directly to the Comanches and Taovayas primarily for horses, not bison products. This allowed the Hasinais to remain independent of Spanish commodity sources and maintain some control over the flow of firearms.

Even after France's retreat from the area, Spanish control remained weak. Chronically underfunded and unable to replicate the quantity or quality of trade goods offered by other nations, Spanish colonists attracted the animus of Native groups. Except for a few brief periods of peace, the Comanches continuously raided Spanish settlements for livestock.

Vicissitudes in the structure of prices, intercolonial trade, and governmental policies kept the Spanish colonies in the region from developing their own independent economic base. Consequently, throughout this period colonial economies depended on Native American groups as conduits for expansion. As indigenous peoples could more easily transport items across international boundaries, Spanish colonists found themselves particularly dependent on Native routes of exchange. In addition, a continual lack of funding and personnel in the colonial sector permitted Native American communities to maintain a high level of autonomy in their relations with colonists. The presence of competing Euroamerican powers further ensured the independence of Native Americans. If indigenous groups became dissatisfied with one country's policies, they allied themselves with another.

Unless the impetus for and strategies of colonialism are understood, it is difficult to understand the emergence and structuring of interactions between the colonizers and the colonized. In world systems 
theories the market provides the critical link between different social units. This linkage forms a conduit for the flow of commodities. The structuring of this conduit occurs through the actions of all its participants. Invariably, these actions are strategic means for obtaining critical products. As world systems theories illustrate, strategies change over time in response to the exigencies of the local, regional, and world economies.

Spain initiated its colonial occupation of the Southern Plains with the establishment of missions. Agents of missionization collected critical information about the locations, governments, population sizes, strengths, and weaknesses of indigenous communities (Bolton 1917: 10). Armed with this information, Spain began a program of colonization. Missions, settlements, and army garrisons were established in east, central, and southern Texas. Lacking financial support from Spain, however, these colonial settlements had to negotiate stable interactions with local communities. The currency of these interactions was the exchange of critical commodities. Colonial settlements needed food products and horses, while indigenous communities required firearms and horses. Colonial administrators attempted to regulate these exchanges through government-sponsored trade fairs and sanctioned gift-giving events. Trade fairs were never held in east Texas, though, because of France's colonial activities in the lower Mississippi Valley. Unable to compete with the quality and quantity of French merchandise, the Spanish residing in east Texas relied upon the giving of gifts to negotiate stable relations with local communities. Because of Spain's refusal to fund large amounts of resources for this activity, gift giving failed to secure allies for the colonies.

In addition, restrictive trade laws precluded Spanish citizens from trading firearms to local communities. Because French traders were not constrained by similar regulations, their importance in local trading activities grew. Locating their trading bases near or in the Hasinais' communities enhanced the role of these villages in local exchange networks. In east Texas, the Hasinais dominated local exchanges. Their ability to trade with both the French and the Spanish precluded the Hasinais' dependence on either colonial power. Organized under the auspices of one leader, this community continued to thrive until France's retreat from Louisiana. 
When Spain gained greater control of the Hasinais' territory, the position of tribal leader became less important. Spanish gift-giving events became more critical, however. During this period, there were many reports of Hasinais visiting Spanish settlements. Lacking a centralized leader may have democratized the giving of gifts. Definitely, though, the absence of a tribal representative kept the Spanish from increasing their hegemony over the Hasinais' communities.

The Comanches' dispersed settlement pattern and frequent migrations allowed them to play an important role in the supply side of the horse trade. In this capacity, the Comanches maintained a series of interaction strategies with the Spanish. These included raiding, alliances through peace negotiations, and the emergence of interstitial brokers. By displacing Apache competitors, the Comanches regularized their participation in New Mexico's government-sponsored trade fairs. Through their raiding proclivities, the Comanches accessed needed commodities for these exchanges. They also used raiding as a means of securing regulated exchanges at specific pueblos. By allying with the Taovayas, the Comanches obtained French weaponry.

As the experience of the Comanches and Hasinais illustrates, Europeans did not entirely control the direction or structure of colonial encounters. Clearly, patterns of exchange did not rise sui generis from the expansion of European colonialism. Rather, local communities defined their own strategies for connecting with colonial powers. 


\section{5 \\ Regional Analysis}

Initially, the methodological techniques and theoretical constructs of regional analysis precluded its application to areas lacking a developed commercial sector. Early models developed by geographers such as Von Thünen (1966), Chisholm (1962), and Christaller (1966) emphasized not only the role markets played in structuring space but also the ways markets conditioned their participants to maximize profits and minimize supply and demand costs (Hodges 1988: 17). Typically, these theorists stressed the ways in which the spatial relationships between market locations and supporting suppliers, consumers, and producers illustrated the most profitable pattern of landscape use. According to this perspective, two factors led to variations in spatial arrangements: the kinds of commodities circulating and the types of transportation available.

For years, anthropologists studying the economic activities of social communities (Clarke 1977; Dalton 1969; Godelier 1972, 1977; LeClair and Schneider 1968; Polanyi 1957; Wolf 1955) have challenged the assumption that "producers not only wish to maximize output, but are in the position to do so" (Hodges 1988: 17).

A society cannot expend in the process of exploiting nature more energy and material than it extracts, nor waste in distribution more than it has gained in production - or else it succumbs, sooner or later.... the procedure of maximization, economizing admits only one solution to any problem of resource allocation: "the one best way." But survival is any way that works. Success is ecologically established from a minimum point-the minimum required of a cultural system to meet the selective pressures that would decompose it. (Sahlins 1972: 314)

Within any society, social factors intervene and determine a culture's perception of maximized profits and minimized costs. In addition, the process of colonialism frequently caused structured inequalities in the 
allocation of resources regardless of the actions of the participants. Cognizant of this issue, geographers began to correlate spatial patterns with the degree of control exchange participants exerted over the distribution of resources (Casagrande, Thompson, and Young 1964; Kelley 1976; Lewis 1976; Smith 1976). Analyzing the deployment of political power over the extraction, circulation, and consumption of resources became critical to this type of research:

Fully elaborating this relation would eventually point out how different stratified political economies, such as archaic and nation-states (Service 1975), or feudal, Asiatic, ancient, capitalist and socialist social formations (e.g., Hindess and Hirst 1975) affect settlement variations. (Paynter 1982: 31)

Through this shift in emphasis, researchers could apply models of regional analysis to areas not yet articulated into a market economy. In cases of weakly developed or nonexistent market economies, these scholars concentrated on other kinds of social structures that mediated political and economic relations between local communities. In order to maintain the spatial component of regional analysis, these structures had to not only be enduring but also form the nexus or nodal point of intersocietal linkages. For example, structures of alliances, systems of kinship, social hierarchies, and even religious activities occurred on a continuous or at least predictable basis and could thus be analyzed as mediating structures (Hodges 1988; Irwin and Kasarda 1994; Paynter 1982; Smith 1985; Verdery 1976).

Because initial colonial encounters often lacked developed markets, the identification and analysis of stable formations prove particularly useful for studying the interactions between the colonizer and the colonized. In the Southern Plains, the Comanches and the Hasinais constructed numerous alliances in order to secure access to the distribution of firearms and horses. These alliances can be correlated with shifts in the locations of markets and/or supplies. Through an examination of alliances as a mediating structure dealing with colonialism, it is possible to gain a better understanding of the settlement locations and the strategies used by the Comanches and Hasinais to maintain access to critical commodities. 
By itself, regional analysis is not a panacea for explicating the entire dialectic among local, regional, and global forces. It is, however, an excellent tool for illustrating and interpreting the systematic relationships between a social group's overt actions and its access to critical commodities. For example, this type of analysis illustrates the strategies used by the Comanches and Hasinais to increase their involvement in the circulation of high-demand commodities such as horses and firearms during Spain's occupation of the Southern Plains.

Throughout this period, the accessibility of high-demand commodities remained competitive. Consequently, significant differences occurred in the level of access communities maintained over these commodities. Both the Comanches and Hasinais relied on alliances, spatial locations, and force to ensure themselves not only access but also increasing control over the distribution of firearms and horses. Acting as conduits for the flow of commodities, alliances of the Comanches and the Hasinais linked territorially distinct communities, regions, and nations across space into exchange relations (Irwin and Kasarda 1994: 342). Strategic changes in the locations of these two communities as well as the composition of their alliances correlated with the distribution of high-demand commodities.

Previous Studies of Indigenous Exchanges, Settlements, and Alliances in the Southern Plains

Numerous researchers have studied the factors controlling the social flow of resources between historic indigenous groups inhabiting the Plains. Until the publication of studies by Goldfrank (1945), Jablow (1950), Lewis (1942), and Secoy (1953), ecological paradigms prevailed, and as a result, the environmental structuring of Native exchanges, alliances, and communities was emphasized (Lowie 1916, 1954; Oliver 1962; Roe 1955; Spielman 1983). In a number of cases, critical commodities, such as firearms and horses, were represented as novel trade goods that benefited subsistence and elaborated earlier patterns of warfare and exchange (Lowie 1954; Oliver 1962).

Jablow (1950), Secoy (1953), and Albers (1991,1993) placed greater emphasis on the relationship between Euroamerican commodities 
and the activities of historic Plains populations. Secoy centers his research on the political and economic importance historical communities placed on high-demand goods, such as firearms and horses. According to Secoy (1953: 95), the successful attainment and incorporation of these two items transformed social activities within and between these communities. Secoy's recognition that Plains communities were not hermetically sealed artifacts led him to argue that

the culture pattern approach is an ineffective tool for the investigation of those aspects of a given culture, which like the military technique pattern, actually have their most potent connections with the similar aspects of a number of other cultures, thus forming a multi-cultural system. (Secoy 1953: 95)

Jablow adds to Secoy's research by discussing the actual strategies used by the Cheyennes between 1795 and 1840 to gain access to and control over guns and horses. In his approach, modified and elaborated later by Moore (1987), Jablow illustrates the ways in which a social group orients itself around a trading economy. As Foster notes in his introduction to Jablow's book:

Intertribal and Indian-Euroamerican trade on the Plains was the dominant context within which Native social organizations were ordered, enabling production, and exchange, alliance and warfare, centralized authority and individual enterprise, in short all of the classic features that Euroamerican texts have reified as traditional Plains life or culture. (Foster 1994: vi)

Although Jablow's ability to explain the Cheyennes' internalization of Euroamerican contact revolutionized Plains scholarship, Albers $(1991,1993)$ pushed this research further by illustrating the systematic relationship between intersocietal relations and a community's production needs. In particular, this market-based production institutionalized and structures the types of linkages between and within Native communities.

According to Albers (1993: 102), "the specialized and surplus production of goods for mercantile markets set into motion a chain of effects which had far-reaching repercussions on native political 
economies." Albers claims that alliances "were based on a fundamental interdependence in the appropriation of labor, land, and resources" (1993: 97). Production needs, which were based on the colonial economy, determined the structuring of these linkages. These alliances mediated through the establishment of kinship ties centered on either cooperation or symbiotic relations. Warfare and raiding occurred when two communities experienced competitive production needs. Consequently, "war was a condition of total competition, and raiding was its principal exchange strategy" (Albers 1993: 122).

Equating linkages with social strategies used by communities to gain access and control over land, labor, and high demand resources, Albers suggests:

On one end were relations based on war where groups divided and competed with one another over access to land, labor, and other resources. At the opposite end were relationships of merger where groups joined together and cooperated in the use of a shared resource base. Towards the middle were relationships built on symbiosis. Here groups were separated, but they maintained interdependence through a specialized division of labor and/or functionally differentiated positions in a wider circulation of commodities. (Albers 1993: 98)

A local community's mode of production acted as the catalyst for the organization of these emergent connective formations. Consequently, the degree to which communities articulated with one another depended on their level of competition. Social ties such as kinship, military sodalities, or shared ritual practices served as the articulating medium. Albers manages to capture the dialectic between local and regional actions and to resist categorizing diverse modes of production "into timeless essences, which are then allowed to... 'articulate' with one another without reference to historical time or circumstance" (Wolf 1982: 401).

According to Hall (1989: 99), the Comanches' displacement of the Apaches disrupted "inter-group relations and intensified fighting among all groups." In addition, Spanish demands for captives, as well as their retaliatory attacks against raiders, contributed to the increase in warfare. This occurred because "retaliations for the actions of a particular band were directed at entire 'nations,' ensuring further vengeance 
raids" (Hall 1989: 99). A contributing factor was that "the trade in captives not only ensured further vengeance raids, but augmented the state policy of encouraging war among the "heathen nations" (Hall 1989: 100-1). As a result, "The intensification of conflict increased the dependence of nomadic groups on European goods. This dependence, in turn encouraged nomads to produce more buffalo products (primarily hides) and captives to trade for the now necessary goods" (Hall 1989: 95).

More recently, Hämäläinen (2001) explores the ways in which the Comanches manipulated the context in which intersocietal connections occurred. In particular, he illustrates the linkages between the Comanches' trade networks and their increasing movement into the hide and silver trade. Building on the works of these earlier scholars, this chapter illustrates the ways local groups reify their own internal transformations through shifts in alliances, locations, and the strategic use of force.

To more clearly show the relationship between these variables, the Comanches and Hasinais are studied during three colonial periods. The first era begins with the construction of six Franciscan missions in east Texas in 1690 and ends with Spain's acquisition of Louisiana from the French in 1763. The period 1764 through 1810 marks the era of Spanish consolidation of power in the region. The last stage, 1810-1821, begins with the Mexican Revolution and terminates with Mexico's independence from Spain. During this period, a reordering of established economic and political relations transpired.

\section{Alliances and Settlement Locations of the Comanches and the Hasinais}

From the beginning of the eighteenth century through independence of Mexico from Spain in 1821, Euroamerican populations in the Southern Plains remained small. Being distant from colonial centers of power, they were unable to fully replicate their countries' systems of production and distribution. In addition, a continual lack of funding and personnel in the colonial sector permitted the Comanches and the Hasinais to maintain a high level of autonomy in their relations with 
the colonists. The presence of competitive Euroamerican powers in the region further ensured the sovereignty of these two communities.

Comanches and Hasinais exploited these colonial weaknesses and became critical to the distribution of high-demand commodities. Increases in exchange opportunities during Spain's occupation of the Southern Plains not only affected the settlement patterns of the Comanches and the Hasinais but also conditioned the development of strategic alliances with neighboring polities.

Through a series of alliances with Puebloan, colonial Spanish, and later the Taovayas, a Wichita community, the Comanches increased their level of access to and degree of control over high-demand commodities. The Comanches' growing importance in the region's economic and political arena led various Apache groups to relocate elsewhere in the Southern Plains. The diaspora of Apache competitors aided the Comanches' continual expansion across the Southern Plains.

For a number of reasons, the Hasinais could not compete with the Comanches' growing importance in the region's political economy. First of all, Spain and France's occupation of the eastern portion of the Southern Plains formed a wedge between the once unbroken territories linking the Hasinais with their Kadohadacho relatives to the north. Second, the Hasinais' reliance on agriculture as a means of generating trade surpluses limited their participation in the increasingly important horse trade. Third, France's retreat from the area weakened the Hasinais' middleman status. Last, their devastation by epidemics and hostile neighbors caused them to retreat from the territory. Each of these factors contributed to the Hasinais' eventual marginalization in the region's political economy.

\section{Alliances and Locations of the Comanches,} 1690-1763

Spanish officials in New Mexico first noted the existence of Comanches in the northwestern portion of the Southern Plains in 1706. Observations at this time suggest that the Comanches' movement into the region related to the presence of Euroamerican commodities. According to the governor of New Mexico at that time, the Comanches, 
in alliance with the Utes, were threatening Apaches north of New Mexico and residents of Taos Pueblo (Thomas 1935: 16, 61, 76; Hackett 1941, 3:382).

Ignoring the fact that Taos served as a major center of exchange for the Apaches, the Utes and Comanches attempted to negotiate their own trade terms with the village's inhabitants between 1710 and 1712 (Twitchell 1914, 2:269). Unable to reach an agreement, the Comanches and Utes began forcing the issue by raiding Taos and the surrounding settlements. Worried residents reported that these raiders regularly looked for weaknesses in the villages' defenses (Kavanagh 1996: 63). Initially, Spanish leaders determined that

war [should] be made against the Ute and Comanche because it is evident that for more than seven or eight years they have come to steal horses and rob herds and run away with the goods in the trade which this kingdom has with the Apaches of El Cuartelejo. Since they have committed three murders, the present is very opportune to make war upon them. (Thomas 1935: 107)

Retaliatory forays against the Comanches and Utes proved ineffectual, however. Invariably, the Spanish encountered abandoned encampments associated with these indigenous allies (Thomas 1935). As nomadic communities, the Comanches and the Utes could easily move when necessary. A French trader captured by the Spanish in 1740 noted that he had observed fifty or sixty villages of Comanches that were "scattered about caring for the many horses which they get from New Mexico" (Hackett 1941, 3:348). Two years later, another French captive of the Spanish mentioned that the Comanches resided in "many rancherías in different places, which according to the seasons, are moved from time to time in search of pasturage, wood, water, and buffalos" (Hackett 1941, 3:323).

Comanches escalated their war against the Spanish between 1740 and 1750. During that decade, the Comanches killed over 150 residents at the pueblos of Pecos and Galisteo (Kessell 1979: 380; Lummis 1898: 77, 127). By the 1740s, the Spanish noted that both hostile and peaceful factions of Comanches resided near Spanish settlements in New Mexico. Apparently, Comanches residing east of the settlements 
at Pecos and Galisteo were hostile, while the ones located northeast of Taos engaged in peaceful trade (Kessell 1979: 380; Lummis 1898: 77, 127). This is not necessarily a political separation. Rather, it reflects different Spanish relations with geographically dispersed Comanches.

As Albers noted (1993: 108, 122), raiding served as an economic mechanism to distribute scarce resources. It also acted as mechanism of terrorism against recalcitrant communities reluctant to engaged in exchanges. Raiding worked for the Comanches. For example, during the 1720s, colonial administrators officially sanctioned trade fairs between the Comanches and the residents of Taos, San Juan, and Pecos (Kavanagh 1996). Colonial leaders attempted to control these fairs by punishing traders who engaged in exchanges with the Comanches "before the time set for the regular trade" (Kavanagh 1996). Administrators also tried to gain a semblance of control over the merchandise traded at the fairs. In 1737, officials mandated that New Mexico's citizens obtain government permission before ransoming non-Christian Natives from the Comanches (Olavide y Micheleña 1737 in Kavanagh 1996: 68). During the decade of violence between 1740 and 1750, residents of Taos were threatened with the death penalty if they engaged in trade with the Comanches (Kessell 1979: 381).

None of these sanctions worked, though. In 1746, the Comanches were observed traveling in a large battle formation of no less than fifteen hundred individuals who were bent on making war on all nations (Robles 1946: 78-79). According to one Spanish source, the Comanches received visits from the Jumanos (probably relatives of the Wichitas), the French, and even German traders, each of whom exchanged muskets, hatchets, glass beads, swords, and ammunition for bison hides, horses, and slaves (Hackett 1941, 3:323-24). Apparently the Comanches' peace negotiations with the Jumanos in the 1730s gained them access to the French (Hackett 1941, 3:303). It also may have resulted in the deep enmity that developed between the Utes and the Comanches.

Spanish officials first recorded a breach between the Utes and the Comanches in the 1730s (Kavanagh 1996: 68). Though some Utes joined the Comanches in a small raid on Pecos Pueblo in 1750, by 1761 Utes served as auxiliary troops during Spanish campaigns against the Comanches (Adams 1953: 218). The relationship between these 
two communities remained hostile throughout the rest of the Spain's colonial era.

Through murder and theft, the Comanches and the Utes successfully dislodged the Apaches from a favorable trade relationship with the Spanish. In addition to their persistent encroachment on the Apaches' trading relations with Taos, the Comanches and Utes also supplanted the Apaches in their settlements along the western portions of the Canadian and Arkansas Rivers (Thomas 1935: 128). Sixty years after the event, New Mexico's governor related that in the early 1720s the Comanches fought and won a nine-day battle with Apaches somewhere in northwestern Texas (Hackett 1934, 2:213). Soon after this battle, the Comanches, probably in concert with the Utes, successfully ejected the entire nation of Apaches residing along the Arkansas and Canadian Rivers.

Admonished to keep alive the Comanches' hatred of the Apaches, lest the two form an alliance, the Spanish failed to intervene on behalf of the Apaches (Hackett 1934, 2:213-14; Wheat 1957, 1:94-116). Consequently, Mescalero and Lipan Apaches residing in eastern New Mexico fought a losing battle against the Comanches' territorial encroachments (Hackett 1934, 2:213-14). By 1745, the Mescaleros, who once utilized the entire upper Rio Grande, had to finally withdraw to the southern extent of their range, near the mouth of the Pecos (Dunn 1911). The Apaches' displacement allowed the Comanches to monopolize the headwaters of major rivers in the western Southern Plains. By occupying the headwaters, the Comanches constrained the level of access other communities maintained with the Pueblos.

As soon as the Apaches began to retreat from their homelands, the Comanches expanded their territory. By 1743, officials in central Texas noted a substantial presence of Comanches in the area (Morfi 1935, 2:294). Apparently this community of Comanches, as well as the groups residing in New Mexico, received firearms on a regular basis from French and Jumano traders (Thomas 1940: 14). According to New Mexico's governor in 1750 ,

the trade that the French are developing with the Comanches by means of the Jumanes [sic], which in time will result in most serious injury to this province. Although the Cumanche $[$ sic $]$ nation carries on a like trade 
with us, coming to the pueblo of Taos, where they hold their fairs and trade in furs and in Indian slaves whom they take from various nations in their wars, and in horses, mares, mules, knives, large knives [belduques], and other trifles, always, whenever the occasion offers for stealing horses or attacking the pueblos of Pecos and Galisteo they do not fail to take advantage of it. (Hackett 1941, 3:328)

Critical to the success of the Comanches in displacing the Apaches and negotiating favorable trade terms with the Spanish includes the emergence of externally peaceful and hostile factions among the Comanches. Spanish authorities first mentioned hostile Comanches in Texas in 1757. During that year, the Comanches in concert with the eastern Caddoans and bands associated with the Taovayas destroyed the San Sabá mission (Castañeda 1936, 190; Weddle 1964: 199). According to eyewitness accounts of the attack, firearms were so prevalent that "not one arrow was seen among the Indians" (Chipman 1992: 161).

Numerous items associated with the attackers were left at the scene (Weddle 1964: 199). Presumably, the public destruction of San Sabá related to the fact that the mission was constructed for Lipan Apaches. In all probability, the Comanches involved in the raid were associated with the Cuchanec division of Comanches. During the 1780s, Spanish documents regularly mention the Cuchanecs (Kavanagh 1996). Whether Comanches in New Mexico engaged in trading activities with their relatives in Texas is unknown at this time, but there are some tantalizing hints that suggest this may have been the case. For example, within a year of the attack on the mission, officials in New Mexico mistakenly identified Caddoan groups as polities associated with the Comanches (Kavanagh 1996). According to the governor of New Mexico in the 1750s, the "Comanches traded buffalo hides to the French through the Taovayas for guns, powder, ammunition, and offensive weapons" (Marín 1758 in Thomas 1940: 83).

Since the Comanches in New Mexico and Texas shared a common ally among the Taovayas, they probably engaged in reciprocal trades during the $1750 \mathrm{~s}$. A trading alliance between the western and eastern factions of the Comanches would be beneficial not only to the Comanches but in some cases to the Spanish as well. This is due to the fact that the Spanish instituted trade barriers in the Southern 
Plains that necessitated incredibly circuitous routes to transport supplies between colonies in Texas and New Mexico. For example, in order to travel from Santa Fe to San Antonio, a colonist had to meander through Saltillo, Chihuahua, and El Paso, Texas, a distance of seventeen hundred miles. Comanches trading across space through the territory of their common Taovaya allies could conceivably cut this distance by seven hundred miles (Loomis and Nasatir 1967: 262).

Even after the Osages displaced the settlements of the Taovayas from the Arkansas River in the 1750 s, the Taovayas remained pivotal to the Comanches' trading patterns. Relocated on the Red River, these communities continued to serve as a trading connection for the eastern and western Comanches. Spanish officials regularly reported on the large volume of goods flowing through the settlements of Taovayas on the Red River (Bolton 1914, 2:201-4).

The concentration of commercial activities in the Taovayas' region served as an excellent area of neutral exchange (Burghardt 1971; John 1975). These villages also acted as the westernmost depot for French traders. During the next few decades, however, changes in Spanish policy and the Comanches' political organization permitted the Comanches to circumvent the Taovayas.

Alliances and Locations of the Comanches, 1764-1810

After France's retreat from Louisiana in 1763, the Comanches' trading and raiding activities in New Mexico and Texas intensified. New market outlets developed north of the Arkansas River, and communities in Louisiana continued to import livestock. In 1768, the British may have traded seventeen horseloads of firearms to Comanches visiting the Taovayas (Kavanagh 1996: 79). A year later, well-armed Comanches raided the pueblos of Picurís and Pecos (Adams and Chavez 1956: 92). In 1773, Comanches committed a series of devastating raids on Spanish-controlled villages in the upper Rio Grande region. During that year, the Comanches orchestrated a large attack on Pecos and Albuquerque, five smaller raids on Picurís, and four others on Galisteo (Thomas 1940: 44). By 1775, Spanish authorities bitterly complained that the colonies no longer owned enough horses to pursue the raiders (Thomas 1940: 180-84). 
During this same period in Texas, Comanches, often in alliance with the Taovayas, constantly raided ranches, missions, and even presidios. In the meantime, other communities of Comanches peacefully exchanged captives, horses, salt, and hide with residents at Taos (Thomas 1940: 169-72). One missionary observed in 1776 that "when the Comanches are at peace and come to trade, they bring a thousand or more animals" (Adams and Chavez 1956: 111; Kavanagh 1996: 127).

The intensification of the Comanches' raiding during this period probably related to the end of French sovereignty in Louisiana. Spain's unwillingness to stabilize the area with an infusion of financial aid allowed the influx of numerous British traders. It also permitted remnant French merchants to increase their smuggling activities with impunity. This period is replete with court cases against individuals involved in smuggling (Hall 1989; Kavanagh 1996).

At this time the Spanish knew little about the Comanches. Officials estimated that the fifteen hundred Comanches residing in the vicinity of New Mexico were organized into three communities: Yamparicas, Jupes, and Cuchanecs (Thomas 1940: 201). Less was known about the Comanches in Texas. One official commented that approximately five thousand Comanches resided north of San Antonio (Kavanagh 1996). Texan leaders also observed the Comanches were "the most populous, modest, and valiant" of the tribes on the borders, but their "great propensity to steal" masked those virtues (Kavanagh 1996: 91).

In 1773, Texas colonists attempted to regulate their relationship with the Comanches through a treaty. For this purpose, they hired a French former trader, who tried to establish contact with the Comanches residing on the Red River. Recognizing the danger of this treaty to their own position, the Taovayas would not let the envoy travel beyond their villages. Though ultimately unsuccessful, the French diplomat managed to convey Spain's desire for peace to a number of Comanches visiting the Taovayas. It was also documented that the Comanches lived equidistant from Santa $\mathrm{Fe}$ and the Taovayas, somewhere near Palo Duro Canyon on the Red River (Bolton 1914, 2:94-95). At this time, the Spanish recognized four divisions of Comanches (Bolton 1914, 2:94-95):

the Jupes and Yamparicas extending from the Rio Napestle [Arkansas] to the north a little beyond the Sierra de Almagre... The Cuchanecs extend 
from the cited river south as far as the Colorado which is distant a few days from New Mexico. Both are separated on the east... from another group of Cuchanecs living in the direction of the Jumanos or Taguayaces [Taovayas]. (Governor Anza, quoted in Thomas 1932: 295)

Apparently the last group of Cuchanecs mentioned resided above the Red River and the head of the Brazos River (Kavanagh 1996: 108).

During the 1770s, the Comanches' alliance with the Taovayas, as well as other Caddoan communities further east, began to unravel (Bolton 1914, 1:210). This may have resulted from the Taovayas' diminishing importance to Spanish diplomacy. Weakened by an epidemic in 1777, the Taovayas could no longer protect themselves from the Osages' debilitating attacks (Bolton 1914, 2:203, 231). Though the Taovayas' trade in agricultural products continued, after 1780 they no longer received artifically high prices promised in the treaty of 1771 (Kinnaird 1946, 2:390-91). Consequently, the Comanches' terms for trade became less and less favorable. As a matter of fact, by the 1780s, the Taovayas were beseeching the Spanish to help protect them from the predatory Comanches (Cabello 1785). Presumably the Comanches' animus toward the Taovayas related to the latter community's proclivity to garner guns from New Orleans, Illinois, and various western Apaches.

Apparently the Yamparica division took control of the middleman role once held by the Taovayas. According to one colonial official:

The trade and interest that some rancherias have with others is that the Eastern Comanche take horses which they acquire in their wars and rapines to the rancheriás of the Western Comanches who are known by the name of Yamberika [sic], who barter for guns, powder, balls, lances, cloth, jars, knives, etc, which the Western Indians acquire... Intervening also is the trade in buffalo hides with and without hair, which benefits them and they prepare very well. (Kavanagh 1996: 107)

As the most powerful indigenous community in the Southern Plains during Spain's colonial era, the Comanches were always being asked by the Spanish to formalize diplomatic relations with them. In 1787, the Spanish offered a peace treaty to the Comanches that required few concessions on the signatories' part. Basically, the Spanish wanted 
to integrate the Comanches' trading network into the region. This must have seemed presumptuous to the Comanches, as they had a far more extensive trade network than the Spanish. According to a report written in 1785:

The Eastern Comanches have as friends the Taovayas and Wichitas, and are also found among the Tawakonis, Yscanis [eastern Caddoans], and Flechazos, but not so much among the others.... Their arms are arrows, lances, and some guns and ammunition provided by the Taovayas and Wichitas, who also provide them to the Yambericas [sic], who also get them from the nations known as Kansas, Guaxes, and Guitavoiratas who are situated north, and who in turn are provided by the traders who come from New Orleans and Illinois, and who are installed along the Missouri River. (Vial and Chavez 1785 in Loomis and Nasatir 1967: 83).

Trading opportunities with merchants from New Orleans and Illinois increased dramatically during the latter half of the eighteenth century. During the 1770 s, administrators in Louisiana commented on the region's desperate need for horses as a means of transport (Hackett 1941, 3:466-67). Apparently the yearly need to transport lumber and eighty thousand sugar casks to Havana led to this request. As one observer in Louisiana noted:

a spirit of foreign intercourse was diffused among all classes of people; exertions were made to prepare raw materials for the West India and other markets... The articles of export were sugar, cotton, indigo, rice, furs, and peltry, lumber, tar, pitch, cattle, horses, lead, flour, beef and port. (Stoddard 1812: 295-96)

Louisiana's expanding European, African, and Native populations during the latter half of the 1700s also increased the region's demand for horses. Between 1769 and 1798, the area's population increased by 14,500 individuals (Martin 1822: 206, 240, 300). Eastern Caddoans complained that "there was a well worn trail leading from the Comanches to Natchitoches" (Hatcher 1919: 52). In addition, the Kadohadachos angrily noted "that the traffic between the Comanches and traders from the interior continues without interruption, and that arms, munitions, and other war supplies are being brought in" (Hackett 1941, 3:239). 
Trade with communities north of the Arkansas River also steadily increased in importance throughout the eighteenth century. By 1785, enough horses had been traded north that the governor of Louisiana was able to state that "all the wealth of the Indians on the Missouri consists in having many horses" (Bolton 1905: 104). The Comanches' patterns of alliance and settlements shifted as trade in the area increased.

New opportunities in New Orleans, as well as north of the Arkansas River, precipitated the Comanches' movement east. Throughout this period, Yamparica and eastern Cuchanec communities controlled the headwaters of the Canadian, Red, and Brazos Rivers (Kavanagh 1996: 136-37). Increasing their involvement in these exchanges led to the Comanches' peace agreement with the Kiowas and the Yamparicas' relocation to the Colorado River's confluence with the Concho River between 1790 and 1806 (Mooney 1898: 164; Battey 1968: 90; Kavanagh 1996: 145).

Spanish authorities in the Southern Plains lacked the necessary resources to combat the Comanches' growing involvement in the regions political economy. Spain's weakened economic role in Europe contributed to the colonies' lack of quality imports and the necessary finances to develop local industries, much less protect them. In addition, after the United States took possession of Louisiana in 1803, foreign merchants immediately established trading posts in eastern Texas. Horses became critical to these settlements. As one trader commented, "The trade of this nation [Comanches] is Horses, Mules, dress'd buffalo skins and Silver ore.... They [Comanches] seem indifferent about those common articles of finery" (Abel 1922: 76-82).

As trading opportunities increased, the eastern Cuchanecs and the Yamparicas fine-tuned their raiding and trading strategies. Cuchanec communities professed their friendship with the Spanish, while Yamparicas engaged in "little robberies and extortions" (Cordero 1806). Throughout Mexico's war with Spain, the Yamparicas continuously raided Spanish settlements and ranches in Texas and northern Mexico. According to Spanish sources, the Yamparicas robbed from the Spanish in order "to trade with the Americans, who were established on the Colorado" (Kavanagh 1996: 155). One American merchant based at Natchitoches during this era commented that the 
Yamparicas lived at the headwaters of the Colorado but extended their range to the tributary streams of the Rio Grande (Wallace 1954: 123). This individual also stated that the "Yamparacks [sic] are most honest and punctilious in their dealings, and much less addicted to thievery" (Wallace 1954: 123).

The Yamparicas' political and economic distancing from the Spanish during Mexico's fight for independence allowed them to maneuver into a trading niche with the Americans. Their political astuteness concerning the benefits of an American alliance rather than a Spanish one allowed them to maintain an important role in the trade networks in the Southern Plains during the nineteenth century.

\section{Hasinai Alliances and Settlements, 1689-1763}

The already developed exchange systems among the Hasinais flourished during Spain and France's colonial presence in the region. Wedged between two competing nations, the Hasinais played a pivotal role in colonial trading ventures. Residing in dispersed agricultural villages, these settlements maintained loose connections with each other through their political system. With an estimated population of 4,500 in the early 1700s, the Hasinais formed the largest eastern Caddoan group (Swanton 1942: 12). They encompassed all of the villages along the upper reaches of the Neches and Angelina Rivers. According to an early missionary in east Texas, Hasinai territory "extends for a distance of more than one hundred leagues in each of the principal directions. To the northward it reaches as far as the bands of the Missouri River which flows into the River of the Palisades [Mississippi]" (Tanner 1974: 20).

Because the Hasinais resided in Spain's colonial territory, they faced continual pressures to live in missions and desist from participation in intercolonial trade. Neither of these policies proved successful, however. Spain's first wave of missions lost credibility as epidemics flourished (Gilmore 1973: 58). Spain's failure to concentrate the Hasinais into missions was matched by the government's inability to control smuggling in the area. Aided by their proximity to overland routes between colonial and indigenous settlements in French and Spanish territories, the Hasinais maintained an important role in early smuggling 
activities. By provisioning the French with corn, horses, mules, and slaves, they received firearms, metal tools, and textiles (Bridges and DeVille 1967: 255; Perttula 1992: 221).

Every fall the Hasinais sponsored a large trading fair near the headwaters of the Guadalupe River (Hackett 1931, 1:138-39). This annual event acted as a conduit for Spanish horses flowing east and French weaponry, textiles, and nonessentials moving west (Bolton 1987: 125, 126-27). Eyewitness accounts of a fair held in the late 1600s noted the exchange of numerous items, including horses, red ochre, deer skins, Osage orange, salt, and European commodities (Wyckoff and Baugh 1980: 229; Bolton 1987: 127). Apparently the Hasinais imported horses, slaves, and mules from the Bidais, a Caddoan community that resided on the lower Trinity River (John 1975: 279). According to a French trader from that era, the Hasinais traded guns to the Bidais, who in turn supplied the Apaches. Using these firearms, the Apaches raided horses and mules from Spanish concerns (Bolton 1914, 2:128, 305).

Alliances with nomadic communities permitted the more sedentary Hasinais to participate in the horse trade without interrupting their agricultural cycle. The most successful and enduring alliances of this type occurred between closely related groups. Consequently, except for periodic alliances with the Lipan Apaches, the Hasinais maintained their strongest connections with Caddoan relatives to the north, south, and west.

Competition over the flow of European commodities led the Hasinais into combat against the Tawakonis and Kichais in 1715 (Pénicault 1953:153-57). At the same time, the Hasinais were constantly battling with the Lipan Apaches over bison hunting grounds (Bolton 1987: 103). Because of the Hasinais' access to French guns, they won these skirmishes.

Spanish officials attempted to stop smuggling in the area by relocating coastal populations into missions as well as patrolling the lower reaches of rivers in east Texas. Lacking the necessary funds or personnel to protect their borders, however, these efforts proved ineffective. In 1746, one Spanish official noted that all the adult male Hasinais owned guns, which they had received from the French (Kinnaird 1949, 3:281). By the late 1740s, the French noted that the Hasinais "would join them 
in a moment and serve them constantly and faithfully" (Smith 1995: 52).

In 1750, irritated by Spain's refusal to trade firearms, the Hasinais told Spanish authorities that they were "ready to take up arms against the Spaniards in favor of the French" (Folmer 1953: 245-46). Outnumbered and outgunned, the Spanish governor assured the Hasinais that their trade with the French would not be disrupted (Elam 1971: 98-104). In addition, the governor licensed two Spanish settlers to import French firearms for the Hasinais.

Though colonial concessions by the governor ruined his career, the Hasinais might have decimated local Spanish settlements had he refused (John 1975: 379). Essentially, the Spanish occupied east Texas at the pleasure of the Hasinais and their French allies (Griffith 1954: 139). As a matter of fact, during the 1750 s, French diplomats proposed that the Hasinais ally with the Apaches and encircle the Spanish (Griffith 1954: 141).

After France's retreat from Louisiana, the Hasinais' political and economic importance in the region diminished. Though smuggling still remained important, changes in the location of established trade routes shifted them away from the Hasinais' territories.

Alliances and Locations of the Hasinais,

1764-1821

British and American traders expanded their trading activities in Louisiana after France's retreat from the region. Though some of these entrepreneurs operated on a sporadic basis from the Texas Gulf Coast, most chose to locate closer to the Kadohadachos. This northern shift in trade routes diminished the Hasinais' access to Euroamerican commodities. Predictably, the Hasinais tried to ally themselves more closely with the Spanish.

As part of the strategy, the Hasinais, in competition with the Kadohadachos, attempted to negotiate a peace between the Spanish and the Wichitas in 1770. Within a year, Bigotes, the Hasinais' leader during these negotiations, presented the Spanish at Natchitoches with evidence of his success. For that purpose, the Wichitas and Kichais, both past trading partners of the Hasinais, gave Bigotes two bison 
hides: a white one to signify that the roads were open and free from blood and one with four crosses painted on it to designate the number of tribes ready to make peace (Bolton 1914, 1:264-65). The grateful Spanish responded by recognizing Bigotes as the head chief of the Hasinais and renaming him Sauto (Smith 1995: 70).

Beyond providing Bigotes with a royal medal, the Spanish did little else. Chronically underfunded, the Spanish could offer only limited help to indigenous communities. Consequently, the Hasinais no longer imported enough trade goods to supply their allies, the Bidais. At the instigation of the Bidais, the Hasinais negotiated an alliance with the Lipan Apaches in 1771 (Bolton 1914, 1:265-67). Presumably this would provide them with a secure source of livestock, which could then be bartered for firearms from traders in Louisiana and further north.

Spanish administrators responded to this event with deadly swiftness. Basically, colonial officials threatened to tell the Comanches that their enemies, the Lipan Apaches, were receiving firearms from the Hasinais. Fearing the Comanches more than the Lipans, the Hasinais rejected an alliance with the Lipans. Instead, Bigotes murdered four of the seven Apaches attending the ceremony celebrating the alliance's ratification (Bolton 1914, 1:269-70).

With the Lipans vowing revenge, the Hasinais were dismayed when the Spanish abandoned their settlements, presidios, and missions in east Texas in 1773 (Bolton 1915: 387, 391). Fortunately, the Spanish government permitted Spaniards to reoccupy the region within a year (Smith 1995: 73). Although the Hasinais were briefly helped by this decision, an epidemic devastated them in 1777. At this time, Bigotes along with many other leaders, died. The Hasinais weakened position may have precipitated the Lipans' renewed efforts to negotiate an alliance (Bolton 1914, 2:230).

In 1779 , severe floods caused the Spanish to relocate their main town in the region to Nacogdoches, a village in the heart of the Hasinais' territory (Bolton 1915: 418-40). Initially, the Spanish did not provision the town with trade goods or traders. Predictably, the Hasinais cemented another alliance with the Lipans in 1782 . To commemorate this event, the Apaches traded a thousand horses to the Tonkawas, Hasinais, and Bidais for 270 firearms (John 1975: 635-36). 
Spanish administrators responded by establishing a trading post at Nacogdoches in 1783 (Kinnaird 1946, 3:80-85). They also threatened to discontinue the distribution of annual gifts if the Hasinais persisted in associating with the Lipans (Smith 1995: 81). By 1786, the Hasinais officially ended their relationship with the Lipans (Smith 1995: 81).

Because debt plagued the licensed trader at Nacogdoches, he failed to import any supplies for the Hasinais in 1789 or 1790 (Kinnaird 1946, $3: 256,301-3)$. In response some Hasinais left the area, and visits to the trading post decreased (Smith 1995: 93). Like the Yamparicas, the Hasinais transferred their alliance from the Spanish to the Americans (Haggard 1945: 46). In 1806, the Americans at Natchitoches established an official trading factory. A year later, the settlement's American agent hosted the Hasinais. During this event, he noted that the boundary between the Spanish and Americans remained vague. Consequently, he determined that all Native nations could trade at Natchitoches regardless of their location (Abel 1922: 48-60).

Devastated again by a series of epidemics in the early 1800 s, the Hasinais concentrated into three villages (Smith 1995: 86). As their population decreased and the Americans relied more on other communities for trade, the Hasinais became increasingly marginal to the region's political economy.

Locations and Alliances of the Hasinais, 1764-1821

Initially, the Hasinais survived the final decade of Spanish rule through their coastal connections and their alliance with the Tawakonis. Additional aid resulted from the Hasinais' close proximity to the Nacogdoches trading post. Concerned about the intentions of the Americans and insurgents, Spanish administrators provided more funding to Nacogdoches during its final decade of colonial control (Magnaghi 1978: 170; 1981: 420).

Unfortunately, external circumstances kept the Hasinais from strengthening their position in local trade networks. During this period, the Tonkawas expanded their territory further south and successfully subjugated the Hasinais' coastal allies. No longer connected to the Bidais, the Hasinais could not maintain their area of influence. By the 
final decade of Spain's colonial presence in the region, the Hasinais had become completely connected to the fortunes of the Kadohadachos.

By 1816, at least two thousand Cherokees had emigrated into the Kadohadochos' region (Carter 1951, 15:121). The founding of the Sulphur Fork Factory trading post by the Americans attracted even more migrants into the community. The Kadohadachos soon became outnumbered by the numerous Choctaws, Delawares, Creeks, Shawnees, and Cherokees in the region (Fowler 1817). By 1835, the Kadohadachos along with the Hasinais had sold their lands to the United States and relocated in Oklahoma (Smith 1995: 122).

\section{Summary of the Historical Experiences}

of the Comanches and the Hasinais

Hampered by shortsighted policies, Spanish colonists never attained control over the distribution of high-demand commodities, such as firearms and horses. Instead, the Comanches and Hasinais maintained an important role in the exchange of these items. This occurred through their development of strategic alliances. In order to understand the strategies of these two communities it is necessary

to view the interaction process as an integrated phenomenon, composed not only of the usual mass and distance effects, but also of the elements of accessibility and competitiveness in flows. (Fike and Mulligan 1990: 527)

By the late 1700 s, the Comanches, initially marginal to these systems of exchange, became critical to them. Apparently their nomadic propensity allowed the Comanches to direct the flow of commodities through the region. Since horses served as both a mode of transportation and a highly valued commodity, these

new technologies allow the emergence of a space of flows, substituting from a space of places, whose meaning is largely determined by their position in a network of exchanges. (Castells 1985: 33)

This fact proved critical to the Comanches' success in the Southern Plains trade. No longer did the fixed markets of the Pueblos render 
the Comanches dependent. Instead, their increased mobility permitted them to control the circulation of commodities through the removal of competitors, raiding, long-distance alliances, a dispersed pattern of settlement, and the ability to control a moveable resource, which they could deliver.

By the 1720s, the Comanches had displaced the Apaches from the Canadian and Arkansas Rivers. This was followed by the retreat of the Mescaleros from the upper Rio Grande in the 1740s. Because of the Apaches' forced retreat from the periphery of the Pueblos, the Comanches managed to monopolize the headwaters of the Canadian River, upper Rio Grande, and Arkansas River by the 1740s.

From this new location the Comanches successfully controlled trading routes on the eastern boundaries of the Pueblos. This allowed them greater flexibility for regulating the flow of commodities to and from the eastern Pueblos. The strategies used by the Comanches to maintain control over the distribution patterns of high-demand items alternated between peaceful and hostile negotiations. The Spanish exerted very little influence in this matter.

As opportunities increased in east Texas, Comanches began to expand into central Texas. Whether this migration precipitated or even represented the emergence of a separate political community is presently unclear. These recent migrants definitely impacted the circulation patterns of commodities in the area, however.

Initially, communities associated with the Taovayas blocked the Comanches from direct access to commodities originating in the east. Wedged between the advancing Comanches and Osages, however, the Taovayas began to migrate south. Weakened further by disease and the collapse of the Hasinais, the Taovayas became increasingly marginal to trading alliances. This in turn allowed the Comanches to continue expanding east. By the late 1700 s, the Comanches were obtaining firearms from the north and east, and horses from the south.

The Hasinais initially thrived due to France's establishment of fixed trading posts in their region. Their reliance on French alliances for commodity access eventually proved disastrous, however, particularly since events outside their control led to fluctuations in the availability of critical commodities. Shifts in the distribution of these items reverberated through the exchange networks of the Hasinais. 
Tied to an agricultural strategy of subsistence, the Hasinais could not seek out new markets or raid for necessary items. In addition, the devastating impact of epidemics proved more disastrous for the sedentary Hasinais than for their nomadic relatives.

Between 1812 and 1821, the Comanches intensified their raiding activities in central and east Texas. Consequently, many land grants around Nacogdoches were abandoned during this period (Jackson 1986: 135). By the end of Spain's colonial reign, the Hasinais had become irrelevant to local exchange networks. The Comanches continued to increase their sphere of influence, however.

As regional analysis shows, indigenous alliances linked themselves to as many colonial sources as possible. In addition, these alliances tried to incorporate both nomadic and more sedentary members. Though the Spanish demanded an exclusive relationship with their allies, they did not have the force to back up the demand, particularly toward a nomadic community. The Comanches' nomadic pattern of settlement and fluid social organization allowed them to circumvent Spanish pressures.

Generally, the Hasinais allied with the colonial power that provided the most trade goods. Until 1763, the Hasinais allied with the French and tolerated the Spanish. Alliances in the Southern Plains remained opportunistic and situational. As the Comanches and Hasinais illustrate, a community's control over the access and distribution of high-demand commodities occurred through strategic political decisions concerning alliances, not shifts in production or the intercession of Euroamerican planners. 


\section{SOCIAL HISTORY}

Many accounts of colonialism produced in the last thirty years have emphasized the shared histories of the colonized and colonizer. If the histories of these two populations become divorced and that of the colonizers is given primacy as a socially transformative mechanism, then the process of colonialism is seen "above all as a coherent imposition, rather than a practically mediated relation" (Thomas 1994: 3). When this happens, ethnographic representations situated in a larger regional or global arena unfold with the neatness of a Cartesian model of society. Invariably, this creates a bizarre dualism between local activities and regional and global realities. The colonized are perceived as chronically static in reaction to the constraints imposed by the colonizers.

A number of scholars studying colonial encounters in the Southern Plains attempted to overcome this shortcoming by focusing instead on the ways marginalized communities mediate their own interpretations and relations with colonial realities (Anderson 1999; La Vere 1993, 2000; Foster 1991; Fowler 1982, 1987; Hall 1989, 2000; Hämäläinen 2001). By conceptualizing interactions as a mediated process, these scholars illustrate how structures of these encounters were continuously constructed, deconstructed, and reconstructed. As Fowler's research with the Arapahos and Gros Ventres illustrates,

an approach that emphasizes the powerlessness of Indian people-the political economy of Indian-white relationships - and overlooks the ways the exploited population interprets and reacts to those relations distorts the process by which Native American societies change. (Fowler 1987:9)

Through localizing the histories of the Cheyennes and Gros Ventres, Fowler explicates the role symbols play in the construction of a community: "Symbols emerged that worked to revitalize or reassert traditional values and relationships, yet at the same time 
reassured whites" (Fowler 1982: 5). With their meaning often contested, these symbols served as expressive representations of a community. They also created a link with the past. This connection, frequently conceptualized as an "invented tradition," institutes an illusion of its immutability in the contemporary community (Hobsbawm 1983). Because of the elasticity of the symbols' content, however, their meaning is continuously transformed. Consequently, they endure while energizing a community's internal and external relations.

Using a "micro-sociological scale," Foster (1991: 19) endeavors to illustrate "how individual members of a community construct their identities and relations with one another in such a way as to constitute a shared social and moral unit." Focusing on the Comanches, Foster moves beyond recapitulation of the political and economic dominance of Euroamericans. Rather than perceiving Comanches as a reflection of colonialism, he illustrates their own strategies of organization and maintenance (Foster 1991: 30). This, in turn, permits the recognition of "the interactional conventions used by Comanches to order their social world" (Foster 1991: 74).

The approaches of Fowler and Foster are two innovative strategies available for elucidating the processual nature of nature of colonial encounters. By focusing on the political economy of the Hasinais and the Comanches during Spain's occupation of the Southern Plains, this chapter attempts to explore this process further.

\section{The Processual Nature of Firearms and Horses}

Throughout Spain's colonial presence in the Southern Plains, firearms and horses remained a constant element of local interactions. Indigenous demand for scarce Euroamerican manufactures such as metals, textiles, and weaponry intensified throughout the colonial era. As one Spanish missionary visiting Taos in the early 1700 s observed:

Here the governor, alcaldes and lieutenants gather together as many horses as they can; here is collected all the ironwork possible, such as axes, hoes, wedges, picks, bridles, machetes, belduques [large knives], and knives... for trade and barter with these barbarians in exchange for deer and buffalo hides, and for Indian slaves, men and women, small and large, a great multitude of both sexes. (Hackettt 1941, 3:486-87) 
High-demand commodities remained scarce throughout the colonial era, however. Along with the inability of colonists to meet the growing demand for manufactured items, these powers also favored some indigenous groups over others. As a result of scarcity and colonial policies privileging some local communities over others, some indigenous communities "came to be identified, named, and classified as welcome participants in the wider systems, where other groups were stigmatized, consigned to the dustbin of backwardness" (Cooper and Stoler 1989).

These two factors along with colonial attempts to expand or contract their alliances with local communities are the primary agents contributing to the instability of the Southern Plains political economy. Rarely working in concert, colonial administrators failed to develop a comprehensive plan to determine which Native communities to negotiate favorable relations of trade. For example, initially the Spanish in New Mexico experienced favorable trade accords with the Lipans. Within two decades of the Comanches' arrival in the region, the Spanish retracted their friendship with the Lipans. Officials in Texas waited another two decades before following suit.

The Spanish ignored their role in the marginalization of the Lipans because "the regnant ideology assumes the equality of all participants in the market, in the face of basic distinctions in political and economic power" (Wolf 1982: 189). Typifying this attitude is a report from New Mexico's governor in 1778:

The perfidy of the Lipanes is exposed, and the necessity to divide and confound that nation, whose wisdom, rapicity and industry are always dismal and indecorous to the progress of the arms of the king and tranquility of these possessions. (Wallace and Vigness 1960: 24-25)

This assumption eased the emergence of a colonial policy that would ultimately led to the near extinction of the Lipans. Through the threat of force and an increasingly strategic alliance with the Comanches, the Spanish began circumventing the Lipans' attempts to acquire firearms. In 1784, the colonial policy toward the Lipans had spread east into central Texas. In one statement, a colonial official managed not only to notify the Comanches about the conditions for successful trading 
relations but also to verify the diminishing status of the Lipans. During that year, one Spanish official warned the Comanches that

if they want to be my friends, and friends of the Spaniards, I will promise not to kill them, and to stop sending my soldiers, those who make war on them. And if they want to come to San Antonio to talk to me, I will give them my hand in advance, like friends, as also they would be to the other nations who are my friends, except the Lipan and Apaches, with whom I do not want anyone to be friends, but to make continual war against them. (Kavanagh 1996: 99)

Maintaining this stance required colonial officials to devise a "behavioral grammar" that served as a "social idiom standardizing interaction" (Wolf 1966: 20). Consequently, allies such as the Comanches and Hasinais were provided with a variety of colonial emblems, including flags, banners, and staffs (Ewers 1974; John 1975). In addition, Spanish negotiators employed the calumet to incorporate themselves into fictive kin networks. De Mézières went so far as to imbue his skin with particular clan tattoos in order to establish a personalized relationship with the Hasinais (Mills 1985: 5).

Closer ties with the Spanish affected the Comanches and Hasinais differently. For the Comanches, their ascendancy as favored allies of the Spanish and their concomitant ability to participate in the exchange of firearms and horses contributed to their increasingly important role in the region's political economy. The closer ties between the Spanish and the Comanches diminished the importance of the Hasinais in exchanges of Euroamerican commodities, however. Though these two communities followed differing trajectories, they were both faced with political and economic uncertainty.

The developing colonial trade in horses and firearms was embedded in shifts in market demand, resource distribution, and capital investments. As participants in a larger social arena, neither community had the ability to control the availability or allocation of firearms and horses. This conundrum, as well as the very nature of these high-demand commodities, challenged a local community's patterns of settlement, production, and social reproduction. As illustrated by the Comanches and Hasinais, this challenge was met in unique ways at the local level. In the Comanches' case, mobility increased, bison hunting probably 
decreased, and more opportunities for exchange developed. Among the Hasinais agricultural production intensified, bison hunting increased, and opportunities for exchange decreased.

These changes transformed the internal political economy of each community. Specifically, they altered the local allocation of power and prestige. In each of these populations, the attainment of power and prestige was linked to the degree of control a community or individual maintained over the circulation of high-demand commodities. The increased availability of firearms among the Hasinais caused the decentralization of local structures of power and prestige. During this same period, the high exchange and use value of horses was reflected in the Comanches' emergence as a major player in the regional political economy.

Values placed on the items offered by the Hasinais and Comanches varied, however. In general, horses appear to have been indexed to higher-value items and, in that role, became a means for accumulating and transforming other kinds of wealth. Corn, though, functioned as a standard for lower-priced objects (Blakeslee 1975). This disparity in product values affected the political and economic roles the Comanches and Hasinais filled during Spain's occupation of the Southern Plains. The Comanches faced increased competition as suppliers of horses, while the Hasinais experienced an accelerated erosion of their middleman status. Through shifts in settlement, production, and social reproduction, these two communities struggled to adapt to those changing circumstances.

\section{Shifts in the Production of the Comanches}

The emergence and expansion of trade fairs along the upper Rio Grande provided an ever-growing market for horses (Kavanagh 1996). By 1787, in addition to seven fairs held at Taos, the Spanish sponsored large annual trades at the Pecos and Picurís Pueblos, as well as San Antonio (Kessell 1979: 408). Not included in these regulated exchanges were those colonial officials did not sanction.

Along the eastern rivers of Spain's territory in the Southern Plains, trading posts operated alongside itinerant and often independent traders. As exchange opportunities increased, the Comanches' 
involvement with the colonial horse trade deepened. Leaders of the Hasinais as well as the Spanish became increasingly alarmed at the Comanches' growing involvement in the expanding opportunities emerging in the area. They were particularly concerned about the exchange of horses for weapons. Hugh O'Connor, a Spanish governor, noted that "the French continue to trade firearms, powder and balls, which they exchange for... beasts of burden. They do not raise horses and mules, hence in order to supply the need, it is necessary to obtain them from Indians in trade" (Bolton 1905: 104). Unable to stem the flow of firearms or profitably compete with Comanche horse traders, Spanish ranchers in east Texas suggested that a brand be designated

with which the people of this jurisdiction could counter mark the horses or mule to indicate the ones that are acquired legitimately, and so that persons introducing others without the said brand may be punished. It would also check the thieving of the Indians for if they found no one to buy them they would desist. (Hackett 1941, 3:463)

By 1786, one of the Comanches' horses commanded a price of thirteen knives (Thomas 1932: 306). Even as late as 1824, Comanche suppliers received $\$ 25$ to $\$ 30$ in goods per horse (James 1953: 150 151). In return, Euroamericans could sell these horses for one hundred dollars in Saint Louis (James 1953: 227).

Lucrative profits and favorable exchange rates attracted the interests of numerous Euroamerican traders as well. During this period, many traders and settlers emigrated into the region of the Red River Valley. One United States agent remarked, "Hordes of hunters and licentious traders have entered the Indian villages and camps on the Red River above this place [Natchitoches] ... of which the Indians have frequently complained" (Carter 1951: 331). Complaints, which emanated mostly from the Kadohadachos, resulted from the growing exchange between the Comanches and Euroamericans. According to one Caddoan leader, "The traffic between the Comanches and the traders from the interior continues without interruption, and that arms, munitions, and other war supplies are being brought in" (Taylor 1957: 136-37). 
Supplying the expanding demand for decent horses in a competitive market required the Comanches to engage in more specialized production. This allowed some sections of the population to engage in raiding, while others maintained local herds and subsistence needs. Raiding, perceived as a type of production, resolved "short-term imbalances in the distribution of goods" (Albers 1993: 108). Through this activity, horses were accumulated "without radically disrupting the trade of other goods" (Albers 1993: 109). Comanches could raid San Antonio, Laredo, Galisteo, and Pecos while peacefully trading at Taos, Natchitoches, or the Taovaya settlements. According to Governor Vélecz Cachupiń(:)

Although the Comanche nations carries on .... a trade with us.... as always, whenever the occasion offers for stealing horses or attacking the pueblos of Pecos or Galisteo, they do not fail to take advantage of it.

(Hackett 1941, 3:328)

Predictably, raiding intensified as competition over the trade in horses increased. During the early 1700 s, the favored status of the Apaches among settlers in New Mexico correlates with the intensity of the Comanches' raiding. During this era, Comanches tended to concentrate their attacks on settlements in New Mexico. Beyond supplying horses, these acts of aggression served two purposes. First, they forced the Spanish into a trading relation. Second, these actions disrupted trade between the Apaches and the settlers.

At this time, raids were carried out by small, highly mobile groups of men (Kessell 1979: 380; Auerbach 1943: 120-21; Loomis and Nasatir 1967: 363). By the 1750s and 1760s, Comanches focused their attacks on settlements in central Texas and the lower Rio Grande region (Allen 1939; Bolton 1914, 1:278). This increase correlates with the southern migration of the Taovayas and the expansion of French and British traders. Colonial administrators in the region bitterly complained that a peace accord could not occur because

these nations depreciate friends who furnish them nothing, and consider it better to continue war on us, since in exchange for the droves of horses which they steal from us they secure what they need from the French, and in default of this, from the English, who are their neighbors. (Bolton 1914, 1:277) 
As opportunities expanded east, so too did the raiding. By the late 1700 s and early 1800 s, the Hasinais complained of a well-worn trail leading from the Comanches to the trading post at Natchitoches (Hatcher 1919: 52). Presumably, this resulted from the vacuum caused by the retreat of France from Louisiana. According to one of the leaders of the Kadohadochos, "The traffic between the Comanches and the foreign traders from the interior continues without interruption, and arms, munitions and other war supplies are being brought in" (Hackett 1941, 3:136-37).

The organization of raids during this period appears to have become more specialized (Hämäläinen 2001). By the 1820s, it was noted that the Comanches "are becoming quite expert in firearms ... having been furnished by traders from the United States, by way of exchange, for horses and mules, which these Indians would from time to time, plunder the Spanish settlements" (Kavanagh 1996). One eyewitness to a Comanches raid observed that the Comanches

generally invaded the country in three divisions, of from two to five hundred warriors in each. Every year their incursions extend farther into the interior.... They are now overrunning the whole department of Durango and Chihuahua... upwards of ten thousand head of horses and mules have already been carried off. (Ruxton 1847: 18, 101-2).

Throughout Spain's presence in the Southern Plains the Comanches continued to engage in raiding when the need arose. In addition, the Comanches managed to successfully incorporate horses into their communities.

Whether for use or exchange, maintaining horse herds required frequent migrations in order to find sufficient pasturage. By the 1730s, the Comanches were "scattered about caring for the many horses which they get from New Mexico" (Hackett 1941, 3:348). In 1749, they remained "dispersed, with their large droves of horses, for which reason they could not live together, having to seek sufficient pasturage and water for their horses" (Hackett 1941, 3:317). Anthony Glass, a trader visiting the Comanches in 1808, noted that "each band contain[ed] from one to four thousand souls and twice that number of Horses \& Mules" (Flores 1985: 81). De Mézières related that the Comanches 
"are skillful in the management of the horse, to the raising of which they devote themselves" (Bolton 1914, 2:297). Reiterating this sentiment, one observer stated:

In one particular the Comanche is noteworthy. He knows more about horses and horse-breeding than any other Indian. He is particularly wedded to and apt to ride a pinto ("painted" or piebald) horse, and never keeps any but a pinto stallion. He chooses his ponies well, and shows more good sense in breeding than one would give him credit for The corollary to this is that the Comanche is far less cruel to his beasts, and though he begins to use them as yearlings, the ponies often last through many years. (Dodge 1891: 862)

As one early American trader commented, the Comanches owned "great numbers of very fine horses - and equal to any I have ever known" (Fowler 1898: 65). Further dispelling any notions about the inferiority of the Comanches' horses, one traveler exclaimed in 1821, "They are beautiful animals, always in excellent condition and although smaller than our American horses, are still very compact, and will bear much fatigue" (Kendall 1929: 94).

Commitment to the maintenance of their horses contributed to the Comanches' success at bison hunting. In general, bison hunting required moments of rapid movement punctuated by prolonged periods of rest (Ingold 1980). Their economic focus on horses, concomitant with larger herd sizes and the necessity of having more grazing areas, resulted in frequent migrations.

Most of their animals [horses mules] they tie every night with ropes made of buffalo skins to stake droves down in the grass round about their camp, thus they never can remain but a short time in the same place, but must move to fresh pasturage. (Sibley, quoted in Flores 1985: 81)

Potentially, though, if an individual's herd population grew beyond the size necessary to supply transport and food, it became a liability in the hunting of wild ungulates (Ingold 1980: 57). As Shimkin points out (1947: 268): "More horses would have meant closer pursuit of the buffalo... but also less fodder per head, consequently more frequent moving." 
Frequent migrations aided the Comanches' efforts to support a surplus of horses. It also required the Comanches to expand their access to grasslands. This was complicated by the fact that horses and bison were sympatric species, both preferring to feed on perennial warmseason grasses (Peden 1972: 8). In addition, weather conditions in the Southern Plains frequently affected the quality of the grasslands. Predictably, in some areas grasslands were overexploited. If overgrazing occurred, warm-season grasses decreased and warm-season forbs increased (French 1968: 49).

A number of travelers through the region noted the degradation of the Southern Plains grasslands during the 1800s. As one man stated: "The soil is rich and well matted with their [bison's] favorite grass, yet it is all (except a very little on the creek bottoms near to timber) eaten down like an overtaxed sheep pasture in a dry August" (Wilcox 1911: 29).

In order to overcome this problem, a community had to alter both the focus and the organization of its subsistence. According to Kavanagh (1996: 59), the importance of bison as a basic item of the Comanches' political economy lessened with the introduction of horses. Though bison continued to be hunted by the Comanches, the mobility and technological advantage offered by horses meant that fewer people were needed to dispatch or transport the animals. In 1772, De Mézières noticed that the Comanches tended to "divide themselves into an infinite number of little bands for the purpose of seeking better pastures for their horses, and cattle [bison] for their own food" (Bolton 1914, 1:175). According to Kavanagh (1996: 59), "The horse democratized access to the buffalo, transforming its economic role from being the basis of the political economy to being primarily an object in the domestic economy." Because of the political and economic salience of horses and guns, bison became the primary means for obtaining agricultural and manufactured products. Adapting to the changing function of bison use, economic activities among the Comanches became more specialized.

For example, the role of captives became more demarcated. Not only did male captives, who were often of Spanish descent, tend the horses, but they also repaired the guns and made the saddles (Burnet 1824: 163). Through specializing aspects of production, the Comanches 
successfully participated in the trading economy while maintaining a secure source of subsistence. Due to these changes, the Comanches retained a sizeable surplus of healthy horses and thus augmented their role as major suppliers of this critical resource.

An added advantage of the transitory nature of the Comanches' pattern of settlement related to their proclivity for raiding. Being a highly mobile society, the Comanches stymied Spain's efforts to halt the practice. Having a dispersed population, along with their access to rapid transport, aided the Comanches' efforts to escape Spanish detection and to supply other colonial powers with their ill-gotten gains. Basically, the Comanches raided with impunity. Noting these factors, one governor of New Mexico reported that after the Comanches

make their attack it is difficult to overtake them, because they cover a great deal of ground, stopping neither by day nor night, until they have behind them a hundred or more leagues and reach the place where they left their ranchería and women. They flee in scattered groups, so that no one can follow their trail. They leave spies behind in the mountains or hills to observe whether they are being followed. (Hackett 1941, 3:328)

The dispersed settlements and migratory patterns of the Comanches settlements allowed them to generate enough horses so that they could exchange the surplus for firearms and agricultural products. The value of horses as an object of use and exchange meant that the Comanches participated in regional trade networks to a greater degree than is usual for a peripheral community. Enhancing this development involved the organizational structure of the Comanches' trading structures.

Concomitant with the transitory character of the Comanches' settlements was the ephemeral nature of the Comanches' trading parties. Organized around a local male leader, these groups maintained a fluid membership (Foster 1991: 61). Joshua Gregg, a merchant involved in the Santa Fe trade, documented the public function of trading leaders:

In Comanche trade the main trouble consists in fixing the price of the first animal. This being settled by the chiefs, it often happens that mule after mule is led up and the price received without further cavil. Each owner usually wants a general assortment; therefore the price must consist of several items as a blanket, a looking-glass, an awl, a flint, a little tobacco, vermilion, beads, etc. (Gregg 1933: 239-40) 
Though these leaders were involved with the structuring of exchanges, the level of control they exerted over their followers appears negligible. Referred to as "captains," "leaders," or "chiefs" by the Spanish, these individuals frustrated colonial efforts to enforce trade accords. According to Governor Cachupin, Comanches trading at Taos participated in raids at Pecos and Galisteo (Hackett 1941, 3:329).

In 1750, Governor Cachupin commented on the "warlike captains...who, with their rancherías, prey upon this province and Pueblos of Pecos and Galisteo" (Hackett 1941, 3:329). More than likely, "warlike captains" easily transformed into peaceful ones when useful. The level of deference colonial officials paid to trading leaders suggests the close connection between raiding and trading leaders. In the early 1750 s, Governor Cachupin suggested that in order for his replacement to retain peaceful trading relations with visiting Comanches, he needed to "have the chiefs called and receive them with every kindness and affection. Sit down with them and command tobacco for them so that they may smoke, as is their custom" (Thomas 1940: 134). By 1786, the Spanish government financed the giving of tobacco and goods to chiefs (Gálvez 1951: 50).

Placating one "chief" did not necessarily incorporate other Comanches into Spain's sphere of influence. For example, Spanish officials repeatedly remonstrated with leaders about the raiding actions of their followers. Typically, the Comanches in power apologized and denied involvement, knowledge, and control over the raiding activities of their members. According to Cachupiń:

They excuse themselves by blaming others of their nation, saying that among them are warlike captains who commit these outrages and those who are well disposed are unable to prevent them. They always say that they know nothing about it. As there is no organization or authority among these Indians. (Hackett 1941, 3:328-29)

Comanches used this same strategy of leadership when dealing with officials or traders from other colonial powers. When Anthony Glass organized a trading expedition with the Comanches in 1808 , he continuously opined that the Comanches sold him horses that they later stole. Glass claimed that the leader "did all they could to recover them for me" and "the principal Chief told me he was truly sorry but that 
there were bad men in all nations" (Flores 1985: 80). At Glass's request, one of leaders returned some of the stolen horses. In return, the trader gave the man "a blanket, some powder and lead" (Flores 1985: 80). In less than a week, however, another forty one horses were stolen from Glass (Flores 1985: 81).

Experiences of traders negotiating with the Comanches indicate that leaders exerted little control over their followers. Kavanagh (1996: 38) differs with this opinion, however. In his analysis, he cites a number of examples where leaders used their power over followers both normatively and pragmatically. Each of his examples addresses events critical to the political relations between the Comanches and colonial authorities. For example, the assassination of Toro Blanco by Ecueracapa in 1787 relates more to economic relations with the Spanish than as evidence of an individual consolidating his power. Ecueracapa represented the Cuchanecs, who were in a position to benefit from Spanish trade agreements once Toro Blanco was neutralized.

A similar explanation describes the threat of twelve chiefs to shoot an individual who raided horses in Mexico in 1758 (Leeper 1858: 175). At this juncture, the Jupes resided on a reservation provided by the Spanish. During their brief occupation of the reservation (less than a year), this division of Comanches wanted to secure stable trade relations with the Spanish. Raiding by some members of the Jupes could potentially sabotage such an agreement.

Essentially, the Comanches organized themselves in ways most useful to their involvement in a wider arena of exchanges. Leaders emerged, but their permanency and authority remained dependent on the economic and strategic success of their actions. According to Richardson (1933: 16), "Chiefs might come and go, but the bands remained, and selected new chiefs to carry on the leadership." An observer in 1818 commented:

Compulsion is seldom exercised on a refractory culprit; and when impervious circumstances require it be done, it is effected by a convention of chiefs whose personal influences become auxiliary to an otherwise impotent authority. (Wallace 1954: 124-25)

In 1821, a Spanish colonialist wrote that the Comanches were "governed by the person most noted for bravery, intrepidity, and 
ferocity"; however, "they obey him when they wish, without noting him" (Hatcher 1919: 55). Politically, the Comanches associated most closely with the Spanish. Strategically, the absence of a centralized position of power aided the Comanches' independence from Spain's

control. Because the Native Americans had adopted a diffuse system of political control, the Spanish could not coerce a "chief" in order to gain the compliance of the leader's followers. A major means for leaders to enhance their prominence in the political arena included the ability to secure stable sources of highly sought commodities and the astuteness to redistribute these items to individuals key to the leader's success. By following this agenda, the flow of commodities within the Comanches' communities became critical to a person's capacity to remain politically important.

\section{Patterns of Social Reproduction Among the Comanches}

As access to guns became tied to the horse trade, the Comanches experienced an influx of wealth. Although the abundance of horses along with their role as a medium of exchange democratized the availability of guns, not all Comanches attained equal levels of wealth with its attendant prerogatives of power and prestige. Instead, these prerogatives remained under the control of a rather small cadre of men. These men served as leaders and controlled far more wealth than their followers. Leaders were men who successfully negotiated strategic exchanges with colonial authorities.

Spanish administrators abetted this development through their practice of bribing the Comanches with gifts. Once identified as leaders by the Spanish, colonial officials gave these individual numerous trade goods to distribute. Consequently, prominent Comanches accrued more prestige through socially generated levels of generosity (Wallace and Hoebel 1952: 131).

Clinton Smith, a captive of the Comanches in the early 1800s, calculated that more than half of the six thousand horses owned by the band he was associated with belonged to the "chief" (Smith and Smith 1927: 50-51). Captain Marcy estimated that successful warriors each owned fifty to two hundred horses (Marcy 1937). The owner of a horse was indicated by a notch on the animal's ear (Gregg 1933: 433). 
Apparently the Comanches' accumulation of wealth followed socially generated rules. Although horses were private property owned by both women and men, men dominated their use and exchange values (Gladwin 1948: 73-94; Wallace and Hoebel 1986: 47, 241). Women used horses and mules to transport tents, poles, hooks, and other items associated with the household (Flores 1985: 81). Men, on the other hand, utilized horses as an aid to bison hunting and as a medium of exchange (Klein 1993: 142).

Within the Comanches' communities, horses could be converted into forms of nondurable wealth. Like the Cheyennes and Blackfeet, bridewealth payments, damage compensation, and political advancement all necessitated the circulation of horses (Lewis 1942; Rister 1989). Men who controlled a surplus of horses converted these domesticates into Euroamerican commodities or socially sanctioned positions of status. Individuals rich in horses supported polygynous households and owned captives who acted as herders (Flores 1985: 81; Burnet 1824: 163; Gregg 1933: 434).

Unlike more durable objects of wealth, however, horses could easily be stolen or adversely affected by climatic events. This ephemeral quality of horse herds limited the development of a hierarchical political system. Numerous descriptions of the Comanches' political system mention that leaders lacked control over their followers.

\section{Shifts in the Production Patterns}

of the Hasinais

The Hasinais' involvement in various long-distance trade routes led them to diversify their economy through greater specialization in different forms of production. During the 1700 s, activities such as hunting, trading, farming, pottery manufacture, livestock management, and salt production became full-time specialized occupations (Gregory 1973: 270). In addition, the incorporation of guns and horses in the local economy increased the importance of bison and deer hunting ( $\mathrm{La}$ Vere 1993: 72; Swanton 1942: 265). Early Spanish missionaries noted that the Hasinais participated in a continuous round of hunting several times a year in late spring after planting and again after harvest in late summer (La Vere 1993: 73). In 1650, Spanish settlers mentioned that the Hasinais "plant and gather their crops of corn; their lands 
are fertile, and they utilize wild cows called cibolas" (Castañeda 1936, 1:205).

The Hasinais' ability to more easily kill bison permitted them to reduce their consumption of agricultural products. Contrary to expectations, though, the communities planted and harvested on substantial tracts of farmland. As a matter of fact, one Spanish administrator noted that the Hasinais' commitment to agricultural production hindered their relocation into local missions (Kress and Hatcher 1931: 67).

One possible explanation for the Hasinais' decision to develop the agricultural sector of their economy may relate to the population's desire to participate in local trade networks. According to Lewis and Clark, a similar type of exchange system developed in the upper Missouri River region (Thwaites 1904, 2:220). In that region, agricultural communities traded surplus domesticates for bison and Euroamerican commodities. The situation in the Hasinais' area differed, however. Climatic conditions in east Texas abetted Euroamerican settlers, along with numerous indigenous communities, in their efforts to successfully participate in farming. As a result, agricultural products swamped the market and could not compete with exchanges involving "firearms, ammo, and knives" (Niles 1818: 42-43).

Adding to the difficulties faced by the Hasinais was the increasingly marginal role played by their trading partners, the Taovayas. By 1818 , the Comanches had successfully bypassed the Taovayas and begun to trade directly with Euroamerican traders. Wrote Anthony Glass:

I have come a long journey to see you and have brought with me some goods to exchange with you and your brothers-the Hietans [Comanches], for horses if you will trade with us on fair and equal terms, you will in the future be supplied with goods brought into your towns. (Quoted in Flores 1987: 47)

At this time, the Comanches maintained substantial numbers of horses. Glass could not meet the demands of the Taovayas. According to Glass, the Taovayas "demanded more for their horses than I could afford to give them" (Flores 1985: 50). A few weeks later, however, Glass met with the Comanches and purchased numerous horses at a reasonable cost (Flores 1985: 51). 
Neither the Taovayas nor the Hasinais could halt the westward movement of Euroamerican traders. By the early 1800s, the Comanches had become the main source of horses, while the Hasinai settlements served as staging areas for provisioning Euroamerican trading expeditions.

\section{Settlement Patterns of the Hasinais}

By 1805 , at least four communities of Hasinais had disappeared as separate entities, and another village had relocated closer to the Kadohadachos (La Vere 1993: 180). These changes in settlement patterns seem to be related to a number of events, including, epidemics, intensive warfare with the Osages and relocated southeastern populations, and changes in Euroamerican trading opportunities. By shifting to a more concentrated pattern of settlement, the Hasinais ensured their survival against encroaching enemies. The locations of these newly constructed settlements were not random. Invariably, the Hasinais migrated closer to trading posts and trading routes. Through these moves, the Hasinais attempted to regain their middleman position in the firearms trade. Strategically, the Hasinais needed not only to attract traders but also to halt colonial traders from directly contracting with nomadic suppliers.

Population decline destabilized the Hasinais' ability to participate in local trade networks, however. Initially, they forestalled their eventual marginality by depending more heavily on their relatives the Taovayas. A number of communities associated with the Taovayas migrated to the periphery of eastern Caddoan territories during the latter half of the 1700 s. Though this allowed the Hasinais to maintain some involvement in the exchange of commodities, they were too politically and militarily weak to control their kin or other traders within their territory.

Community leaders bitterly complained about the illicit trade occurring between the Comanches and the Taovayas (Niles 1818: 43). Although the Spanish granted the Hasinais permission to seize contraband traders, these villagers lacked the necessary military and equipment. Unable to insert themselves between colonial and indigenous traders belonging to other nations, the Hasinais became increasingly marginal to trade networks in the Southern Plains. 
Shifts in Patterns of Social Reproduction Among the Hasinais

Immediately upon encountering colonial representative of France and Spain, the Hasinais endeavored to negotiate alliances with both countries. Leaders successfully convinced Spanish Franciscans to construct missions. Offering little but epidemics, these missions quickly lost credibility among the Hasinais. When one Franciscan commented that smallpox emanated from God's will, parishioners suggested that he either leave or be killed (Hatcher 1927: 295; Gilmore 1973: 58).

As the initial rarity of Euroamerican commodities gave way to their eventual ubiquity in the region, shifts in the Hasinais' social organization occurred. Originally the Hasinais incorporated items of Euroamerican manufacture into ceremonial realms of activity (Sabo 1987: 38-39; Perttula 1992: 222). With greater accessibility to these foreign articles, however, the Hasinais began to expand their uses into other areas of social life. Increased availability of guns and horses transformed earlier patterns of local distribution. This is most clearly seen with the emergence of the caddi as a powerful village leader.

During the first half of the eighteenth century these village leaders controlled their settlements' importation and circulation of French and Spanish manufactures. Bypassed in these exchanges were the hereditary religious authorities, the xinesis. Prior to their demise, each xinesi acted as a spiritual leader for a number of villages (Leutnegger 1979: 42-53). At the time of initial Spanish contact, these men extended their control over both the sacred and mundane aspects of the Hasinais' society. Because of this role, the caddis owed the xinesis their allegiance (Wyckoff and Baugh 1980). Contrary to expectations, however, the structural position of the xinesis became less elaborate as colonial contact expanded. This occurred in response to colonial manipulations, as well as changes in patterns of distribution.

Early in the eighteenth century, Spanish agents manipulated the xinesis' rule of succession. For example, in 1690 a Spanish administrator stated:

I should like very much, Your Excellency, for something to be given the Xinesi, since he is the chief of the province. I have already honored him by making him governor and have presented him with the staff of command. $\mathrm{He}$ is no more than a caddi, and as such, he together with the other eight 
caddices is subject to a grand Xinesi. But because of the thing given him, it is impossible for him not to be recognized as the Xinesi rather than as a caddi. This done, all the Caddices will be obliged to recognize him as their grand Xinesi. (Wyckoff and Baugh 1980: 223)

By the early 1700 s, the xinesis' power had been supplanted by the elevated role of the caddis.

Spanish actions alone did not cause this shift in Caddoan power relations. Instead, these external contingencies acted in concert with changes in the types of commodities available to the Hasinais. Firearms and horses proved particularly important in this regard. As Richard White's Choctaw research illustrates, these two commodities served as a democratizing factor within a community (White 1983: 67). Both of these items permitted individuals to circumvent earlier structural constraints against the mass distribution of goods. With a gun and a horse, anyone could participate in Euroamerican trade networks. No longer beholden to the xinesis for surplus distribution, these individuals appear to have allied with particular caddis. According to Domingo Ramon's experience in 1716, goods that he gave the caddi were immediately redistributed among the leader's followers until nothing was left for the caddi (Woodall 1969: 36).

With the democratization of product distribution among the Hasinais, status privileges and civic positions were no longer coterminous with kinship relations. Succession to leadership positions became structured around ambilineal kinship ties (Wyckoff and Baugh 1980: 225). In addition, the relational differences between matrilateral and patrilateral cousins were eliminated as the two were merged into one category (Wyckoff and Baugh 1980: 231). Probably these changes in kinship relations augmented the decentralization of the Hasinais' power structure.

Though the caddis had been equal in status when the Spanish first encountered the Hasinais, by the early 1700 s, not all caddis held the same amount of power. In fact, the relationship between the caddis had become more hierarchical (Foik 1933: 21). Attracting followers seems to have become dependent on an individual's ability to negotiate stable trade alliances. This trend continued, until by the 1750 s, Spanish documents note that one caddi acted as the leader for the entire nation of Hasinais (Griffith 1954: 64). 
Shared Histories of the Colonizers and the Colonized

Clearly, a community's patterns of settlement, production, and social reproduction are more than static reflections of local concerns. Both the Comanches and the Hasinais actively participated in their construction of new patterns of settlements, production, and social reproduction. They structured these changes according to their interpretations of colonial processes. The fact that exchange opportunities increased for the Comanches while those of the Hasinais diminished led to different strategies of interactions with colonial authorities. This, in turn, reverberated through the social organizations of both communities. In the Comanches' case, they migrated more frequently and placed less value on bison hunting as opportunities for exchange increased. Among the Hasinais, agricultural production intensified, bison hunting increased, and opportunities for exchange decreased. 


\section{CONCLUSION}

During the past twenty years, researchers focusing on the Great Plains have explored strategies employed by indigenous communities to utilize colonial policies to their own advantages. By applying world systems perspectives, regional analysis, and/or social history theories, scholars successfully illustrated that indigenous communities are best understood by studying the political and economic dynamics of the region. This approach allows researchers to move beyond the view that Native communities were static except for changes caused by the creative powers of colonial constraints.

Thomas's (1994: 3) critique that anthropological studies on indigenous populations invariably "seem to do more to recapitulate than subvert the privileged status and presumed dominance of the discourse" has diminished in most recent ethnohistorical accounts of Native histories. Instead, current scholars studying the dynamics of colonial encounters no longer perceive indigenous populations as passive recipients of colonial actions.

Recent historical studies of the Great Plains emphasize the myriad of strategies implemented by nonstate indigenous communities to retain sovereignty and maintain control over their relations with encroaching colonial nations. Adherents of a world systems perspective focus on structures that articulate the Spanish colonial government with local inhabitants (Baugh 1991; Hall 1987, 1988, 1989, 1993, 1998, 1999; Klein 1993). Researchers utilizing world systems approaches, as well as regional analysis and social history theories, also focus on the advantages of a local community's internal organizational changes in order to counteract an expanding colonial government (Perttula 1991, 1992; Hämäläinen 1998, 2001; Hickerson 1996, 1997; La Vere 1998, 2000).

In an effort to gain greater insight into the Comanches' ability to withstand incorporation into Spain's regional political economy, 
Hall $(1989,1999,2000)$ applied a world systems perspective. As he pointed out (1989), Spain's colonial expansion into the Southern Plains emanated from events beyond the control of indigenous inhabitants in the region. Even so, colonization of the region necessitated that the colonists stabilize their relations with indigenous residents. Both the French and the Spanish attempted to regulate their encounters with Native groups through the establishment of trade, alliances, and treaties. Unlike the French, however, the Spanish also established missions and presidios. Although the function of these institutions was to aid Spain's efforts to incorporate Native peoples into the colonial enterprise, this strategy failed.

Researchers studying colonial expansion elsewhere in the United States often found that colonial encounters left indigenous communities "destabilized and marginalized, as their land and surplus labor are expropriated and they are insidiously incorporated into the metropolitan political economy as a peripheral enclave proletariat" (Faiman-Silva 1997: 4). In the Great Plains, however, the Comanches and the Hasinais successfully defined the terms of their incorporation into the colonial political economy. How these communities managed to forestall annihilation or forced incorporation requires a close study of the strategies used by the Comanches and the Hasinais to "control, shape, and resist the encroaching world-system" (Hall 1999: 10).

As Hall's research on the Comanches' relations with the Spanish illustrates, Spain's inability to provide the necessary funding or personnel to conquer the Comanches contributed to Spain's failure to colonize the region. Other equally important factors responsible for Spain's lack of success involved the availability of trade goods from other colonial powers and the political organization of the Comanches. Superior firearms offered by the French, British, and later the Americans diminished Spain's ability to monopolize the distribution of manufactured items critical to Native survival. Ultimately, this meant that Spanish officials lacked the requisite items to maintain the loyalty of Native allies.

Recognizing these problems, colonial officials offered favorable trade terms to communities deemed to be of strategic importance to the colonial ambitions of the Spanish. Initially, the Lipan Apaches benefited from this approach. Although unable to legally garner firearms from the Spanish, they were the first community to receive horses. In 
addition, Spain supported the Lipans' established role as trading partners of Puebloan communities along the upper Rio Grande. After the Comanches migrated into the Southern Plains, the Spanish originally acted as a neutral party during the ensuing battles between the Lipans and the Comanches over access to Puebloan trade goods.

Once the Comanches had successfully dislodged the Lipans from the Puebloan trading sphere, the Spanish ended their neutral stance and supported the Comanches' expansion into other lucrative trading regions. A number of policies introduced by the Spanish aided this endeavor. Specifically, they introduced scheduled markets in the Puebloan region as well as in central Texas. In order to maintain a modicum of control over their trading relations with the Comanches, administrators forbade independent Spanish traders from engaging in exchanges with the Comanches without official approval. Documents associated with Spain's colonial era in the Southern Plains are replete with cases involving colonial citizens ignoring this policy and maintaining illicit trade relations with the Comanches.

Spanish officials in Texas also attempted to manage trade networks developed by the Taovayas. During the Taovayas' heyday, they had access to commodities offered by the Spanish, French, and British, and later by American traders. Located along a major route of trade, the Taovayas acted as middlemen for their Caddoan relatives to the east as well as the Comanches to the west. In order to gain a modicum of control over the situation, the Spanish offered to pay artificially high prices for goods offered by the Taovayas. In return, the Taovayas agreed to trade only with the Spanish and their allies. Without the necessary resources to monitor the situation, however, the Spanish could not guarantee the Taovayas' compliance.

After the Comanches expanded east, the Taovayas' importance in local trade routes diminished. No longer did the Comanches need to rely on the Taovayas for access to commodities offered by colonial powers other than the Spanish. Instead, they could meet directly with foreign nationals and negotiate their own trade terms. They also increased their sphere of influence by strategically using their alliances with the Spanish as well as indigenous communities to develop bands that specialized in either raiding or trading (Hämäläinen 1998, 2001). As a result, a number of bands maintained peaceful trading relations 
with northern New Mexico and Louisiana, while other bands regularly raided Spanish settlers in central and southern New Mexico and Texas (Hämäläinen 2001: 288). Both Kavanagh's (1996) and Hämäläinen's $(1998,2001)$ research shows that the raiding and trading bands of the Comanches worked in concert. For example, items taken by the bands specialized in raiding not only were traded to other colonial powers but also were used by peaceful trading bands in their exchanges at markets in New Mexico as well as with allies in Louisiana.

Spanish administrators had few options for dealing with this practice. Unable to muster a strong military force or the necessary firearms to pursue the perpetrators of these raids, Spain had a limited ability to retaliate against these attacks. Instead, local officials attempted to transform the political organization of the Comanches. Because the Comanches' "political system offered bands substantial flexibility and independence" (Anderson 1999: 237), this policy ultimately failed. When colonial officials confronted leaders of bands involved in raiding, these individuals invariably denied responsibility for the actions of their followers. Time after time, political leaders noted that members of a band retained autonomy from the band's leadership.

In response to this reality, the Spanish tried to develop a more centralized political system among the Comanches by offering incentives to the community's leadership. This strategy was introduced in 1786, when Spanish officials offered military aid, favorable trading terms, and gifts to various leaders in order to facilitate the emergence of centralized authority. In 1786, Ecueracapa became the titular head of the Comanches.

The western Cuchanecs, a peaceful trading group that also was the most populous division of the Comanches, backed Ecueracapa's ascendancy to this role. According to New Mexico's governor, by "means of his person [Ecueracapa], elevating him above the rest of class, we would be able, perhaps to submit subtly all his nation to the dominion of the king without using violent means contrary to his sovereign intentions" (Thomas 1932: 302).

In order for this strategy to succeed, followers of Ecueracapa assassinated Toro Blanco, the main opposition to the scheme. As the leader of the eastern Cuchanecs, Toro Blanco and his followers derived colonial resources from foreign nationals. They also relied on raiding to 
supplement their material wealth. By killing Toro Blanco and dispersing his followers, Ecueracapa managed to negotiate a peace with the Spanish.

In reality, the adoption of a centralized leader by the Comanches related to the fact that "indigenous peoples make pragmatic responses" to political and economic events (Ferguson and Whitehead 1992: 17). Part of the pragmatism was the recognition that the Spanish were too weak to defeat the Comanches but powerful enough to provide economic benefits. Only with Spain's passage of favorable trading terms, bribery of various leaders, and the promise of military aid were the Comanches willing to adopt a principal leader. After Ecueracapa's reign ended with his death in 1793, various Comanches from the western Cuchanecs briefly filled the office (Kavanagh 1996: 143; Simmons 1967: 31). Within less than two decades, the Comanches had rid themselves of this externally invented structure.

Obviously, centralization did little for the political economies of divisions and bands residing further away from the Spanish markets. As a result, these other political grouping continued to rely on trade items from sources besides the Spanish. Had Ecueracapa and his successors had real power, they could have kept their brethren from acquiring commodities from non-Spanish sources. Clearly, the chronically underfunded Spanish colonies allowed the other bands and divisions in the Plains to maintain their independence from agreements made on their behalf by the western Cuchanecs and Spanish diplomats.

By supporting numerous leaders instead of one paramount chief, the Comanches not only escaped the coercive force of colonial sanctions but also managed to set the terms of their incorporation into Spain's peripheral frontier. Trade frequently acted as the centerpiece of Spanish diplomacy. As Dunaway notes, "Trade was essential to the diplomatic process ... and no alliances could be secured without the exchange of commodities" (1996: 27). The importance of colonial items to local economies guaranteed the survival of colonial trade centers in the region. Ultimately, the Comanches were a greater threat to Spain's continual occupation of the Southern Plains than vice versa.

Until France's retreat from Louisiana in 1763, the Hasinais profited from the ability to negotiate with two competing colonial powers. Because France did not restrict the trade of firearms to Native peoples, the 
Hasinais allied more closely with the French. Essentially, the Spanish resided in the area at the pleasure of the Hasinais and their French allies. One Spanish missionary complained that "the French have complete hold upon the Indians and have subjected them entirely to their will by means of gifts and flattery" and the French "take their shirts off to give them to the Indians" (Smith 1995: 46).

This situation began to deteriorate later in the 1750s when other indigenous populations began to compete for access to French commodities.

Increased competition for trade with Europeans within their region, combined to deprive the Hasinai of their status as a regional trade gateway. The loss of their gateway position contributed to the decline and eventual demise of the Hasinai Confederacy, and the shift of the highest locus of political authority and status from the confederacy level to the local level. (Hickerson 1996: 165)

Because the Hasinais specialized in the production of surplus agricultural products, this disparity in locally generated items for trade weakened the ability of the community to compete effectively with the Comanches. The nomadic Comanches easily transformed their subsistence economy into one that raised and raided livestock to exchange for commodities controlled by colonial traders. Raiding livestock from the Spanish for the American market became a major economic endeavor for the Comanches. In return, they received firearms with which to further expand their sphere of influence.

Few options were available to the Hasinais attempting to respond to this changing political and economic landscape. Lack of reliable trade items from various Spanish trading posts and the difficulty of obtaining horses left the Hasinais with limited choices. Forming an alliance with the Lipan Apaches proved to be one of the few options available to them. Due to the antipathy of the Spanish and the Comanches toward the Lipans, the Hasinais faced immediate retaliation from these nations if an alliance was negotiated with the Lipans. In order to either repudiate or mask their relationship with the Lipans, the Hasinais killed a number of the diplomats representing the Lipans who had attended the ceremony celebrating a treaty with the Hasinais. 
Soon after this debacle, the Hasinais continued to decentralize their political organization. After the villages became autonomous, each negotiated its own trade arrangements with the Lipans. As was the case with the Comanches, no outside government could sanction the entire community through the auspices of one leader.

As the history of the Comanches and Hasinais show, neither community succumbed to "the seductive lure of manufactured goods and powerful backing" or the "unpredictable behavior of the colonizers ... and loss of autonomy that comes with cooperation" (Ferguson and Whitehead 1992: 17). Rather than becoming marginalized through colonial expansion, each of these communities maintained sovereignty by applying various strategies to gain greater access to critical resources.

As world systems perspectives illustrate, incorporation into a colonial political economy can be forestalled in a number of circumstances. These include the presence of competing colonial governments, chronic shortages in funding and personnel among the colonialists, decentralized political systems among indigenous communities, and militarily prepared local communities.

Regional analysis shows the importance of strategic alliances with both colonial governments and indigenous communities. Ultimately, however, the most lucrative strategy involved the ability to bypass indigenous middlemen and trade directly with colonial agents. This system worked well for the Comanches. It proved disastrous for the Taovayas and the Hasinais, however. Policies beyond their control meant that neither one of the communities managed to regain its role as middleman or gateway community.

Social history theories offer insights into the reasons a community transforms its political and economic organizations. An excellent example of this fact emerges through studying changes in the Hasinais' political organization. Soon after the arrival of the Spanish, the government became more secularized. After the disappearance of the xinesis, who acted as both political and religious leaders, the caddis filled the vacuum. Initially, the caddis acted as the secular leaders of their villages. Eventually, however, one caddi became the titular head of the entire nation of Hasinais. Unlike the case of the xinesis, the caddis' role remained secular in nature (La Vere 2001). Having one leader 
represent the entire nation worked as long as two competing colonial powers remained in the region. After France retreated from the area, however, the Hasinais rejected the presence of a central leader. Instead they adopted a decentralized government in which each village acted independently of a central authority.

An analysis of global forces offers an external framework for understanding regional and local strategies. Without this component, the flow of commodities, the development of alliances, the relocation of communities, and political change appear to occur in a vacuum. Within the parameters of colonial constraints, social change represented strategic actions, not a reactive reflection of externally constructed forces.

Regional analysis contributes to world systems perspectives through its focus on the relationship between a community's economic and political prominence and the dispersal of high-demand commodities. By studying the role alliances played in the circulation of horses and firearms, changes in a community's production become more easily explained. The Comanches' expansion into new territories can be attributed to the need to raise large herds of horses rather than an inherent need to engage in warfare. The reasons for the intensification of agricultural production among the Hasinais become clearer when the products are viewed as exchange items for firearms.

Social history theories inform both world systems perspective and regional analysis by providing a microanalysis of local change. Understanding political organization moves beyond heritage or environmental explanations by discussing the strategic advantages of specific organizations in order to gain access to critical resources, negotiate with colonial governments, and engage in agreements with other indigenous communities. 


\section{BIBLIOGRAPHY}

Abel, Annie, editor. 1922. A Report from Natchitoches in 1807, by John H. Sibley. New York: Museum of the American Indian Foundation.

Adams, Eleanor. 1953. Bishop Tamarón's Visitation of New Mexico, 1760. New Mexico Historical Review 28: 193-221.

Adams, Eleanor, and Fray Angelico Chavez. 1956. The Missions of New Mexico, 1776: A Description by Fray Francisco Atanasio Dominguez with Other Contemporary Documents. Albuquerque: University of New Mexico Press.

Adams, R. 1970. Crucifixion of Power. Austin: University of Texas Press.

Adams, R. 1974. Anthropological Perspectives on Ancient Trade. Current Anthropology 15: 239-58.

Albers, Patricia. 1991. Horses Without People: A Critique of Neoclassical Ecology. In Explorations in Political Economy: Essays in Criticism. Edited by R. K. Kanth and E. K. Hunt. Savage, MD: Rowman and Littlefield Publishers, Inc.

Albers, Patricia. 1993. Symbiosis, Merger, and War: Contrasting Forms of Intertribal Relationships Among Historic Plains Tribes. In The Political Economy of Native American Indians. Edited by J. Moore. Norman: University of Oklahoma Press.

Alcocer, Fray José Antonio. 1958. Bosquejo de la Historía del Colegío de Nuestra Señora de Guadalupe Sus Missiones, Año de 1788. Mexico City: Porrúa Biblioteca.

Allain, Mathé. 1988. Not Worth a Straw: French Colonial Policy and the Early Years of Louisiana. Lafayette: Louisiana State University.

Allen, Henry E. 1939. The Parilla Expedition to the Red River in 1759. Southwestern Historical Quarterly 43: 274-97.

Amin, Samir. 1989. Eurocentrism. New York: Monthly Review Press.

Anderson, Clayton. 1999. The Indian Southwest, 1580-1830: Ethnogenesis and Reinvention. Norman: University of Oklahoma Press. 
Aten, Lawrence. 1983. Indians of the Upper Texas Coast. New York: Academic Press.

Auerbach, Herbert. 1943. Father Escalante's Journal with Related Documents and Maps. Utah Historical Quarterly 11.

Bamforth, Douglas. 1988. Ecology and Human Organization on the Great Plains. New York: Plenum Press.

Barth, Frederick, editor. 1969. Ethnic Groups and Boundaries: The Social Organization of Cultural Differences. Boston: Little, Brown.

Battey, Thomas. 1968. The Life and Adventures of a Quaker Among the Indians. 1877, reprint. Norman: University of Oklahoma Press.

Baugh, Timothy G. 1982. Edwards I (34BK2): Southern Plains Adaptations in the Protohistoric Period. Studies in Oklahoma's Past. No. 8. Norman: Oklahoma Archaeological Survey.

Baugh, Timothy G. 1984. Northern Plains Societies and Eastern Frontier Pueblo Exchange during the Protohistoric Period. Papers of the Archaeological Society of New Mexico. 9: 156-67. Albuquerque: Archaeological Society Press.

Bensen, Nettie. 1947. Bishop Marín de Porras and Texas. Southwestern Historical Quarterly 51: 16-40.

Berkhofer, Robert. 1978. The White Man's Indian: Images of the American Indian from Columbus to the Present. New York: Alfred A. Knopf.

Bhabha, Homi. 1986. The Other Question: Difference, Discrimination, and the Discourse of Colonialism. In Literature, Politics and Theory. Edited by F. Barker, P. Hulme, M. Iversen, and D. Loxley. London: Methuen.

Blakeslee, Donald J. 1975. The Plains Interband System. Ph.D. dissertation. University of Wisconsin, Milwaukee.

Boas, Franz. 1896. The Limitations of the Comparative Method of Anthropology. Science 4: 901-8.

Bolton, Herbert Eugene. 1905. The Spanish Abandonment and Reoccupation of East Texas, 1773-1779. Southwestern Historical Quarterly 9: 63-137.

Bolton, Herbert Eugene. 1913. Spanish Activities on the Lower Trinity River, 1746-1771. Southwestern Historical Quarterly 15: 339-47.

Bolton, Herbert Eugene. 1914. Athanase de Mézières and the Louisiana-Texas Frontier, 1768-1780. 2 volumes. Cleveland, Ohio: Arthur H. Clark Co.

Bolton, Herbert Eugene. 1915. Texas in the Middle Eighteenth Century: Studies in Spanish Colonial History and Administration. Berkeley: University of California Publications.

Bolton, Herbert Eugene. 1917. The Mission as a Frontier Institution in the Spanish-American Colonies. American Historical Review 23: 42-61.

Bolton, Herbert Eugene. 1987. The Hasinais: Southern Caddoans as Seen by the Earliest Europeans. Norman: University of Oklahoma Press.

Bonacich, Edna. 1973. A Theory of Middleman Minorities. American Sociology Review 38: 583-94.

Bourdieu, Pierre. 1977. Outline of Theory and Practice. Translated by R. Nice. Cambridge: Cambridge University Press.

Bourdieu, Pierre. 1984. Distinction: A Social Critique of the Judgement of Taste. Translated by R. Nice. Cambridge: Harvard University Press.

Braudel, Fernand. 1984. The Perspective of the World. New York: Harper and Row. 
Bridges, Katherine, and Winston De Ville, editors and translators. 1967. Natchitoches and the Trail to the Rio Grande: Two Early Eighteenth Century Accounts by Sieur Derbanne. Louisiana History 8: 23959.

Brown, William. 1987. Comancheria Demography. Panhandle Plains Historical Review 59: 1-17.

Burghardt, A. F. 1971. An Hypothesis About Gateway Cities. Annals of the Association of American Geographers 61: 269-85.

Burnet, David G. 1824. American Aborigines, Indians of Texas. The Cincinnati Literary Gazette 1: May 22.

Cabello y Robles, Domingo. 1785. Letter to Joseph Antonio Rengel. February 18, 1785. Bexar Archives 16F447.

Campbell, Thomas N. 1988. Indians of Southern Texas and Northeastern Mexico. Selected Writings of Thomas N. Campbell. Texas Archeological Research Lab. Austin: University of Texas.

Carrier, James G. 1992. Occidentalism: The World Turned Upside-Down. American Ethnologist 18: 195-212.

Carter, Cecile E. 1995. Caddo Indians. Where We Come From. Norman: University of Oklahoma Press.

Carter, Clarence E., and John P. Bloom, editors. 1951. The Territory of Louisiana-Missouri, 1815-1821. The Territorial Papers of the United States. Volume 15. Washington, D.C.: Government Printing Office.

Casagrande, J. B., S. I. Thompson, and P. D. Young. 1964. Colonization as a Research Frontier: The Ecuadorian Case. In Process and Pattern in Culture: Essays in Honor of J. H. Steward. Edited by R. A. Manners. Chicago: Aldine.

Castañeda, Carlos E. 1935. Our Catholic Heritage in Texas. Volume 1. Austin, Texas: Von Boeckmann-Jones.

Castañeda, Carlos E. 1936. Our Catholic Heritage in Texas. Volume 2. Austin, Texas: Von Boeckmann-Jones.

Castells, Manuel. 1985. High Technology, Space and Society. Beverly Hills, California: Sage.

Cavelier, Jean. 1922. An Account of Robert Cavelier. In The Journeys of Réné Robert Cavelier, Sieur de La Salle, as related by his faithful lieutenant Henri de Tonty; his missionary colleagues, Fathers Zenobrus Mebre and Louis Hennepin and Anastasiur Doway; his early biographer Father Christian LeClerq; his brother, Jean Cavelier; together with memoirs, commissions, etc. Edited by Isacc J. Cox, pp. 268-98. New York: Allerton.

Chafe, W. 1983. The Caddo Language, Its Relatives, and Its Neighbors. In North American Indians: Humanistic Perspectives. Edited byJ. S. Thayer. Papers in Anthropology 24. Department of Anthropology. Norman: University of Oklahoma.

Chase-Dunn, Christopher, K., and Thomas Hall 1997. Rise and Demise: Comparing World-Systems. Boulder, Colorado: Westview Press.

Chipman, Donald E. 1992. Spanish Texas, 1519-1821. Austin: University of Texas Press.

Chisholm, Michael. 1962. Rural Settlement and Land Use. Chicago: Aldine.

Christaller, Walter. 1966. Central Places in Southern Germany. Englewood Cliffs, New Jersey: Prentice-Hall. 
Christaller, Walter. 1972. How I Discovered the Theory of Central Places: A Report About the Origin of Central Places. In Man, Space and Environment. Edited by P. English and R. Mayfield. New York: Oxford University Press.

Clarke, David, editor. 1977. Introduction. In Spatial Archaeology. New York: Academic Press.

Cole, John, and Eric Wolf. 1973. The Hidden Frontier: Ecology and Ethnicity in an Alpine Village. New York: Academic Press.

Colson, Elizabeth. 1954. Review of Ernest Wallace and E. Adamson Hoebel, The Comanches: Lords of the Southern Plains. Man 54: 13-14.

Comaroff, John, and Jean Comaroff. 1992. Ethnography and the Historical Imagination. Boulder, Colorado: Westview.

Cooper, Frederick, and Ann Stoler. 1989. Tensions of Empire: Colonial Control and Visions of Rule. American Ethnologist 16: 609-21.

Cordero, Manuel Antonio. 1806. Letter to Nemesio Salcedo. June 20, 1806. Bexar Archives 34F799.

Curtis, E. S. 1926. The North American Indian. In Being: A Series of Volumes Picturing and Describing the Indians of the United States and Alaska. Edited by F. W. Hodge. Norwood, MA: Plympton Press.

Dalton, George. 1969. Theoretical Issues in Economic Anthropology. Current Anthropology 10: 63-102.

Davis, E. M. 1961. Proceedings of the Fifth Conference on Caddoan Archaeology. Bulletin of the Texas Archeological Society 31: 77-150.

Dodge, T. A. 1891. Some American Riders. Harper's New Monthly Magazine. May: 862.

Dorsey, G. A. 1905a. Caddo Customs of Childhood. Journal of American FolkLore 18: 226-28.

Dorsey, G. A. 1905b. Traditions of the Caddo. Publication 41. Washington, D.C.: Carnegie Institution of Washington.

Dunaway, W. A. 1994. The Southern Fur Trade and the Incorporation of Southern Appalachia into the World Economy, 1690-1763. Fernand Braudel Center for the Study of Economics, Historical Systems, and Civilizations Review 17(2): 215-42.

Dunaway, W. A. 1996. The First American Frontier: Transition to Capitalism in Southern Appalachia into the World-Economy, 1690-1763. Fernand Bruadel Center for the Study of Economics, Historical Systems, and Civilization Review 17(2): 215-42.

Dunn, William E. 1911. Apache Relations in Texas, 1718-1750. Texas State Historical Association Quarterly 14 (3): 198-274.

Dunn, W. E. 1916. Spanish and French Rivalry in the Gulf Region of the United States, 1578-1702; The Beginning of Texas and Pensacola. Univ. of Texas Bulletin, No. 1705. Austin: Univ. of TX.

Durkheim, E. 1915. The Elementary Forms of the Religious Life. Translator, W. J. Swain. London: Allen and Unwin.

Eggan, Fred. 1937. Social Anthropology of North American Tribes. Chicago: University of Chicago Press.

Eggan, Fred. 1952. The Ethnological Cultures and Their Archeological Background. In Archeology of the Eastern United States. Edited by T. Griffen. Chicago: University of Chicago Press. 
Eggan, Fred. 1966. The American Indian: Perspectivefor the Study of Social Change. Chicago: Aldine.

Ekholm, Kajsa, and Jonathan Friedman. 1982. Capital Imperialism and Exploitation in Ancient World-Systems. Review IV(1): 87-109.

Elam, Earl H. 1971. The History of the Wichita Indian Confederacy to 1868. Ph.D. dissertation. Texas Tech University.

Espinosa, Father Isidro Felíx. 1746. Chrónica Apostólica y Seráphica de Todos los Colgio de Propaganda Fide de Esta Nueva-Espana de Missioneros Franciscanos Observantas: Erigidos con Authoridad Pontifica y Regia para la Reformaciones de los Fieles y Conversion de los Gentiles. Mexico City: Hogal.

Ewers, John. 1955. The Horse in Blackfoot Indian Culture: With Comparative Material from Other Tribes. Washington, D.C.: Smithsonian Institution Press.

Ewers, John. 1973. The Influence of Epidemics on the Indian Populations and Cultures of Texas. Plains Anthropologist 18: 104-15.

Ewers, John. 1974. Symbols of Chiefly Authority in Spanish Louisiana. In The Spanish in the Mississippi Valley, 1762-1804. Edited by John F. McDermott. Urbana: University of Illinois Press.

Faiman-Silva, Sandra. 1997. Choctaws at the Crossroads: The Political Economy of Class and Culture in the Oklahoma Timber Region. Lincoln: University of Nebraska Press.

Farriss, Nancy. 1984. Maya Society Under Colonial Rule: The Collective Enterprise of Survival. Princeton, New Jersey: Princeton University Press.

Faulk, Odie B. 1964. The Last Years of Spanish Texas, 1778-1821. The Hague: Mouton and Company.

Ferguson, B., and N. Whitehead, editors. 1992. War in the Tribal Zone: Expanding States and Indigenous Warfare. Santa Fe, NM: School of American Research Press.

Fike, T. J., and G. F. Mulligan. 1990. Spatial Flows and Competing Central Places: Toward a General Theory of Hierarchical Interaction. Environment and Planning 22: 527-49.

Flores, Dan, editor. 1985. Journal of an Indian Trader: Anthony Glass and the Texas Trading Frontier, 1790-1810. College Station: Texas A\&M Press.

Foik, Paul. 1933. Captain Don Domingo Ramon's Diary of his Expedition in Texas, 1716. Texas Catholic Historical Society Preliminary Studies 2(1).

Folmer, Henry. 1953. Franco-Spanish Rivalry in North America, 1564-1763. Glendale, CA: Arthur H. Clark Company.

Forbes, Jack D. 1959. Apache, Navaho and Spaniard. Norman: University of Oklahoma Press.

Forrestal, Peter, editor. 1935. Peña's Diary of the Aguayo Expedition. Preliminary Studies of the Texas Catholic Historical Society 2(7): 1-68.

Foster, Morris. 1991. Being Comanche: A Social History of an American Indian Community. Tucson: University of Arizona Press.

Foster, Morris. 1992. Introduction to Rank and Warfare Among the Plains Indians. In Rank and Warfare Among the Plains Indians. By B. Mishkin. 1940, reprint. Lincoln: University of Nebraska Press.

Foster, Morris. 1994. Introduction. The Cheyenne in Plains Indian Trade Relations: 1795-1840. By Joseph Jablow. 1950, reprint. Lincoln: University of Nebraska Press. 
Fowler, Glenn. 1898. The Journal of Jacob Fowler. Edited by E. Coues. New York: Francis Harper.

Fowler, John. 1817. Fowler to McKenney April 1, 1817. Letterbook of the Natchitoches-Sulphur Fork Factory, 1808-1821. Records of the Bureau of Indian Affairs, Record Group 75. 29F52-53.

Fowler, Loretta. 1982. Arapabo Politics, 1851-1878: Symbols in Crisis of Authority. Lincoln: University of Nebraska Press.

Fowler, Loretta. 1987. Shared Symbols, Contested Meanings: Gros Ventre Culture and History, 1778-1984. Ithaca, NY: Cornell University Press.

Frank, Andre Gunder. 1966. The Development of Underdevelopment. Monthly Review 18: 17-31.

Frank, Andre Gunder. 1969. World Accumulation, 1492-1789. New York: Monthly Review Press.

French, N. 1968. Preliminary Analysis of Structure and Function in Grasslands Range. Science Department Science Series 10: 46-52. Fort Collins: Colorado State University.

Friedman, Jonathan. 1992. General Historical and Culturally Specific Properties of Global Systems. Review 15(3): 335-72.

Friedman, Jonathan. 1993. Order and Disorder in Global Systems: A Sketch. Social Research 60(2): 205-34.

Fritz, G. J. 1989. Evidence of Plant Use from Copple Mound at the Spiro Site. In Contribution to Spiro Archeology: Mound Excavations and Regional Perspectives. Edited by J. D. Rogers, D. Wyckoff, and D. Peterson. Studies in Oklahoma's Past no. 161. Norman: Oklahoma Archeological Survey.

Gálvez, Bernardo de. 1951. Instructions for Governing the Interior Provinces of New Spain, 1786. Translated by D. Worchester. Albuquerque: New Mexico University Press.

Gelo, Daniel. 1986. Comanche Belief and Ritual. Ph.D. dissertation. Rutgers University.

Gelo, Daniel. 1987. On a New Interpretation of Comanche Social Organization. Current Anthropology 28: 551-56.

Gelo, Daniel. 2000. Comanche Land and Ever Has Been: A Native Geography of the Nineteenth-century Comanchería. Southwestern Historical Quarterly 1111: 272-307.

Gilmore, Kathleen K. 1973. Caddoan Interaction in the Neches Valley, Texas. Ph.D. dissertation. Southern Methodist University.

Giraud, Marcel. 1974. A History of French Louisiana: The Reign of Louis XIV, 1698-1715. Translated by Joseph C. Lambert. Baton Rouge: Louisiana State University Press.

Gladwin, Thomas. 1948. Comanche Kin Behavior. American Antbropologist 50: 73-94.

Godelier, Maurice. 1972. Rationality and Irrationality in Economics. New York: Monthly Review Press.

Godelier, Maurice. 1977. Perspectives in Marxist Anthropology. New York: Cambridge University Press.

Goldfrank, Esther. 1945. Changing Configurations in the Social Organization of a Blackfoot Tribe During the Reserve Period. American Ethnological Society Monograph 8. 
Gregg, Josiah. 1933. Commerce of the Prairies: The Journal of a Santa Fe Trader. Dallas: Southwest Press.

Gregory, H. F. 1973. Eighteenth Century Caddoan Archeology: A Study in Models and Interpretation. Ph.D. dissertation. Southern Methodist University.

Gregory, H. F. 1986. Introduction. In The Southern Caddo: An Anthology. Edited by H. F. Gregory. New York: Garland Publishing.

Griffin, W. J. 1967. Eastern North America. Archaeology: A Summary. Science 156: $175-91$.

Griffith, William J. 1954. The Hasinai Indians of East Texas as Seen by the Europeans, 1687-1772. In Philological and Documentary Studies. New Orleans: Tulane University Middle American Research Institute.

Grinnell, George B. 1910. The Great Mysteries of the Cheyenne. American Anthropologist 16: 542-75.

Grinnell, George B. 1920. Who Were the Padoucas? American Anthropologist 22: 248-60.

Grinnell, George B. 1923. The Cheyenne Indians. 2 volumes. New Haven: Yale University Press.

Gunnerson, Dolores. 1973. The Jicarilla Apaches: A Study in Survival. DeKalb: Northern Illinois University Press.

Hackett, C. W., editor. 1931. Pichardo's Treatise on the Limits of Louisiana and Texas. Volume 1. Austin: University of Texas Press.

Hackett, C. W., editor. 1934. Pichardo's Treatise on the Limits of Louisiana and Texas. Volume 2. Austin: University of Texas Press.

Hackett, C. W., editor. 1941. Pichardo's Treatise on the Limits of Louisiana and Texas. Volume 3. Austin: University of Texas Press.

Haggard, Villasana. 1945. The House of Barr and Davenport. Soutbwestern Historical Quarterly 49: 66-88.

Haggett, P., A. D. Cliff, and A. Frey. 1977. Locational Analysis in Human Geography. New York: Wiley.

Haines, Helen. 1891. History of New Mexico. New York.

Hall, Thomas. 1987. Incorporation in the World-System: Toward a Critique. American Sociological Review 45(3): 390-402.

Hall, Thomas. 1988. Patterns of Native American Incorporation into State Societies. In Public Policy Impacts on American Indian Economic Development. Edited by C. M. Snipp, pp. 23-38. Development Series No. 4. Native American Studies, Albuquerque, New Mexico.

Hall, Thomas. 1989. Social Change in the Soutbwest, 1350-1880. Lawrence: University Press of Kansas.

Hall, Thomas. 1993. Review of War in the Tribal Zone. American Indian Culture and Research Journal 17: 239-245.

Hall, Thomas. 1994. The Case for a World-Systems Approach to Civilizations: A View from the "Transformationist" Camp. Comparative Civilizations Review 30: 30-49.

Hall, Thomas. 1998. The Rio de la Plata and the Greater Southwest: A View from World System Theory. In Contested Ground: Comparative Frontiers on the Northern and Southern Edges of the Spanish Empire. Edited by Donna J. Guy and Thomas E. Sheridan. Tucson: University of Arizona Press. 
Hall, Thomas. 1999. World-Systems and Evolution: An Appraisal. In WorldSystems Theory in Practice: Leadership, Production, and Exchange. Edited by P. Kardulias, pp. 1-24. Rowman \& Littlefield Publishers, Inc.

Hall, Thomas. 2000. World Systems Analysis: A Small Sample from a Large Universe. In $A$ World Systems Readers: New Perspectives on Gender, Urbanism. Edited by Thomas Hall. Lanham, MD: Rowman and Littlefield.

Hämäläinen, Pekka. 1998. The Western Comanche Trade Center: Rethinking the Plains Indian Trade System. Western History Quarterly 29: 485-513.

Hämäläinen, Pekka. 2001. The Comanche Empire: A Study of Indigenous Power, 1700-1875. Helsinki: Helsinki University Press.

Hass, Jonathan. 1990. Warfare and the Evolution of Tribal Polities in the Prehistoric Southwest. In The Antbropology of War. Edited by Jonathan Hass. New York: Cambridge University Press.

Hatcher, Mattie A., translator. 1919. Report on the Barbarous Indians of the Province of Texas. Southwestern Historical Quarterly 23(1): 47-68.

Hatcher, Mattie A. 1927. The Opening of Texas to Foreign Settlement: 18011821. University of Texas Bulletin No. 2714. Austin: University of Texas.

Hickerson, Daniel A. 1996. Trade, Mediation, and Political Status in the Hasinai Confederacy. Research in Economic Anthropology 17(1): 149-68.

Hickerson, Daniel A. 1997. Historical Processes, Epidemic Disease, and the Formation of the Hasinai Confederacy. Ethnobistory 44: 31-51.

Hindess, B., and P.Q. Hirst. 1975. Pre-Capitalist Modes of Production. Cambridge: Cambridge University Press.

Hobsbawm, Eric, and Terrence Ranger, editors. 1983. The Invention of Tradition. Cambridge: Cambridge University Press.

Hodges, Richard. 1982. Dark Age Economics. London.

Hodges, Richard. 1988. Primitive and Peasant Markets. New York: Basil Blackwell, Inc.

Hoebel, E. 1940. The Political Organization and Law-ways of the Comanche Indians. American Antbropological Society Memoir 54.

Hoebel, E. 1954. The Law of Primitive Man: A Study in Comparative Legal Dynamics. Cambridge: Harvard University Press.

Hoya, Eugenio del, and Malcolm D. McLean, editors. 1967. Diario y Derrotero: 1777-1781, Por Fray Juan Agustin Morfi. Monterrey, Mexico: Instituto Technológico de Estudios Superiores.

Ingold, Tim. 1980. Hunters, Pastoralists and Ranchers. Cambridge: Cambridge University Press.

Innis, Harold. 1973. The Fur Trade in Canada: An Introduction to Canadian Economic History. Toronto: University of Toronto Press.

Irwin, Michael, and John Kasarda. 1994. Trade Transportation and Spatial Distribution. In The Handbook of Economic Sociology. Edited by N. Smelser and R. Swedberg. Princeton: Princeton University Press.

Jablow, Joseph. 1950. The Cheyenne in Plains Indian Trade Relations, 17951840. American Ethnological Society Monograph 12.

Jackson, Jack. 1986. Los Mesteños: Spanish Ranching in Texas, 1721-1821. College Station: Texas A\&M University Press.

James, Thomas. 1953. Three Years Among the Indians and Mexicans. Reprint. 
The Lakeside Classics Series. Edited by Milo M. Quaife. Chicago: The Lakeside Press.

Jameson, F. 1981. The Political Unconsious. Ithaca: Cornell University Press.

Jennings, Francis. 1976. The Invasion of America: Colonialism and the Cant of Conquest. New York: W. W. Norton.

John, Elizabeth. 1975. Storms Brewed in Other Men's Worlds: The Confrontation of Indians, Spanish, and French in the Soutbwest, 1540-1795. College Station: Texas A\&M University Press.

John, Elizabeth. 1984. Nurturing the Peace: Spanish and Comanche Cooperation in the Early Nineteenth Century. New Mexico Historical Review 59(4): 345-69.

Kavanagh, Thomas. 1996. Comanche Political History: An Ethnohistorical Perspective, 1706-1875. Lincoln: University of Nebraska Press.

Kelley, K. B. 1976. Dendritic Central-Place Systems and the Regional Organization of Navajo Trading Posts. In Regional Analysis. 2 volumes. Edited by Carol Smith. New York: Academic Press.

Kendall, George W. 1929. Narrative of the Texas Santa Fe Expedition. The Lakeside Classics Series. Chicago: The Lakeside Press.

Kessell, John. 1979. Kiva, Cross, and Crown: The Pecos Indians and New Mexico, 1540-1840. Washington, D.C.: U.S. Government Printing Office.

Kinnaird, Lawrence, editor. 1946. Spain in the Mississippi Valley, 1765-1794: Translations of Materials from the Spanish Archives in the Bancroft Library. Volume 2. Washington, D.C.: U.S. Government Printing Office.

Kinnaird, Lawrence, editor. 1949. Spain in the Mississippi Valley, 1765-1794: Translations of Materials from the Spanish Archives in the Bancroft Library. Volume 3. Washington, D.C.: U.S. Government Printing Office.

Kipp, Rita, and Edward Schortman. 1989. The Political Impact of Trade in Chiefdoms. American Antbropologist 91: 370-85.

Klein, Alan. 1993. Political Economy of the Buffalo Hide Trade: Race and Class on the Plains. In The Political Economy of North American Indians. Edited by John Moore. Norman: University of Oklahoma Press.

Kress, M. K., and M. A. Hatcher. 1931. Diary of a Visit of Inspection of the Texas Missions Made by Fray Gaspar José de Solis in the Year 1767-1768. Southwestern Historical Quarterly 35: 28-76.

Krieger, Alex. 1946. Culture Complexes and Chronology in Northern Texas. Publication 4640. Austin: University of Texas.

Kroeber, Alfred. 1907. The Ceremonial Organization of the Plains Indians of North America. Congrés International des Americanistes XV, session 2: 53-70.

Kroeber, Alfred. 1939. Cultural and Natural Areas of Native North America. University of California Publications in American Archaeology and Ethnology 38.

La Vere, David. 1993. Reciprocity and Kinship in Caddoan-EuroAmerican Relations, 1685-1835: EuroAmerican, Native American Trade. Ph.D. dissertation. Texas A\&M.

La Vere, David. 1998. The Caddo Chiefdoms: Economics and Politics, 700-1835. Lincoln: University of Nebraska Press. 
La Vere, David. 2000. Contrary Neighbors: Southern Plains and Removed Indians in Indian Territory. Norman: University of Oklahoma Press.

Leach, E. R. 1954. Political Systems in Highland Burma. Cambridge: Harvard University Press.

LeClair, E., and H. Schneider, editors. 1968. Economic Anthropology. New York: Holt, Rinehart, and Winston.

Lee, Aubra. 1990. Fusils, Paint, and Pelts: An Examination of Natchitoches-Based Indian Trade in the Spanish Period, 1766-1791. M.A. thesis. Northwestern State University.

Leeper, Mathey. 1858. Letter to R. Neighbor, February 12, 1858. National Archives and Record Service 861F295.

Lesser, Andrew. 1933. The Pawnee Ghost Dance Hand Game. Columbia University Contributions to Anthropology. 16: 1-337.

Lesser, Andrew, and Gene Weltfish. 1932. Composition of the Caddoan Linguistic Stock. Smithsonian Miscellaneous Collections. 87. Washington, D.C.: Smithsonian Publication.

Leutnegger, Benedict, editor. 1977. Management of the Missions in Texas. Friar Jose Rafael Oliva's Views Concerning the Problem of the Temporalities in 1788. Old Spanish Missions Historical Research Library at San José. San Antonio, Texas.

Leutnegger, Benedict. 1979. The Texas Missions of the College of Zacatecas, 1749-1759. Old Spanish Missions Historical Research Library at San José. Documentary series, no. 5. San Antonio, Texas.

Lewis, K. 1976. Camden: Frontier Town. Occasional Papers of the Institute of Archeology and Anthropology. No. 2: 47-56. Department of Anthropology. University of South Carolina.

Lewis, Oscar. 1942. The Effects of White Contact on Blackfoot Culture. American Ethnological Society. Monograph 6.

Loomis, Noel, and Abraham Nasatir. 1967. Pedro Vial and the Roads to Santa $\mathrm{Fe}$. Norman: University of Oklahoma Press.

Lowie, Robert. 1909. The Northern Shoshone. Anthropological Papers of the American Museum of Natural History. 2: 165-306.

Lowie, Robert. 1916. Dance Associations of the Eastern Dakota. Anthropological Papers of the American Museum of Natural History. 9: 101-42.

Lowie, Robert. 1920. The Tobacco Society of the Crow Indians. Antbropological Papers of the American Museum of Natural History 21: 103-200.

Lowie, Robert. 1954. Indians of the Plains. New York: McGraw-Hill.

Lowie, Robert. 1956. Studies in Plains Indian Folklore. University of California Papers of the American Museum of Natural History. 21: 103-200.

Lowie, Robert. 1982. Indians of the Plains. Reprint. Lincoln: University of Nebraska Press.

Lummis, Charles. 1898. Some Unpublished History: A New Mexico Episode in 1748. Land of Sunshine 8: 75-78, 126-130.

Magnaghi, Russell M. 1978. Sulphur Fork Factory, 1817-1822. Arkansas Historical Quarterly 37: 167-75.

Magnaghi, Russell M. 1981. Changing Material Culture and the Hasinai of East Texas. Southern Studies 20: 412-26.

Marcy, Captain Randolph. 1937. Adventure on the Red River. Edited by Grant Foreman. Norman: University of Oklahoma Press. 
Martin, Francis. 1822. The History of Louisiana. New Orleans: Privately published.

Marx, Karl, and Friedrich Engels. 1959. Basic Writings on Politics and Philosophy. Edited by Lewis S. Feuer. Garden City: New York.

Mason, O. T. 1896. Influence of Environment Upon Human Industries or Arts. Smithsonian Institution Annual Report for 1895. Washington D.C.: Smithsonian Press.

McNeill, John R. 1985. Atlantic Empires of France and Spain: Louisbourg and Havana, 1700-1763. Chapel Hill: University of North Carolina Press.

Meyers, Sandra. 1967. The Development of the Ranch as a Frontier Institution in the Spanish Province of Texas, 1691-1800. Ph.D. dissertation. Texas Christian University.

Milloy, John S. 1988. The Plains Cree: Trade, Diplomacy and War, 1790-1870. Winnipeg: University of Manitoba Press.

Mills, Elizabeth. 1981. Natchitoches Colonials: Census, Military Rolls and Tax Lists, 1722-1803. Chicago: Adams Press.

Mintz, Sidney. 1972. Caribbean Transformations. Chicago: Aldine.

Mishkin, Bernard. 1940. Rank and Warfare Among the Plains Indians. Monographs of the American Ethnological Society 3. New York: J. J. Augustin.

Mooney, James. 1896. The Ghost-Dance Religion, and the Sioux Outbreak of 1890. Fourteenth Annual Report of the Bureau of Ethnology, 1892-1893. Part 2. Bureau of Ethnology. Washington, D.C.: Smithsonian Institution.

Mooney, James. 1898. Calendar History of the Kiowa Indians. Seventeenth Annual Report of the Bureau of American Ethnology for the Years 1895-96. Part 2. Washington, D.C.: U.S. Government Publishers.

Moore, John. 1988. The Cheyenne Nation: A Social and Demographic History. Lincoln: University of Nebraska Press.

Moore, John, editor. 1993. The Political Economy of Native American Indians. Norman: University of Oklahoma Press.

Moorhead, Max L. 1961. The Presidio Supply Problem of New Mexico in the Eighteenth Century. New Mexico Historical Review 36: 210-29.

Moorhead, Max L. 1968. The Apache Frontier:Jacobo Ugarte and Spanish-Indian Relations in Northern New Spain, 1769-1791. Norman: University of Oklahoma Press.

Moran, Emilio F. 1982. Ecosystem Ecology in Biology and Anthropology: A Critical Assessment. In The Ecosystem Approach in Anthropology: Concept to Practice. Edited by Emilio Moran. Ann Arbor: University of Michigan Press.

Morfi, Fray Juan Agustín. 1935. History of Texas, 1673-1779. Translated by Carlos E. Castañeda. 2 volumes. Albuquerque: Quivira Society Publications.

Morgan, Lewis. 1877. Ancient Society. Chicago: Kerr.

Morris, Wayne. 1970. The Wichita Exchange: Trade on Oklahoma's Fur Frontier, 1719-1812. Great Plains Journal 9(2): 79-84.

Murphy, Retta. 1937. The Journey of Pedro Rivera, 1724-1728. Southwestern Historical Quarterly 41: 125-41.

Newell, H. P., and A. Krieger. 1949. The George C. Davis Site, Cherokee County, Texas. Society for American Archaeology, Memoirs No. 5. 
Newkumet, V., and H. Meredith. 1988. Hasinai: A Traditional History of the Caddo Confederacy. College Station: Texas A\&M Press.

Niles, H., editor. 1818. Weekly Register Documents Essay and Facts: Together With Notices of the Arts and Manufactures and A Record of the Events of the Times. September 1817-March 1818. Volume 13. Baltimore: Franklin Press.

Oliver, Symmes C. 1962. Ecology and Cultural Continuity as Contributing Factors in the Social Organization of Plains Indians. University of California Publications in American Archaeology and Ethnology 43: 1-90.

Opler, Morris. 1942. The Origins of the Comanche and Ute. American Antbropologist 45: 155-58.

Opler, Morris. 1983. The Apachean Culture Pattern and Its Origins. In Handbook of North American Indians. Edited by W. C. Sturtevant. Volume 10. Southwest. Washington, D.C.: U.S. Government Printing Office.

Parsons, Elsie. 1941. Notes on the Caddo. Memoirs of the American Anthropological Association. 57: 1-76.

Paynter, R. 1982. Models of Spatial Inequality: Settlement Patterns in Historical Archaeology. New York: Academic Press.

Peden, D. G. 1972. The Trophic Relations of Bison bison to the Shortgrass Plains. Ph.D. Colorado State University. Fort Collins, Colorado.

Pellicani, Luciano. 1994. The Genesis of Capitalism and the Origins of Modernity. Translated by James G. Colbert. New York: Telos Press.

Pénicault, André. 1953. Fleur de Lys and Calumet: Being the Pénicault Narrative of French Adventure in Louisiana. Edited and translated by Richebourg G. McWilliams. Baton Rouge: Louisiana State University Press.

Peregrine, Peter. 1999. Legitimization Crises in Prehistoric Worlds. In World Systems Theory in Practice: Leadership, Production, and Exchange Edited by P. Nick Kardulias, pp. 37-52. Boulder: Rowman \& Littlefield Publishers.

Perttula, Timothy K. 1992. The Caddo Nation: Archaeological and Ethnohistoric Perspectives. Austin: University of Texas Press.

Polanyi, K. 1957. The Economy as Instituted Process. In Trade and Market in the Early Empires. Edited by K. Polanyi, H. Pearson, and C. Arensberg. Chicago: Henry Regnery.

Powell, J. W. 1898. Report of the Director. 17th Annual Report. Bureau of American Ethnology. Washington, D.C.: Smithsonian Institution.

Prewitt, T. J. 1974. Regional Interaction Networks and the Caddoan Area. Papers in Anthropology 15(2): 73-101.

Priestly, Hubert I. 1939. France Overseas Through the Old Regime: A Study in European Expansion. New York: D. Appleton-Century.

Ramenofsky, A. F. 1985. The Introduction of European Disease and the Aboriginal Population Collapse. Mississippi Archaeologist 20: 2-18.

Rappaport, R.A. 1968. Pigs for the Ancestors. New Haven: Yale University Press.

Redfield, Robert. 1940. The Folk Culture of Yucatan. Chicago: University of Chicago Press.

Reher, Charles A. 1974. Population Study of the Casper Site Bison. In The Casper Site: A Hell Gap Bison Kill on the High Plains. Edited by George C. Frison. New York: Academic Press.

Richardson, Jane. 1940. Law and Status Among the Kiowa Indians. American Ethnological Society Monograph 1. 
Richardson, Rupert. 1929. The Culture of the Comanche Indians. Texas Archeological and Paleontological Society Bulletin 1: 43-65.

Richardson, Rupert. 1933. The Comanche Barrier to South Plains Settlement. Glendale, CA: Arthur H. Clark.

Rister, Carl. 1989. Comanche Bondage. Reprint. Glendale: A. H. Clark Company.

Robles, Alessio V. 1938. Coabuila y Texas en la Época Colonia. Mexico City: Editorial Cultura.

Robles, Alessio V., editor. 1946. Diario y Derrotero de lo Caminado, Visto y Observado en al Visita que Hizo a los Presidios, a Pedro de Rivera. Archivo Historico Militar Mexicano. Number 2. Mexico City: Autográfico.

Roe, Frank. 1955. The Indians and the Horse. Norman: University of Oklahoma Press.

Roseberry, William. 1991. Anthropologies and Histories: Essays in Culture, History, and Political Economy. New Brunswick: Rutgers University Press.

Rowlands, Michael, M. Larsen, and K. Kristiansen, editors. 1987. Centre and Periphery in the Ancient World. Cambridge: Cambridge University Press.

Ruxton, George F. 1847. Adventures in Mexico and the Rocky Mountains. London, England.

Sabo, George. 1987. Reordering Their World: A Caddoan Ethnohistory. In Visions and Revisions: Ethnohistorical Perspectives on Southern Cultures. Edited by G. Sabo and W. M. Schneider. Athens: University of Georgia Press.

Sahlins, Marshall. 1972. Stone Age Economics. Chicago: Aldine Publishing Company.

Sahlins, Marshall. 1985. Islands of History. Chicago: University of Chicago Press.

Sahlins, Marshall. 1993. Goodbye to Tristes Tropes: Ethnography in the Context of Modern World History. Journal of Modern History 65: 1-25.

Said, Edward. 1989. Yeats and Decolonization. In Remaking History. Edited by Barbara Kruger. Seattle: Bay Press.

Schneider, Jane. 1977. Was There a Pre-Capitalist World System? Peasant Studies 4(1): 20-29.

Schneider, Jane. 1978. Peacocks and Penguins: The Political Economy of European Cloth and Colors. Ethnohistory 3: 413-47.

Schneider, Jane, and Rayna Rapp, editors. 1978. Articulating Hidden Histories: Exploring the Influence of Eric $R$. Wolf. Berkeley: University of California Press.

Schuetz, M. 1980. The Indians of the San Antonio Missions, 1781-1821. Ph.D. dissertation. University of Texas at Austin.

Secoy, Frank R. 1953. Changing Military Patterns on the Great Plains. American Ethnological Society Monograph 21. Washington, D.C.: Smithsonian Institution.

Service, Elman. 1975. Origins of the State and Civilization: The Process of Cultural Evolution. New York: W. W. Norton.

Shimkin, Demitri. 1940. Origins and Migrations. Proceedings of the Sixth Pacific Science Congress 5: 17-25.

Sibley, John H. 1922. A Report from Natchitoches in 1807. Edited by A. H. Abel. New York: Museum of the American Indian Foundation. 
Simmons, Marc. 1967. Border Comanches. Santa Fe: Stagecoach Press.

Simmons, Marc. 1968. Spanish Government in New Mexico. Albuquerque: University of New Mexico Press.

Skinner, G. W. 1964. Marketing and Social Structure in Rural China, Part I. Journal of Asian Studies 24: 3-43.

Smith, Carol, editor. 1976. Regional Analysis. 2 volumes. New York: Academic Press.

Smith, Carol. 1985. Local Histories in Global Context: Social and Economic Transitions in Western Guatemala. In Micro and Macro Levels of Analysis in Anthropology. Edited by B. R. Dewalt and P. J. Pelto, pp. 83-120. Boulder: Westview Press.

Smith, Clinton, and Jeff Smith. 1927. The Boy Captives. Edited by J. Marvin Hunter. Bandera, Texas: Frontier Times.

Smith, Todd. 1995. The Caddo Indians: Tribes at the Convergence of Empires, 1542-1854. College Station: Texas A\&M Press.

Solís, Fray Gaspár José de. 1931. Diary of a Visit of Inspection of the Texas Missions made by Fray Gaspár José de Solís in the Year 1767-1768. Translated by Margaret K. Kress. Southwestern Historical Quarterly 35: 28-76.

Spencer, Hubert. 1896. Principles of Sociology. Appleton.

Spicer, Edward. 1962. Cycles of Conquest: The Impact of Spain, Mexico and the United States on the Indians of the Southwest, 1533-1960. Tucson: University of Arizona Press.

Spielman, Katherine. 1983. Late Prehistoric Exchange between the Southwest and the Southern Plains. Plains Antbropologist 28: 257-72.

Spier, Leslie. 1921. The Sun Dance of the Plains Indians: Its Development and Diffusion. Anthropological Papers of the American Museum of Natural History 16: 451-527.

Spier, Leslie. 1924. Wichita and Caddo Relationship Terms. American Anthropologist 26(2): 57-73.

Steward, Julian. 1955. Theory of Culture Change: The Methodology of Multilinear Evolution. Urbana: University of Illinois Press.

Stoddard, A. 1812. Sketches, Historical and Descriptive, of Louisiana. Philadelphia: William Carey.

Story, Dee, J. A. Guy, B. A. Burnett, M. D. Freeman, J. C. Rose, D. G. Steele, B. W. Olive, and K. J. Reinhard. 1990. The Archeology and Bioarcheology of the Gulf Coastal Plain. Arkansas Archeological Research Series no. 38. Fayetteville: Arkansas Archeological Survey.

Swanton, John R. 1931. The Caddo Social Organization and Its Possible Historic Significance. Journal of the Washington Academy of Sciences 21: 203-6.

Swanton, John. 1942. Source Material on the History and Ethnology of the Caddo Indians. Bureau of American Ethnology Bulletin 132. Washington, D.C.: Smithsonian Institution. Government Printing Office.

Swanton, John. 1952. Indian Tribes of North America. Bureau of American Ethnology. Bulletin 145. Washington D.C. Smithsonian Institution. Government Printing Office.

Tanner, Helen. 1974. The Territory of the Caddo Tribe of Oklahoma. In The Southern Caddo: An Anthology. Edited by H. F. Gregory, pp. 66-104. New York: Garland Publishing Company. 
Taylor, Virginia, editor. 1957. The Letters of Antonio Martinéz, Last Spanish Governor of Texas: 1817-1822. Austin: Texas State Library.

Tefft, S. 1964. From Band to Tribe on the Plains. Plains Anthropologist 10: $166-70$.

Thomas, Alfred B. 1932. Forgotten Frontiers: A Study of the Spanish Indian Policy of Don Juan Bautista de Anza, Governor of Nerw Mexico, 1777-1787. Norman: University of Oklahoma Press.

Thomas, Alfred B., editor and translator. 1935. After Coronado, Spanish Exploration Northeast of New Mexico, 1696-1727, Documents from the Archives of Spain, Mexico, and New Mexico. Norman: University of Oklahoma Press.

Thomas, Alfred B. 1940. The Plains Indians and New Mexico. Albuquerque: University of New Mexico Press.

Thomas, Alfred B., editor. 1941. Teodoro de Croix and the Northern Frontier of New Spain, 1776-1783. Norman: University of Oklahoma Press.

Thomas, Nicholas. 1994. Colonialism's Culture: Antbropology, Travel and Government. Princeton: Princeton University Press.

Thornton, Russell. 1987. American Indian Holocaust and Survival: A Population History Since 1492. Norman: University of Oklahoma Press.

Thurman, Melburn. 1980. Comanche. Dictionary ofIndian Tribes of the Americas 2:48-67. Newport Beach: American Indian Publishers.

Thurman, Melburn. 1987. Reply to Gelo. Current Anthropology 28: 552-55.

Thwaites, Reuben G. 1904. A Brief History of Rocky Mountain Exploration, with Especial Reference to the Expedition of Lewis and Clark. New York: Appleton and Company.

Tjarks, Alicia. 1974. Comparative Demographic Analysis of Texas, 1777-1793. Southwestern Historical Quarterly 77: 291-338.

Todorov, Tzvetan. 1984. The Conquest of America: The Question of the Other. New York: Harper and Row.

Trouillot, Michel-Rolph. 1984. The Economic Integration of a Caribbean Peasantry: The Case of Dominica. Ph.D. dissertation John Hopkins University.

Trubowitz, N. 1987. New Goods on Old Routes: Exchange in the Contact Era in Eastern North America. Paper Presented at the Fifty-Second Annual Meeting of the Society for American Archaeology. May 6-10. Toronto, Canada.

Twitchell, Ralph E. 1914. The Spanish Archives of New Mexico. 2 volumes. Torch Press: Cedar Rapids: Sowa.

Tylor, Edward B. 1889. Primitive Cultures: Researches into the Development of Mythology, Philosophy, Religion, Languages, Art and Custom. 2 volumes. New York.

Usner, Daniel H. 1992. Indians, Settlers, and Slaves in a Frontier Exchange Economy: The Lower Mississippi Valley Before 1783. Chapel Hill: University of North Carolina Press.

Verdery, Katherine. 1976. Ethnicity and Local Systems: The Religious Organization of Welshness. In Regional Analysis. Edited by Carol Smith. New York: Academic Press.

Von Thünen, J. H. 1966. Von Thünen's Isolated State. Translated by C. M. Watenburg. London: Pergamon Press. 
Wallace, Ernest. 1954. David G. Burnet's Letters Describing the Comanche Indians. West Texas Historical Association Year Book 30: 115-40.

Wallace, Ernest, and E. Adamson Hoebel. 1952. The Comanches: Lord of the Southern Plains. Norman: University of Oklahoma Press.

Wallace, Ernest, and David Vigness, editors. 1960. Documents in Texas History, 1528-1846. Lubock: The Library of Texas Technological College.

Wallerstein, Immanuel. 1974. The Modern World-System: Capitalist Agriculture and the Origins of the European World-Economy in the Sixteenth Century. New York: Academic Press.

Wallerstein, Immanuel. 1979. Kondratieff Up or Kondratieff Down? Fernand Braudel Center for the Study of Economics, Historical Systems, and Civilizations Review 2: 663-73.

Weber, M. 1976. The Agrarian Sociology of Ancient Civilization. New York: Academic Press.

Weddle, Robert S. 1964. The San Saba Mission: Spanish Pivot in Texas. Austin: University of Texas Press.

Wheat, Carl I. 1957. Mapping of the Transmississippi West. Volume 1. San Francisco: Institute of Historical Cartography.

White, Leslie. 1959. The Evolution of Culture. New York: McGraw-Hill.

White, Richard. 1983. The Roots of Dependency: Subsistence, Environment, and Social Change Among the Choctaws, Pawnees, and Navajos. Lincoln: University of Nebraska Press.

Wilcox, Elam. 1911. The Grazing Industry. Hawaii Agricultural Experiment Station. Honolulu: Paradise of the Pacific Print.

Wissler, Clark. 1907. Some Dakota Myths. Journal of American Folklore 20: 121-31: 195-206.

Wissler, Clark. 1914. The Influence of the Horse in the Development of Plains Culture. American Anthropologist 16: 1-25.

Wissler, Clark. 1922. The American Indians of the Plains. New York: American Museum of Natural History.

Wissler, Clark. 1926. Relation of Man to Nature in Aboriginal North America. New York: D. Appleton-Century Co.

Wissler, Clark. 1938. The American Indian: An Introduction to the Anthropology of the New World. New York: Oxford University Press.

Wolf, Eric. 1955. Types of Latin American Peasantry: A Preliminary Discussion. American Anthropologist 57: 452-71.

Wolf, Eric. 1957. Closed Corporate Communities in Mesoamerica and Central Java. Soutbwestern Journal of Anthropology 13: 1-18.

Wolf, Eric. 1959. Sons of the Shaking Earth. Chicago: University of Chicago Press.

Wolf, Eric. 1966. Peasants. Englewood Cliffs, New Jersey: Prentice-Hall.

Wolf, Eric. 1969. Peasant Wars of the Twentieth Century. New York: Harper and Row.

Wolf, Eric. 1982. Europe and the People Without History. Berkeley: University of California Press.

Wolf, Eric, and Sidney Mintz. 1957. Haciendas and Plantations in Middle America and the Antilles. Social and Economic Studies 6: 386-412. 
Wood, W. Raymond. 1972. Contrastive Features of Native North American Trade Systems. In For the Chief: Essays in Honor of Luther S. Cressman. Edited by F. Voget and R. Stephenson. University of Oregon Anthropological Papers.

Wood, W. Raymond. 1973. Northern Plains Village Cultures: Internal Stability and External Relationships. Journal of Anthopological Research 30: 1-16.

Wood, W. Raymond. 1980. Plains Trade in Prehistoric and Protohistoric Tribal Relations. In Anthropology on the Great Plains. Edited by W. R. Wood and Margot Liberty. Lincoln: University of Nebraska Press.

Woodall, J. Ned. 1969. Cultural Ecology of the Caddo. Ph.D. dissetation. Southern Methodist University.

Worcester, Donald E., editor and translator. 1951. Instructions for Governing of the Interior Provinces of New Spain. Berkeley: The Quivera Society.

Wright, Muriel H. 1977. The Shoshonean Migration Problem. Plains Antbropologist 23: 113-37.

Wyckoff, Donald G. 1970. Archaeological and Historical Assessment of the Red River Basin in Oklahoma. In Archaeological and Historical Assessment of the Red River Basin. Edited by H. A. Davis. Arkansas Archeological Research Series no. 1. Fayetteville: Arkansas Archeological Survey.

Wyckoff, Donald G., and Timothy Baugh. 1980. Early Historic Hasinai Elites: A Model for the Material Culture of Governing Elites. Midcontinental Journal of Archaeology 5: 225-88.

Zingg, Robert. 1939. A Reconstruction of Uto-Aztekan History: Contributions to Ethnography. New York: G. E. Stechert. 



\section{INDEX}

Albuquerque, 78

Allotment, 13

Ambilineal kinship, 109

Angelina River, 37, 51, 83

Apaches, 53, 54, 56, 59, 61, 66, 71, 73-77, 80, 84, 85, 89, 94, 97.

See also Lipan Apaches

Arapahos, 91

Arkansas River, 9, 34, 76, 78, 79, 82, 89. See also Rio Napestle

baptism, 40

barter exchange, 23

Bidais, 84, 86, 87

big game hunting, 14

big man, 25

Bigotes, 85,86 . See also Sauto

bison hunting, 10, 30, 32, 84, 95, 99, $100,105,110$

Blackfeet, 105

bounded network systems, 25

Brazos River, 25, 80, 82

bridewealth, 22

Caddo language, 37

Calumet, 94

Camargo, 53
Canadian River, 76, 82, 89

Canary Islands, 52

capital accumulation, 22, 23

capitalism, 18, 20-22, 26

Caribbean, 20

carrying capacity, 17

Cherokees, 38, 88

Cheyennes, 4, 70, 91, 105

Chihuahua, 78, 98

Choctaws, 39, 88, 109

client, 55, 63

Colorado River, 80, 82, 83

Comanche government

advisory council, 17

bands, 31-34, 71, 98, 103, 104, 113-115

chiefs or leaders, $31,63,101-105$, $114,115,117$

cuchanecs, 33, 77, 79, 80, 82, 103, 114,115

divisions, $31,33-35,98,115$

headman, 31

jupes, 33, 79, 103

kotsotckas, 33

yamparicas, 33, 79, 80-83, 87

competence, 27

Concho River, 82 
Confederacies, 37, 116

Creeks, 88

culture area concept, 19, 29

Delawares, 88

diffusion, 19, 31

Dolores, 53

Durango, 98

Eastern Maize Area, 15

economic liberalism, 48

Ecueracapa, 103, 114, 115

Edict of Nantes, 46

El Cuartelejo, 74

El Paso, 78

epidemics and diseases, $1,5,7,36$, $37,40,51,60,61,73,83,86$, $87,89,90,107,108$

measles, 1

smallpox, 1, 108

typhoid, 1

extended kin, 31

extended network systems, 25

Flanders, 45

Florence, 45

French revolution, 48

functionalism, 11

Galveston Bay, 53

Ghost Dance, 38

gift-giving, 57, 66

gifts, 56, 62, 63, 65, 87, 104, 114,116

fund for allies, 57

fund of gratification, 57

Glass, Anthony, 102, 103, 106

Great Basin, 30

Gregg, Joshua, 101

Gros Ventres, 91

Guadalupe River, 84

Gulf Coast, 85

Gulf of Mexico, 9, 46

\section{Hasinai government caddi, 38, 39, 41, 61, 108 109,117 \\ connas or canahas, 38,40}

village councils, 41

village leader or chief, 38,39 , $60,61,65,66,107-109$, 117,118

xinesi, 38-40, 60, 61, 108, 109,117

Havana, 81

Holland, 45

horses

affect on warfare, 14, 58, 69, 70, $74,77,78,80$

breeding, 4, 14, 58, 59, 62, 64, 99,100

grazing, 8, 100

herds, 8, 35, 55, 58, 97-99, 105,118

hunting aid, 14, 99, 100

social affect, 1, 14, 16, 28, 30, 60, 105

trade, $2,15,16,25,35,42,54,58$, $59,62,63,65,66,68,69,73$, $75,77,79,81,82,84,86,87$, $89,92,94,96-98,100,101$, $103,104,107-109,112,118$ value, $18,19,23,26,64,70,96$, $100,101,105$

House of Trade, 47

Huguenots, 46

Industrial Revolution, 48

Italy, 45

Jumanos, 56, 75, 76, 80. See also Taovayas; Wichitas

Kadohadachos, 37, 73, 81, 85, 88, $96,98,107$

Kansas, 81

Kiowas, 4, 82

Kitchais or Kitsai, 37, 84, 85

Laredo, 53, 97

La Salle, Jean, 37, 47

Levant, 47

Lipan Apaches, 4, 8, 41, 52, 53, 59, $61,76,77,84,86,87,93$, $94,112,113,116,117$. See also Apaches 
Llano Estacado, 34

London, 45

Louisiana, 2, 65, 72, 78, 81, 82, 85, $86,98,114,115$

Madrid, 45

medicine societies, 33

mercantile or mercantilism, $7,19,44$, $45,47,70$

Merchant's Guild, 47

Mescaleros, 76, 89

Mexican Revolution, 9, 72

Mexico, 72, 83, 103

Mier, 53

Milan, 45

military societies, $12,30,32,33$

mission industries, 51

missionaries, 29, 37, 40, 41, 49, 50, $51,60,78,83,108,116$

missions, $2,9,23,49,50-53,58,60$, $65,72,78,83,84,86,106$, 108,112

Missouri River, 81-83, 106

Mississippi River, 9, 83. See also River of the Palisades

Mississippi valley, 46, 47, 56, 65

Mississippian culture, 36

mounds, 36

Nacogdoches, 51, 86, 87, 90

Natchitoches, $51,56,81,82,85,87$, 96, 97, 98

Neches River, 37, 50, 83

New Orleans, 80-82

nonstate societies, 5

Nueces River, 52

Nueces Triangle, 50, 52, 53, 58

O'Connor, Hugh, 96

Oklahoma, 5, 88

Osages, 4, 62, 78, 80, 89, 107

Palo Duro Canyon, 79

patron-client, 25

Pawnees, 37, 56, 62

peasants, $20,45,50$

Platte River, 34

precapitalism, 18 presidios or army garrisons, 23, 49, $51-53,65,79,86,112$

Puebloan region or area, $4,43,62$, 113

Puebloan villages, $2,35,66,73,76$, $88,89,113$

Galisteo, 74, 75, 77, 78, 97, 102

Pecos, 62, 63, 74-78, 95, 97, 102

Picurís, 63, 78, 95

Taos, 56, 61, 63, 74-77, 79, 92, $95,97,102$

raiders and raiding, $3,32,51,53,57$, $58,66,71,75,78,79,82,90$, $97,98,101-103,113,114,116$

Ramon, Domingo, 109

rancherías, 52, 59, 74, 80, 101, 102

ransom, 35, 75

Red River, 37, 78-80, 82, 96

Revilla, 53

Reynosa, 53

Rio Grande River, 1, 2, 4, 9, 52, 76, $78,83,89,95,97,113$

Rio Napestle, 79. See also Arkansas River

ritualized exchange, 23, 25

River of the Palisades, 83. See also Mississippi River

Sabine River, 51

Saint Louis, 96

Saltillo, 48, 53, 78

San Antonio, 52, 53, 63, 78, 79, 94, 95, 97

San Antonio River, 52

San Juan, 75

San Sabá, 77

Santa Fe, 78, 79

Sauto, 86. See also Bigotes

Seville, 47

Shawnees, 88

Shoshones, 30, 31

Sierra de Almagre, 79

Smith, Adam, 21

Smith, Clinton, 104

smuggling, 9, 48, 60, 79, 83, 84

sodalities, 33,71

solar networks, 25 
structure of conjunction, 27

Sulphur Fork Factory, 88.

See also trading posts

Sun Dance, 12, 30, 32

Taovayas, 4, 62, 64, 66, 73, 77-81, 89, 97, 106, 107, 113, 117.

See also Jumanos; Wichitas

Tawakonis, 81, 84, 87

theocracy, 3

tobacco societies, 12

Tonkawas, 86, 87

Toro Blanco, 103, 114, 115

trade fairs, $25,42,57,63,65,75,77$, 84,95

trade goods or items, $1,2,6,34,40$, $44,45,54-57,64,69,72,74$, $86,90,104,112,116$

beaver, 47

bison, $2,3,19,35,54,62,64,72$, $74,77,80,82,85,92,94,99$, 100,106

captives, $35,59,63,71,72,74$, $79,100,104,105$

commodities, 54, 56, 57, 65-69, $71,73,88,89,93,95,104,107$, $109,113,115,116,118$

Euro-American commodities, 37, $39,41,48,53-56,73,84,85$, $92,94,105,106,108$

firearms, $1,2,3,8,9,16,19,23$, $25,26,28,35,39,42,54-56$, $58-62,64,65,68-70,78,80$, $81,84-86,88,89,92-96,98$, $100,101,104-109,112$, 114-116, 118

gold, 45

hides, $35,45,54,62,72,75,77$, $79,80,82,92,99$

imports, 7, 28, 40, 41, 45, 47, 48

jewelry, 2

manufactured commodities, 35 , $39,45,47,54,93,100,112$, 117

meat, 35 metal tools or objects, $2,25,45$, $55,61,84,92$

silver, $2,45,46,52,72,82$

slaves, 35, 47, 54, 75, 77, 84, 92

tallow, 35

textiles, 2, 84, 92

wild game, 4

See also horses

traders, 3, 32, 35, $4647,53,58,59$, $63,75,78,81,86,87,95,96$, $98,106,107,116$

American, 2, 3, 4, 85

British, 2, 3, 4, 78, 79, 85, 97

French, 2, 3, 4, 41, 53, 56, 57, 59, $65,74,76,78,79,97$

German, 75

Spanish, 2, 4, 29, 113

trading posts, $1,2,53,87,89,95$, 107, 116. See also Sulphur Fork Factory

Treaty of Medicine Lodge, 5

Treaty of Paris, 4, 47, 48

tribute systems, 22

Trinity River, 84

United States, 48, 98

Utes, 4, 54, 74, 75, 76

Uto-Aztecan, 30

Veracruz, 48

warfare and combat, $39,43,55,61$, 69-71, 76, 84, 94, 107, 118

army, 45

battle strategies, 4, 6, 14, 23, 33, 59,75

campaigns, 52,75

military, 34, 53, 55, 60, 70, 71, $107,114,115$

soldiers, $14,50,51,56$

See also military societies; raiding

Weberian economics, 18

West Indies, 81

Wichitas, 4, 37, 60, 73, 81, 85. See also Jumanos; Taovayas 



